UNIVERSIDADE DE SÃO PAULO

ESCOLA DE ENFERMAGEM

ALEXANDRA BULGARELLI DO NASCIMENTO

COMO AS NECESSIDADES EM SAÚDE DO TERRITÓRIO PODEM SER ACOLHIDAS E MONITORADAS PELOS INSTRUMENTOS DE GESTÃO MUNICIPAL?

SÃO PAULO

2017 


\title{
COMO AS NECESSIDADES EM SAÚDE DO TERRITÓRIO PODEM SER ACOLHIDAS E MONITORADAS PELOS INSTRUMENTOS DE GESTÃO MUNICIPAL?
}

\author{
Versão corrigida da Tese apresentada ao \\ Programa de Pós-graduação em Enfermagem \\ da Escola de Enfermagem da Universidade de \\ São Paulo, como exigência parcial, para a \\ obtenção do título de Doutora. \\ Área de concentração: Cuidado em Saúde \\ Orientadora: Profa. Dra ${ }^{a}$. Emiko Yoshikawa Egry
}

\begin{abstract}
VERSÃO CORRIGIDA
A versão original encontra-se disponível na Biblioteca da Escola de Enfermagem da Universidade de São Paulo e na Biblioteca Digital de Teses e Dissertações da Universidade de São Paulo.
\end{abstract}

SÃO PAULO 
AUTORIZO A REPRODUÇÃO E DIVULGAÇÃO TOTAL OU PARCIAL DESTE TRABALHO, POR QUALQUER MEIO CONVENCIONAL OU ELETRÔNICO, PARA FINS DE ESTUDO E PESQUISA, DESDE QUE CITADA A FONTE.

Assinatura:

Data:

Escola de Enfermagem da Universidade de São Paulo

Nascimento, Alexandra Bulgarelli do

Como as necessidades em saúde do território podem ser acolhidas e monitoradas pelos instrumentos de gestão municipal? / Alexandra Bulgarelli do Nascimento. São Paulo, 2017.

$120 \mathrm{p}$.

Tese (Doutorado) - Escola de Enfermagem da Universidade de São Paulo.

Orientadora: Prof. ${ }^{a}$ Dr. ${ }^{a}$ Emiko Yoshikawa Egry

Área de concentração: Cuidado em Saúde

1. Políticas públicas. 2. Saúde. 3. Planejamento em saúde. 4. Saúde Pública. 5. Enfermagem. I. Título. 
Nome: Alexandra Bulgarelli do Nascimento

Título: Como as necessidades em saúde do território podem ser acolhidas e monitoradas pelos instrumentos de gestão municipal?

Tese apresentada ao Programa de Pós-Graduação em Enfermagem da Escola de Enfermagem da Universidade de São Paulo para obtenção do título de Doutora em Ciências.

Aprovado em:

Banca Examinadora

Prof. Dr. Instituição:

Julgamento: Assinatura:

Prof. Dr. Instituição:

Julgamento: Assinatura:

Prof. Dr. Instituição:

Julgamento: Assinatura:

Prof. Dr. Instituição:

Julgamento: Assinatura:

Prof. Dr. Instituição:

Julgamento: Assinatura: 


\section{AGRADECIMENTOS}

À Profa . Dra . Emiko Yoshikawa Egry, da Escola de Enfermagem da Universidade de São Paulo, pela orientação brilhante, confiança e contribuição significativa para o meu aprendizado e amadurecimento acadêmico.

À Profa ${ }^{a}$ Dra . Maria Amélia de Campos Oliveira, da Escola de Enfermagem da Universidade de São Paulo que, gentilmente, acolheu ao meu e-mail para orientação do doutorado e colocou-me em contato com a Prof ${ }^{a}$. Dr ${ }^{\mathrm{a}}$. Emiko Yoshikawa Egry.

À Profa. Dra. Maria Marta Nolasco Chaves, à Profa. Dra. Sayuri Tanaka Maeda, ao Prof. Dr. Áquilas Nogueira Mendes, ao Prof. Dr. Jaime Breilh e ao Prof. Dr. Oswaldo Yoshimi Tanaka, que prontamente aceitaram ao convite para participar da banca avaliadora deste trabalho.

À minha mãe, Bernadete Bulgarelli do Nascimento, pela compreensão, ajuda, tolerância e paciência em todos os meus projetos pessoais e profissionais.

Ao meu pai, José Aparecido do Nascimento, pelo exemplo de caráter, trabalho e resiliência.

Aos meus colegas de trabalho do Centro Universitário Senac - Unidade

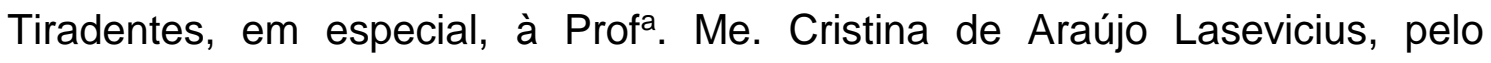
incentivo e confiança.

Ao meu namorido, Rodrigo Pires de Andrade, pelo apoio, companheirismo, cuidado, amor e compreensão, principalmente, nos meus momentos de ausência.

Aos meus cãezinhos, pela alegria e bagunça gostosa ao longo deste processo.

Aos meus alunos, que são a minha inspiração para perseverar no meu aprimoramento, a fim de contribuir para o desenvolvimento de pessoas e profissionais comprometidos com uma sociedade equitativa. 
[...] embora tenha havido avanços significativos em práticas discursivas contemporâneas sobre conceitos de saúde mais abrangentes e dialetizados, todavia faltam rumos emancipadores para concretizá-los como direitos e garantias fundamentais aos sujeitos da vida social.

(Arreaza, 2012) 
Nascimento AB. Como as necessidades em saúde do território podem ser acolhidas e monitoradas pelos instrumentos de gestão municipal? [tese]. São Paulo: Escola de Enfermagem, Universidade de São Paulo; 2017.

\section{RESUMO}

Introdução: O plano municipal de saúde e os relatórios anuais de gestão municipal são ferramentas de planejamento para identificar, sistematizar e monitorar as ações em saúde, com vistas a responderem às necessidades da população. Neste contexto, a Enfermagem como prática social destaca-se, pois a compreensão dialética da realidade permite a proposição de mudanças do concreto, no sentido de contribuir qualitativamente para a ruptura de modos de produção e reprodução do cotidiano que impactem o adoecimento e a morte de grupos sociais vulneráveis. Objetivo: Compreender os limites e as potencialidades do plano municipal de saúde e dos relatórios anuais de gestão municipal como instrumentos para o assessment de políticas públicas municipais em saúde. Metodologia: Estudo quanti-qualitativo dos planos municipais de saúde, dos períodos de 2010-2013 e 2014-2017, e dos relatórios anuais de gestão municipal dos anos de 2011, 2012, 2013, 2014 e 2015, disponíveis no Sistema de Apoio à Construção do Relatório de Gestão (SARG-SUS). O software WebQDA ${ }^{\circledR}$ foi utilizado para a organização dos dados, os quais foram analisados por meio da Teoria da Intervenção Práxica em Enfermagem em Saúde Coletiva, da análise de conteúdo de Bardin, e da estatística descrita e inferencial. Os municípios participantes foram: Araraquara, Santos, Valinhos e Vinhedo, os quais atenderam aos seguintes critérios de elegibilidade: são municípios pertencentes ao estado de São Paulo, entretanto, não à Região Metropolitana, com 50 mil habitantes ou mais, apresentaram melhor Índice de Desenvolvimento Humano e pior coeficiente de Gini, bem como disponibilizaram no SARG-SUS os planos municipais de saúde e os relatórios anuais de gestão municipal. 
Resultados: Os planos municipais de saúde e os relatórios anuais de gestão municipal se mostraram como instrumentos com potencialidade para a compreensão do SUS como política pública de proteção social; como ferramenta de planejamento em saúde; como metodologia para compreensão e identificação das necessidades em saúde e como mecanismos de monitoramento das ações em saúde propostas no PMS. Entretanto, foi demonstrado que a concepção do processo saúde-doença presente nesses instrumentos esteve alicerçada sobre a multicausalidade, evidenciando grandes limitações para acolher as necessidades em saúde da população e, consequentemente, identificar os grupos socialmente vulneráveis, impactando negativamente as práticas de gestão ancoradas na equidade. Conclusões: Os planos municipais de saúde e os relatórios anuais de gestão municipal mostraram-se como instrumentos de extrema validade para o assessment de políticas públicas municipais de saúde. No entanto, eles somente conseguirão reduzir as desigualdades sociais, rumo à equidade e integralidade, quando se utilizarem da concepção da produção e reprodução socialmente determinados para compreender saúde, o que por sua vez permitirá a identificação das vulnerabilidades. Consequentemente, esses instrumentos fortalecerão práticas direcionadas à equidade, sobre as quais a Enfermagem em Saúde Coletiva pode atuar de forma significativa no desenvolvimento, implantação, avaliação e monitoramento de políticas públicas de saúde que contribuam para a superação de realidades limitantes que pouco agregam para a melhoria da condição de saúde de grupos sociais vulneráveis.

PALAVRAS-CHAVES: Políticas públicas em saúde. Saúde Coletiva. Planejamento em saúde. Avaliação das necessidades de cuidados de saúde. Avaliação em saúde. Gestão em saúde. Administração Pública. Enfermagem. 
Nascimento AB. How can the health needs of a territory be met and monitored using municipal government management tools? [thesis]. São Paulo: Escola de Enfermagem, Universidade de São Paulo; 2017.

\section{ABSTRACT}

Introduction: The municipal health plan and the annual reports of the municipal government serve as tools for planning and for identifying, organizing and monitoring activities in the health sector, with the aim of meeting the population's needs. In this context, nursing has an important role to play as a social practice, since the dialectical understanding of the local reality makes it possible to propose concrete changes, with a view to making a qualitative contribution towards disrupting those daily means of production and reproduction that impact on the levels of illness and mortality among vulnerable social groups. Objective: To understand the limitations and the potential of the municipal health plan and annual reports from the municipal government to serve as assessment instruments for municipal level public policies in health. Methodology: This was a quanti-qualitative study of municipal health plans for the periods 2010-2013 and 2014-2017 and of annual reports from the municipal government for all years between 2011 and 2015, which were available on the System for Supporting the Construction of a Management Report (SARG-SUS in the Portuguese). The WebQDA® software was used to organize the data, which was analyzed using the Theory of Praxis Intervention in Nursing in Public Health, Bardin's content analysis, and descriptive and inferential statistics. The participating Brazilian municipalities were: Araraquara, Santos, Valinhos and Vinhedo, which comply with the following eligibility criteria: municipalities in the State of Sao Paulo, but not part of the Greater Sao Paulo city region, with at least 50,000 inhabitants, the highest Human Development Index rankings and the lowest Gini coefficients for inequality, as well as having their municipal health plans and annual reports from 
the municipal government available on the SARG-SUS. Results: The municipal health plans and the annual reports from the municipal government were found to be instruments with the potential of understanding SUS as a public policy for social protection; as a tool for health planning; as a methodology for understanding and identifying health needs; and as monitoring mechanisms for activities in the health sector that were proposed in the municipal health plan. Nonetheless, the conception of the health-illness process that was present in these instruments was shown to be based on the idea of multi-causality and to have major limitations in terms of meeting the health needs of the population and, consequently, identifying socially vulnerable groups. This has a negative impact on management practices that are anchored upon the concept of equity. Conclusions: The municipal health plans and the annual reports of the municipal government proved to be highly robust for assessing public health policies at the municipal level. However, they would only managed to reduce social inequalities, and therefore contribute towards equity and integrality, when used in light of socially determined production and reproduction for understanding health, which in turn will make it possible to identify vulnerabilities. This will subsequently strengthen practices aimed at improving equity, an area in which Public Health Nursing can have a significant impact by means of the development, establishment, monitoring and evaluation of public health policies that contribute towards overcoming limitations that do not improve the health conditions of socially vulnerable groups.

KEYWORDS: Public health policy. Public Health. Health planning. Needs assessment. Health evaluation. Management health. Public administration. Nursing. 


\section{LISTA DE FIGURAS}

Figura 1 - Redes de atenção à saúde do estado de São Paulo, segundo os DRSs. São Paulo, 2017 (adaptado).

Figura 2 - Método de seleção dos municípios participantes. São Paulo, 2017.

Figura 3 - Ilustração da apresentação dos resultados. São Paulo, 2017.

Figura 4 - Evolução do RAGM no período de 2011 a 2015. São Paulo, 2017.

Figura 5 - Temas para superação da realidade da gestão municipal, a fim de contribuir com o acolhimento e monitoramento das necessidades em saúde do território. São Paulo, 2017.

\section{LISTA DE QUADROS}

Quadro 1 - Síntese dos resultados, segundo os limites e as potencialidades identificados nos PMSs e RAGMs dos municípios. São Paulo, 2017. 


\section{LISTA DE GRÁFICOS}

Gráfico 1 - Pirâmide etária do estado de São Paulo, segundo o censo de 2010. São Paulo, 2017 (adaptado).

Gráfico 2 - Coeficiente de mortalidade infantil, pós-neonatal e neonatal do estado de São Paulo, segundo os anos. São Paulo, 2017 (adaptado).

Gráfico 3 - Coeficiente de mortalidade materna no estado de São Paulo, segundo os anos. São Paulo, 2017 (adaptado).

Gráfico 4 - Número de equipes da ESF no estado de São Paulo, segundo o ano. São Paulo, 2017 (adaptado).

Gráfico 5 - Comparativo das pirâmides etárias do município $A$, segundo os dados do RAGM de 2015 e do IBGE de 2010. São Paulo, 2017.

Gráfico 6 - Comparativo das pirâmides etárias do município C, segundo os dados do RAGM de 2015 e do IBGE de 2010. São Paulo, 2017.

Gráfico 7 - Comparativo das pirâmides etárias do município D, segundo os dados do RAGM de 2015 e do IBGE de 2010. São Paulo, 2017.

Gráfico 8 - Perfil de mortalidade descrito nos RAGMs do município A, segundo o ano e a CID-10. São Paulo, 2017.

Gráfico 9 - Perfil de mortalidade descrito nos RAGMs do município C, segundo o ano e a CID-10. São Paulo, 2017.

Gráfico 10 - Perfil de mortalidade descrito nos RAGMs do município D, segundo o ano e a CID-10. São Paulo, 2017. 
Gráfico 11 - Perfil de morbidade descrito nos RAGMs do município A, segundo o ano e a CID-10. São Paulo, 2017.

Gráfico 12 - Perfil de morbidade descrito nos RAGMs do município C, segundo o ano e a CID-10. São Paulo, 2017.

Gráfico 13 - Perfil de morbidade descrito nos RAGMs do município D, segundo o ano e a CID-10. São Paulo, 2017.

Gráfico 14 - Distribuição dos equipamentos de saúde do município A, segundo os anos dos RAGMSs. São Paulo, 2017.

Gráfico 15 - Distribuição dos equipamentos de saúde do município $C$, segundo os anos dos RAGMSs. São Paulo, 2017.

Gráfico 16 - Distribuição dos equipamentos de saúde do município D, segundo os anos dos RAGMSs. São Paulo, 2017. 


\section{LISTA DE TABELAS}

Tabela 1 - Departamentos Regionais de Saúde do estado de São Paulo, em 2008, segundo o número de municípios e a população total. São Paulo, 2017 (adaptado).

Tabela 2 - Causas de mortalidade no estado de São Paulo, segundo a CID 10 e o sexo. São Paulo, 2017 (adaptado).

Tabela 3 - Mortalidade, em 2009, segundo os tipos de causas externas e sexo. São Paulo, 2017 (adaptado).

Tabela 4 - Variação percentual do coeficiente de mortalidade infantil no estado de São Paulo, entre os anos de 2000 e 2009, segundo os DRSs. São Paulo, 2017 (adaptado).

Tabela 5 - Causas de mortalidade materna no estado de São Paulo, em 2009, segundo a CID - 10. São Paulo, 2017 (adaptado).

Tabela 6 - Variação percentual das internações hospitalares no estado de São Paulo, nos anos de 2001 e 2010, segundo a CID - 10. São Paulo, 2016 (adaptado).

Tabela 7 - Equipamentos de saúde, em 2010, no estado de São Paulo, segundo os DRSs. São Paulo, 2017 (adaptado).

Tabela 8 - Cobertura estimada da população do estado de São Paulo, pelas equipes da ESF, segundo os DRSs. São Paulo, 2017 (adaptado).

Tabela 9 - Faixas de desenvolvimento humano, segundo o IDH. São Paulo, 2017. 


\section{LISTA DE SIGLAS}

\begin{tabular}{ll} 
APS & Atenção Primária à Saúde \\
CID -10 & Classificação Internacional de Doenças - versão 10 \\
CIPESC & Classificação Internacional de Práticas de Enfermagem em \\
& Saúde Coletiva \\
CIT & Comissão Intergestora Tripartite \\
CMS & Conselhos Municipais de Saúde \\
COAP & Contrato Organizativo da Ação Pública da Saúde \\
DRS & Departamentos Regionais de Saúde \\
EC & Emenda Constitucional \\
ESF & Estratégia Saúde da Família \\
EUA & Estados Unidos da América \\
HIV & Vírus da Imunodeficiência Adquirida \\
IBGE & Instituto Brasileiro de Geografia e Estatística \\
IDH & Índice de Desenvolvimento Humano \\
LDO & Lei de Diretrizes Orçamentárias \\
LOA & Lei Orçamentária Anual \\
MHD & Materialismo Histórico-Dialético \\
OMS & Organização Mundial da Saúde \\
OPAS & Organização Pan-americana de Saúde \\
PES & Plano Estadual de Saúde \\
PIB & Produto Interno Bruno \\
PMS & Plano Municipal de Saúde \\
PNUD & Programa das Naçães Unidas para o Desenvolvimento \\
PPA & Plano Plurianual \\
RAGM & Relatório Anual de Gestão Municipal \\
RAS & Redes de Atenção à Saúde \\
SARG-SUS & Sistema de Apoio à Construção do Relatório de Gestão \\
SINASC & Sistema de Informação sobre Nascidos Vivos \\
SIOPS & Sistema de Informações sobre Orçamentos Públicos em \\
& Saúde \\
SUS & Sistema Único de Saúde \\
TIPESC & Teoria da Intervenção Práxica da Enfermagem em Saúde \\
& Coletiva \\
\hline
\end{tabular}




\section{SUMÁRIO}

1 INTRODUÇÃO

2 OBJETIVOS $\ldots$

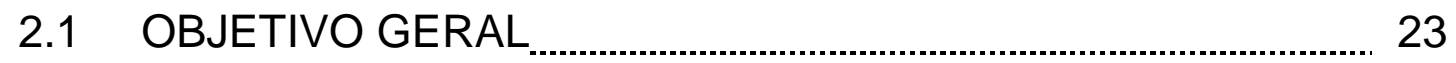

2.2 OBJETIVOS ESPECÍFICOS 23

3 JUSTIFICATIVA

4 METODOLOGIA

4.1 MARCO TEÓRICO-FILOSÓFICO _............................................... 29

4.2 MARCO TEÓRICO-METODOLÓGICO ……...................................... 33

4.3 DELINEAMENTO DO ESTUDO ...................................................... 35

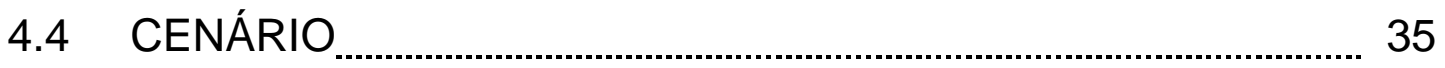

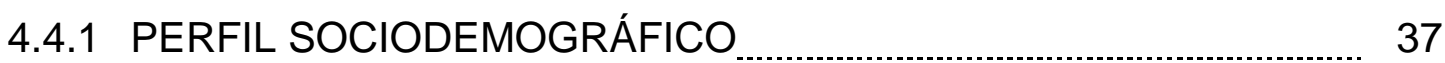

4.4.2 PERFIL EPIDEMIOLÓGICO .......................................................... 38

4.4.3 REDE DE ATENÇÃO À SAÚDE ...................................................... 48

4.5 FONTES E ANÁLISE DOS DADOS EMPÍRICOS _.................... 52

4.6 ASPECTOS RELATIVOS À ÉTICA EM PESQUISA ................... 56

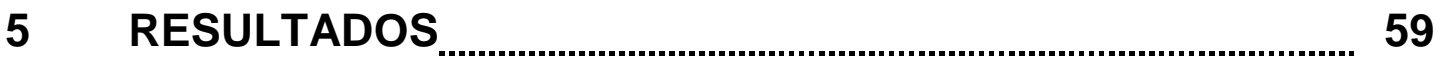

5.1 LIMITES E PONTECIALIDADES .................................................... 60

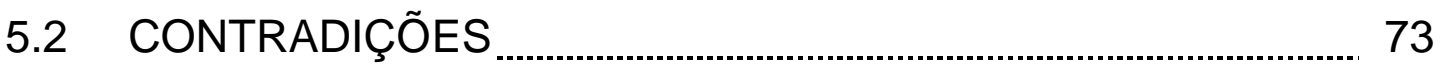

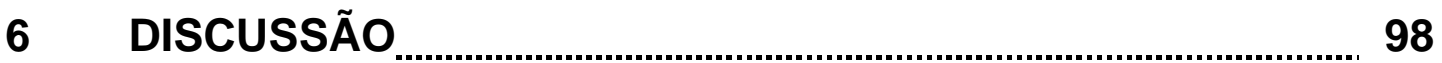

6.1 POLÍTICAS PÚBLICAS _................................................................ 98

6.2 NECESSIDADES EM SAÚDE

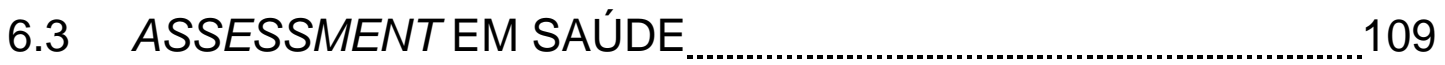

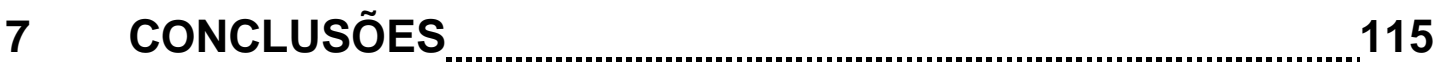

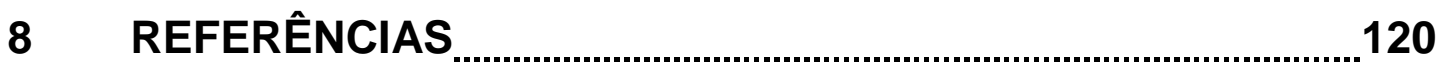

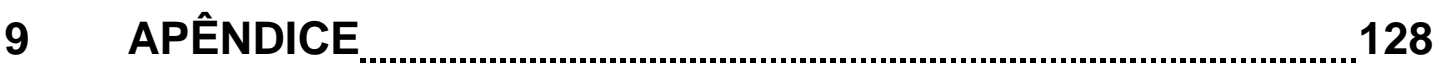


1 INTRODUÇÃO 


\section{INTRODUÇÃO}

A Enfermagem é inerente à experiência humana desde os seus primórdios, quando o cuidado era direcionado à maternidade, às crianças, aos idosos, aos doentes e aos feridos (Alves et al., 2015).

Ao longo do tempo ela foi influenciada por diferentes contextos sociais, políticos, econômicos e históricos a que esteve submetida (Alves et al., 2015).

Como consequência, o cuidado de Enfermagem transitou entre diferentes representações e agentes sociais, tendo momentos de avanço e retrocesso, a depender das transformações sociais que ocorreram (Egry, Cubas, 2006).

A natureza científica da Enfermagem teve como precursora a inglesa Florence Nightingale, que durante a Guerra da Crimeia (1854-1855) atuou de forma significativa na recuperação de soldados ingleses nos campos de batalha. A sua educação diferenciada, para as mulheres da época, permitiu que ela sistematizasse os cuidados, por meio da observação, do acompanhamento dos cuidados prestados e da mensuração dos resultados (Carvalho, 2013).

Após o término da guerra, ela implantou no Hospital Saint Thomas (Londres), em 1860, a Escola Nightingale para Treinamento de Enfermeiras (Carvalho, 2013), cujo objetivo da atuação das enfermeiras, segundo Nightingale (1989), era:

Promover a saúde e manter a vida mediante novo estilo do que fazer, e como ajuda aos indivíduos e seus familiares acometidos pelas enfermidades ou carentes de se manterem sadios e, acima de tudo, pelo seu saber fazer em âmbito da arte de cuidar como a mais bela das belas artes [...].

Os conhecimentos utilizados por Florence Nightingale eram provenientes do pensamento iluminista, que se utilizou dos modelos mecanicista e cartesiano, por meio da estatística, microbiologia, administração, entre outras áreas, o que contribuiu para o avanço da Enfermagem como área de conhecimento científico organizada em quatro dimensões: assistência, gerência, pesquisa e educação (Alves et al., 2015). 
No entanto, as limitações deste modelo funcionalista de explicar e acompanhar os fenômenos do processo saúde-doença fizeram com que novos referenciais para a abordagem da saúde fossem discutidos, como, por exemplo, o Materialismo Histórico-Dialético (MHD). Esta base teórico-filosófica tem a potencialidade para a transformação da realidade por meio dos conhecimentos qualitativamente acumulados que permitem a superação da realidade (Egry, Cubas, 2006; Fonseca, Egry, Bertolozzi, 2006).

Neste sentido, a atuação do enfermeiro como agente do processo de trabalho em saúde, problematizador da realidade, ganha destaque, pois a apropriação desse modo de pensamento fornece-lhe instrumentos para colaborar com a transformação da realidade (Egry, Fonseca, Campos, 2013).

O trabalho da Enfermagem no Brasil, assim como das demais áreas profissionais em saúde, tem o Sistema Único de Saúde (SUS) como marco jurídico-político, estruturante e organizador dos processos de produção em saúde. O SUS configura-se como a maior política de proteção social e um desafio, haja vista a dimensão continental do país e de sua diversidade cultural, demográfica, econômica e epidemiológica. Acresce-se o subfinanciamento do setor público, considerando-se a disparidade entre suas fontes e o montante direcionado à alocação dos recursos para viabilizar a oferta de serviços (Ferraz, Vieira, 2009), bem como a coexistência do setor público e privado na gestão e oferta de serviços à população (Menicucci, 2007).

Nesta realidade, a equipe de Enfermagem contribui para a prestação de cuidados integrais e equitativos, nos mais diversos serviços de saúde (públicos e privados), inclusive, com a identificação e o enfrentamento de vulnerabilidades (Rocha, Almeida, 2000).

Desta forma, para operacionalizar o sistema de saúde, destacam-se a proposição, a implantação e o monitoramento de políticas públicas de governança local, bem como de natureza intersetorial, integradas e articuladas, visando minimizar a presença de iniquidades sociais que influenciem a situação de saúde das pessoas (Andrade, Vaitsman, 2013; Blackman et al., 2012; Gram et al., 2014; Larsen et al., 2014; Santos, Giovanella, 2014). 
Neste sentido, denota-se a importância da implantação de ferramentas gerenciais articuladas nas três esferas de governança do SUS, a federal, a estadual e a municipal.

Na esfera municipal, o Plano Municipal de Saúde (PMS) e os Relatórios Anuais de Gestão Municipal (RAGM) foram concebidos como ferramentas de planejamento para identificar, sistematizar e monitorar as ações em saúde que respondam às necessidades da população (Brasil, 2009b; Brasil, 2013b; Brasil, 2016).

A compreensão do PMS e do RAGM como ferramentas de planejamento e gestão local é proveniente do Pacto da Saúde, composto pelo Pacto pela Vida, Pacto em Defesa do SUS e Pacto de Gestão (Brasil, 2006).

O Pacto de Gestão foi proposto em 2006 com o objetivo de implantar e viabilizar ações sistematizadas com potencialidade para a operacionalização do SUS (Brasil, 2006).

Entre essas ações, destacaram-se o PMS e os RAGMs como ferramentas gerenciais disponíveis aos secretários de saúde para 0 planejamento e o monitoramento de ações com vistas ao atendimento das necessidades em saúde da população (Brasil, 2005; Brasil, 2009b; Brasil, 2013b; Brasil, 2016; Bueno et al., 2013).

O PMS tem vigência de quatro anos, e tem por finalidade planejar as intervenções por meio do mapeamento da situação de saúde da população, bem como propor prioridades e objetivos visando contribuir para a efetiva atenção à saúde da população. Deve estar alinhado com o Plano Plurianual (PPA), a Lei de Diretrizes Orçamentárias (LDO) e a Lei Orçamentária Anual (LOA). Já o RAGM tem o objetivo de monitorar as ações propostas no PMS, por meio de indicadores e metas propostas (Brasil, 2009a; Brasil, 2013b).

Para a concepção, o acompanhamento, a elaboração ou a divulgação desses documentos, o enfermeiro pode estar envolvido e contribuir de forma significativa, uma vez que a Lei do Exercício Profissional de Enfermagem, no artigo $11^{\circ}$, dispõe que cabe ao enfermeiro durante a sua atuação em equipe de saúde a "[...] participação no planejamento, execução e avaliação da programação de saúde [...]", bem como "[...] na elaboração, execução e 
avaliação dos planos assistenciais de saúde [...]" (Brasil, 1986), o que, por sua vez, reforça a contribuição deste profissional para a gestão de sistema e serviços de saúde, bem como para a superação da realidade.

Desta forma, faz-se pertinente pensar para além da oferta isolada de serviços de saúde, pois o atendimento das necessidades em saúde da população não está pautado no oferecimento linear, desenfreado e desarticulado de serviços, mas na identificação sistemática dessas necessidades com vistas a ofertar serviços articulados e sustentáveis economicamente, que contribuam para a melhoria dos padrões de saúde do indivíduo, da família e das coletividades (OPAS, 2011).

Portanto, o PMS e os RAGMs podem ser concebidos como ferramentas gerenciais de planejamento de grande relevância para a gestão em saúde municipal, para os quais o enfermeiro pode contribuir de forma significativa.

Diante do exposto, questiona-se: quais seriam as potencialidades e os limites do PMS e dos RAGMs, como instrumentos para assessment de políticas públicas municipais em saúde? 
2 OBJETIVOS 


\section{OBJETIVOS}

\section{$2.1 \quad$ OBJETIVO GERAL}

Compreender os limites e as potencialidades do PMS e dos RAGMs como instrumentos para o assessment de políticas públicas municipais em saúde.

\subsection{OBJETIVOS ESPECÍFICOS}

- Verificar a maneira como os PMSs e os RAGMs identificam as necessidades em saúde da população em geral e, em específico, as vulnerabilidades dos grupos sociais.

- Analisar a articulação entre as ações em saúde propostas nos PMSs e os RAGMs, bem como as necessidades em saúde da população.

- Identificar as métricas de monitoramento das ações em saúde propostas nos PMSs.

- Analisar as ações propostas nos PMSs e RAGMs como garantidoras da efetividade da assistência à saúde da população. 
3 JUSTIFICATIVA 


\section{JUSTIFICATIVA}

Alguns estudos discutem as dificuldades dos sistemas de saúde em atender às necessidades em saúde da população (Albuquerque et al., 2011; Meyer et al., 2013).

Entre os estudos destacados, um deles, cujo objetivo foi analisar o reconhecimento das necessidades de grupos sociais vulneráveis, identificados como pessoas trabalhadoras, mulheres, com sofrimento psíquico e provenientes de áreas de pobreza, observou que no nível do município conseguiu mapear e incluir esses grupos na atenção à saúde. Porém, foi evidenciada a fragilidade na articulação dos mecanismos de referência e contra-referência entre os níveis de atenção, o que por sua vez comprometeu a efetividade da assistência prestada e, consequentemente, a qualidade percebida pela população (Albuquerque et al., 2011).

Outros estudos nacionais e internacionais pesquisaram o custoefetividade das ações de promoção e prevenção para a sociedade, visando a otimização do sistema de saúde e o bem-estar da população (Andrade, Vaitsman, 2013; Blackman et al., 2012; Gram et al., 2014; Larsen et al., 2014; Santos, Giovanella, 2014).

No Brasil, as políticas neoliberais adotadas exercem influência sobre a oferta de serviços de saúde, uma vez que tais políticas têm o objetivo de minimizar o compromisso do Estado com a população, restringindo a implementação e a manutenção de políticas públicas efetivas e contributivas para a melhoria da situação de saúde das pessoas (Mendes, 2015).

Neste sentido, o modo de produção capitalista contribui negativamente para a operacionalização dos sistemas de saúde universais (Mendes, 2015), uma vez que ele impõe a lógica produtivista pautada na mais-valia, na financeirização e no estabelecimento de relações de submissão ao capital em detrimento do bem-estar social (Mendes, 2015).

Deste modo, verifica-se o descompasso entre a demanda e a oferta, o que, consequentemente, contribui para as desigualdades alocativas de recursos 
em saúde, já que este desequilíbrio pode dificultar, por exemplo, o acesso aos serviços (Ferraz, Vieira, 2009).

Os serviços, organizados em níveis de atenção, devem prover à população ações em saúde que visem a promoção, a prevenção, a restauração, a reabilitação e os cuidados paliativos (Paim et al., 2011). Em detrimento disso, observa-se o uso inadvertido dos hospitais e serviços de urgência, os quais são responsáveis por $67 \%$ dos gastos totais em saúde e $70 \%$ dos gastos públicos na área, um dos equipamentos de saúde mais onerosos para a sociedade e que não têm potencialidade para responder à totalidade das necessidades em saúde da população (La Forgia, Couttolenc, 2008).

Para superar esta realidade, a Organização Pan-americana de Saúde (OPAS, 2011) e Mendes (2011) propõem a operacionalização dos sistemas de saúde organizados em redes de atenção à saúde (RAS) colaborativas e contributivas, tendo o paciente como centro do cuidado, e a Atenção Primária à Saúde (APS) como coordenadora desse cuidado à população adstrita ao seu território sanitário (Starfield, 2002).

Para a operacionalização do sistema de saúde em RAS, destaca-se a pertinência da teoria interpretativa da determinação social do processo saúdedoença (Conrad, Leiter, 2013), que impõe aos gestores municipais a compreensão do processo saúde-doença de forma integral e articulada. Tal teoria considera a obrigatoriedade de mapear e descrever os perfis epidemiológicos da população e, assim, identificar os grupos sociais vulneráveis (Albuquerque et al., 2011), dada a presença de iniquidades na oferta de serviços dos sistemas de saúde locais frente às necessidades identificadas (Bueno et al., 2013; Gram et al., 2014; Larsen et al., 2014).

A municipalização se destaca como um mecanismo político de gestão de natureza colaborativa, em que os PMSs e os RAGMs têm importante papel como ferramentas gerenciais para a identificação, a proposição, a implantação e o monitoramento dessas ações, por meio de indicadores e metas que tenham acurácia suficiente para traduzir a efetividade do sistema (Brasil, 2016; Bueno et al., 2013). 
Nesta perspectiva, o PMS é uma política pública municipal de saúde de extrema relevância para a identificação das necessidades e o planejamento em saúde durante o período de quatro anos, em conjunto com os RAGMs. Ambos se propõem a monitorar a efetividade das ações em saúde planejadas, inclusive, no que tange aos grupos sociais vulneráveis (Brasil, 2009b; Brasil, 2013b; Brasil, 2016). 
METODOLOGIA 


\section{METODOLOGIA}

\subsection{MARCO TEÓRICO-FILOSÓFICO}

Este estudo utilizará como marco teórico-filosófico a Saúde Coletiva, o Materialismo Histórico e Dialético, a Teoria da Determinação Social do Processo Saúde-Doença, a Epidemiologia Crítica e a Enfermagem como prática social.

A Saúde Coletiva materializa-se, no Brasil, no final da década 1970, como desdobramento das discussões teóricas acerca de outras áreas do conhecimento, como Saúde Pública, Medicina Comunitária, Medicina Preventiva e Medicina Social. Inicialmente, estas concebiam os aspectos relacionados com o processo saúde-doença para além da esfera biológica do ser humano, compreendendo o indivíduo ou grupo inseridos num determinado contexto social (Regis, Batista, 2015).

Entretanto, essas áreas do conhecimento ainda não abarcavam a densidade filosófica que a Saúde Coletiva se propôs a adentrar (Breilh, 2013).

Em meados da década de 1970, o campo da Saúde Coletiva emerge na América Latina em um contexto sócio-político-econômico de profunda desigualdade social exercendo impacto direto sobre a morbidade e mortalidade da população (Fonseca, Egry, Bertolozzi, 2006).

Nesta perspectiva, a Saúde Coletiva avançou e uma de suas correntes desenvolveu-se a partir do Materialismo Histórico Dialético (MHD) (Fonseca, Egry, Bertolozzi, 2006).

O MHD se ancora na análise de Marx e Engels, do século XIX, acerca do modo de produção capitalista. A intensificação das diferenças sociais entre as classes nesse modo de produção contribuíram para um novo modo de pensar as relações de causa e efeito entre vários fenômenos, entre eles, o processo saúde-doença (Fonseca, Egry, Bertolozzi, 2006).

É considerada uma visão de mundo realista por partir da análise do concreto, da sua historicidade e das relações dialéticas que se apresentam. 
Assim, incrementa a possibilidade de transformação da realidade a partir da superação das contradições dialéticas (Fonseca, Egry, Bertolozzi, 2006).

A Teoria da Determinação Social do Processo Saúde-Doença surge a partir da visão de mundo do MHD e da limitação do movimento da Medicina Social em explicar o processo saúde-doença a partir da multicausalidade. Tal explicação limitava-se a analisar o perfil de morbimortalidade por meio, por exemplo, das precárias condições de vida das pessoas, e não englobava as formas de produção e reprodução socialmente determinadas (Fonseca, Egry, 2010).

Desta forma, a Teoria da Determinação Social do Processo SaúdeDoença avança ao analisar o processo saúde-doença a partir da dimensão estrutural societária, bem como dos perfis de produção e reprodução social, em dada realidade, considerando a sua historicidade e dinamicidade, que determinam socialmente os aspectos de fortalecimento e desgaste do processo de adoecer e morrer dos grupos sociais (Fonseca, Egry, 2010).

Em última análise, a Teoria da Determinação Social do Processo SaúdeDoença parte do pressuposto de que a esfera biológica do ser humano, em determinados grupos sociais, pode desenvolver-se de forma diferente do esperado, ao se considerar somente a história natural da doença, por exemplo (Laurell, 1983).

Isto ficou evidente, uma vez que a Epidemiologia Clássica não conseguia explicar, por meio dos seus instrumentais, as especificidades dos diversos grupos sociais quanto ao aparecimento e à manutenção de determinados fatores de adoecimento e morte. Aspectos relacionados com a conformação das dimensões estrutural, particular e singular da organização da sociedade, influenciavam diretamente nos processos de saúde e doença (Breilh, 2013).

Diante desta necessidade, a Epidemiologia Crítica surgiu no século XX, na América Latina, durante intensa crise política, econômica e social. Sob o modo de produção capitalista, as condições de vida e saúde dos grupos sociais subalternos se agravaram, devido à intensificação das desigualdades de classe, gênero, etnia e geração (Breilh, 2014). 
Incrementa-se a presença de regimes ditatoriais em países dessa região cerceando a liberdade de pensamento, inclusive, no que tange ao processo saúde-doença. Neste contexto, esse processo era explicado de forma cartesiana, o que também influenciou o desenvolvimento do pensamento revolucionário de classes, no sentido de repensar a sociedade e, consequentemente, o processo saúde-doença como socialmente determinados (Egry, 1996).

Diante da necessidade de repensar esse processo, foram desenvolvidas teorias e práticas que buscavam evidenciar a sua determinação social. Para tanto, foi necessário construir um conjunto de conhecimentos que permitissem evidenciar tal determinação (Breilh, 2014).

A Epidemiologia Crítica, a partir da Teoria da Determinação Social do Processo Saúde-Doença, ambas originárias do pensamento contra-hegemônico latino-americano e que tem em Jaime Breilh seu maior defensor, propõe a compreensão do processo saúde-doença a partir de três dimensões: estrutural, particular e singular (Breilh, 2006).

A dimensão estrutural corresponde aos processos gerais de organização social que impõem o materialismo como realidade a ser vivenciada pelas coletividades. Um exemplo se refere ao modo de produção capitalista vigente que exige certo padrão de vida e, para que este seja alcançado, a sociedade necessita se organizar em classes, consequentemente, há uma distribuição desigual de renda, a qual influencia na forma de produzir e reproduzir saúde (Breilh, 2006).

Já a dimensão particular diz respeito aos processos de organização social em grupos determinados por classes sociais, etnia, gênero e geração, cujas características inerentes aos seus processos de produção e reprodução socialmente determinados podem se traduzir em vulnerabilidades traduzidas, por exemplo, por limitação de renda, acesso a alimentos, educação e serviços de saúde, o que por sua vez determina as formas de adoecimento e morte desses grupos (Breilh, 2006).

Por fim, a dimensão singular se relaciona com o núcleo familiar e suas formas de produção e reprodução social que são determinadas pelo sistema de 
crença e valores, inserção no mercado de trabalho, acesso às instituições educacionais e de saúde, dinâmica familiar e conflitos existentes, entre outros, os quais, conjuntamente, determinam socialmente os modos de produção e reprodução social, e consequentemente, o processo saúde-doença (Breilh, 2006).

Portanto, a depender da realidade social em que estas pessoas estão inseridas e, consequentemente, dos desgastes e potencialidades presentes nesta realidade, pode-se ter influência sobre as causas de adoecimento e morte de grupos sociais distintos, as quais passam a ser compreendidas como socialmente determinadas (Breilh, 2014; Breilh, 2015).

Assim, surgiu, a partir da década de 1970, a Epidemiologia Crítica como um conjunto de conhecimentos que demonstraram os diferentes potenciais de desgaste e fortalecimento dos indivíduos e grupos sociais, de acordo com a inserção desses na estrutura social (Breilh, 2014).

Entre os referenciais teóricos da Epidemiologia Crítica, é possível destacar a fundamentação na visão de mundo do $\mathrm{MDH}$ e na Teoria da Determinação Social do Processo Saúde-Doença (Breilh, 2013; Breilh, 2014; Breilh, 2015).

Portanto, enquanto a Epidemiologia Clássica fundamenta-se na visão de mundo idealista, alicerçada sobre a história natural da doença, a qual desconsidera os diferentes modos socialmente determinados de adoecer e morrer dos indivíduos e grupos sociais, a Epidemiologia Crítica - por estar fundamentada na visão de mundo do MHD e na Teoria da Determinação Social do Processo Saúde-Doença - permite descrever os diferentes perfis epidemiológicos por grupos sociais, considerando as suas formas socialmente determinadas de morbimortalidade e, em última análise, identificar grupos sociais vulneráveis (Breilh, 2014).

E, desta forma, aproxima-se da Saúde Coletiva enquanto gênese, pois ambas emergem como desdobramento dos aspectos sociais precários e injustos vivenciados pelas sociedades, e contribui para as ações de planejamento em saúde que tenham em sua essência uma prática gerencial norteada pela equidade (Breilh, 2014). 
A partir desse arcabouço teórico-filosófico destaca-se a Enfermagem como prática social, pois passa a ser compreendida como meio para transformação da realidade, de grupos sociais vulneráveis (David, Bonetti, Silva, 2012).

Esta forma de compreender a Enfermagem como práxis emerge pela compreensão das contradições, utilizando-se da visão de mundo do MHD que, por sua, vez permite a proposição de mudanças do concreto, com vistas a contribuir qualitativamente para a ruptura de modos de produção e reprodução do cotidiano que impactem sobre as formas de adoecimento e morte de grupos sociais vulneráveis (Fonseca, Egry, Bertolozzi, 2006).

\subsection{MARCO TEÓRICO-METODOLÓGICO}

Este estudo utilizará como marco teórico-metodológico a Teoria da Intervenção Práxica em Saúde Coletiva e as Matrizes Críticas da Epidemiologia Crítica.

\section{A Teoria da Intervenção Práxica da Enfermagem em Saúde Coletiva} (TIPESC) ancora-se filosoficamente no MHD e parte dos seguintes pressupostos: realidade, historicidade e dinamicidade (Egry, 1996).

A realidade debruça-se sobre 0 fenômeno sob investigação considerando a sua concretude; a historicidade analisa o objeto a partir de seu contexto histórico, político, social e econômico; e a dinamicidade compreende que as relações sociais acontecem de forma dialética, ou seja, à medida que as contradições se estabelecem, a transformação da realidade pode ocorrer (Egry, 1996).

Portanto, como define Egry (1996), a TIPESC se refere à

[...] sistematização dinâmica de captar e interpretar um fenômeno, articulado aos processos de produção e reprodução social, referentes à saúde-doença de uma dada coletividade, no marco de sua conjuntura e estrutura, dentro de um contexto social historicamente determinado; de intervir nessa realidade e, nessa intervenção, prosseguir reinterpretando a realidade para novamente interpor instrumentos de intervenção [...].

Neste sentido, a TIPESC é sistematizada em cinco etapas, quais sejam, a captação da realidade objetiva, a interpretação desta realidade captada 
utilizando-se de referenciais teóricos da Saúde Coletiva, o projeto de intervenção sobre esta realidade, a intervenção propriamente dita, e a reinterpretação da realidade, a fim de verificar se foi transformada.

Para melhor compreender a realidade objetiva, faz-se necessária a articulação dos conhecimentos propostos pela Saúde Coletiva com uma prática profissional disponível para captar as necessidades em saúde da população, inclusive dos grupos sociais vulneráveis. Para tanto, destaca-se a Matriz Crítica como um referencial desenvolvido a partir dos conhecimentos construídos pela Epidemiologia Crítica (Breilh, 2013; Breilh, 2015).

A Matriz Crítica compreende a ordem, o movimento, a sazonalidade, e o espaço social e os elementos do objeto sob análise (Breilh, 2013; Breilh, 2015).

A ordem compreende a percepção sobre o contexto social e suas relações que podem exercer influência sobre um fenômeno complexo, como por exemplo, as formas de adoecer e morrer de um grupo social vulnerável. $O$ objetivo é compreender a ordem em que as relações acontecem, visando permitir a intervenção no contexto social (Breilh, 2013; Breilh, 2015).

Para isto, faz-se necessário entender como o fenômeno sob análise tem sua origem e reprodução, com vistas a perceber a densidade e complexidade do fenômeno, o que é denominado de movimento do objeto (Breilh, 2013; Breilh, 2015).

A sazonalidade do objeto se refere à sua temporalidade, a seus elementos constitutivos e à compreensão da influência da historicidade sob o fenômeno, como por exemplo, situações político-econômicas, de desigualdades e disputas sociais (Breilh, 2013; Breilh, 2015).

Por fim, o espaço social e os elementos do objeto relacionam-se com a importância e conexão histórica dos elementos constitutivos do objeto, como, por exemplo, quando da compreensão do contexto do atual do SUS (Breilh, 2013; Breilh, 2015).

Desta forma, considerando-se os PMSs como uma política pública municipal e os RAGMs como instrumentos de monitoramento das ações implantadas, estes têm potencialidade para identificar as necessidades em 
saúde (Brasil, 2009b; Brasil, 2013b; Brasil, 2016), em especial, de grupos sociais vulneráveis, com vistas a melhorar a situação de saúde da população.

\subsection{DELINEAMENTO DO ESTUDO}

Este trabalho é do tipo quanti-qualitativo, uma vez que foi realizada a análise dos PMSs, com vigência quadrienal, e dos RAGSs, que são emitidos anualmente pelas secretarias de saúde e têm potencialidade para verificar a efetividade das ações em saúde propostas nos PMSs.

Os dados foram analisados pelo método de análise de conteúdo utilizando-se da metodologia preconizada por Bardin (1977), a qual, por meio da hermenêutica crítica, estrutura a elaboração e a análise de unidades de significado que objetivem a sistematização e a captura da essência do fenômeno sob análise (Rocha, Deusdará, 2005). Utilizou-se, ainda, de estatística descrita e inferencial, evidenciando o caráter quantitativo do estudo (Vieira, 2011).

Para a análise de conteúdo foram utilizadas as seguintes categorias de análise:

- Limites dos PMSs e dos RAGMSs;

- Potencialidades dos PMSs e dos RAGMSs; e

- Contradições e proposição para a transformação da realidade.

\subsection{CENÁRIO}

O estudo foi delimitado aos PMSs dos períodos de 2010-2013 e 20142017 e aos RAGMs dos anos de 2011, 2012, 2013, 2014 e 2015 de alguns municípios do estado de São Paulo. Dessa forma, para a caracterização do cenário foram utilizadas as informações do Plano Estadual de Saúde (PES) referente ao período de 2013-2015 (São Paulo, 2012).

Este estado localiza-se na região sudeste do país, ocupando uma área de, aproximadamente, $248 \mathrm{mil} \mathrm{km}{ }^{2}$ em que residem 42 milhões de habitantes distribuídos em 645 municípios. Ele possui o melhor Índice de Desenvolvimento Humano (IDH) do país, com 0,783, e é responsável por $31 \%$ do Produto Interno 
Bruto (PIB) do país. O estado se organiza em 17 Departamentos Regionais de Saúde (DRS) (São Paulo, 2012), como demonstrado na tabela 1.

Tabela 1 - Departamentos Regionais de Saúde do estado de São Paulo, em 2008, segundo o número de municípios e a população total. São Paulo, 2017 (adaptado).

\begin{tabular}{lcc}
\hline $\begin{array}{l}\text { Departamentos Regionais } \\
\text { de Saúde }\end{array}$ & $\begin{array}{c}\text { Número de } \\
\text { municípios }\end{array}$ & $\begin{array}{c}\text { Número de } \\
\text { habitantes }\end{array}$ \\
\hline Grande São Paulo & 39 & 19.616 .060 \\
Campinas & 42 & 3.920 .022 \\
Taubaté & 39 & 2.235 .894 \\
Sorocaba & 48 & 2.209 .159 \\
Bauru & 68 & 1.657 .801 \\
Baixada Santista & 9 & 1.651 .906 \\
São José do Rio Preto & 101 & 1.467 .391 \\
Piracicaba & 26 & 1.401 .210 \\
Ribeirão Preto & 26 & 1.271 .440 \\
Marília & 62 & 1.089 .058 \\
Araraquara & 24 & 906.261 \\
São João da Boa Vista & 20 & 786.201 \\
Presidente Prudente & 45 & 727.879 \\
Araçatuba & 40 & 718.858 \\
Franca & 22 & 653.370 \\
Barretos & 19 & 417.479 \\
Registro & 645 & 281.646 \\
\hline Total & & 41.011 .635 \\
\hline
\end{tabular}

Fonte: São Paulo, 2012. 


\subsubsection{PERFIL SOCIODEMOGRÁFICO}

O estado de São Paulo tem sua população, majoritariamente, residente na zona urbana (95,9\%). Sendo que as mulheres representam $51,3 \%$ da população e os homens, 48,7\% (São Paulo, 2012).

Da população total, 21,5\% é representada por crianças menores de 14 anos e 11,6\% pela população com mais de 60 anos (São Paulo, 2012). O gráfico 1 apresenta a pirâmide etária do estado de São Paulo segundo o censo de 2010 (São Paulo, 2012).

Gráfico 1 - Pirâmide etária do estado de São Paulo, segundo o censo de 2010. São Paulo, 2017 (adaptado).

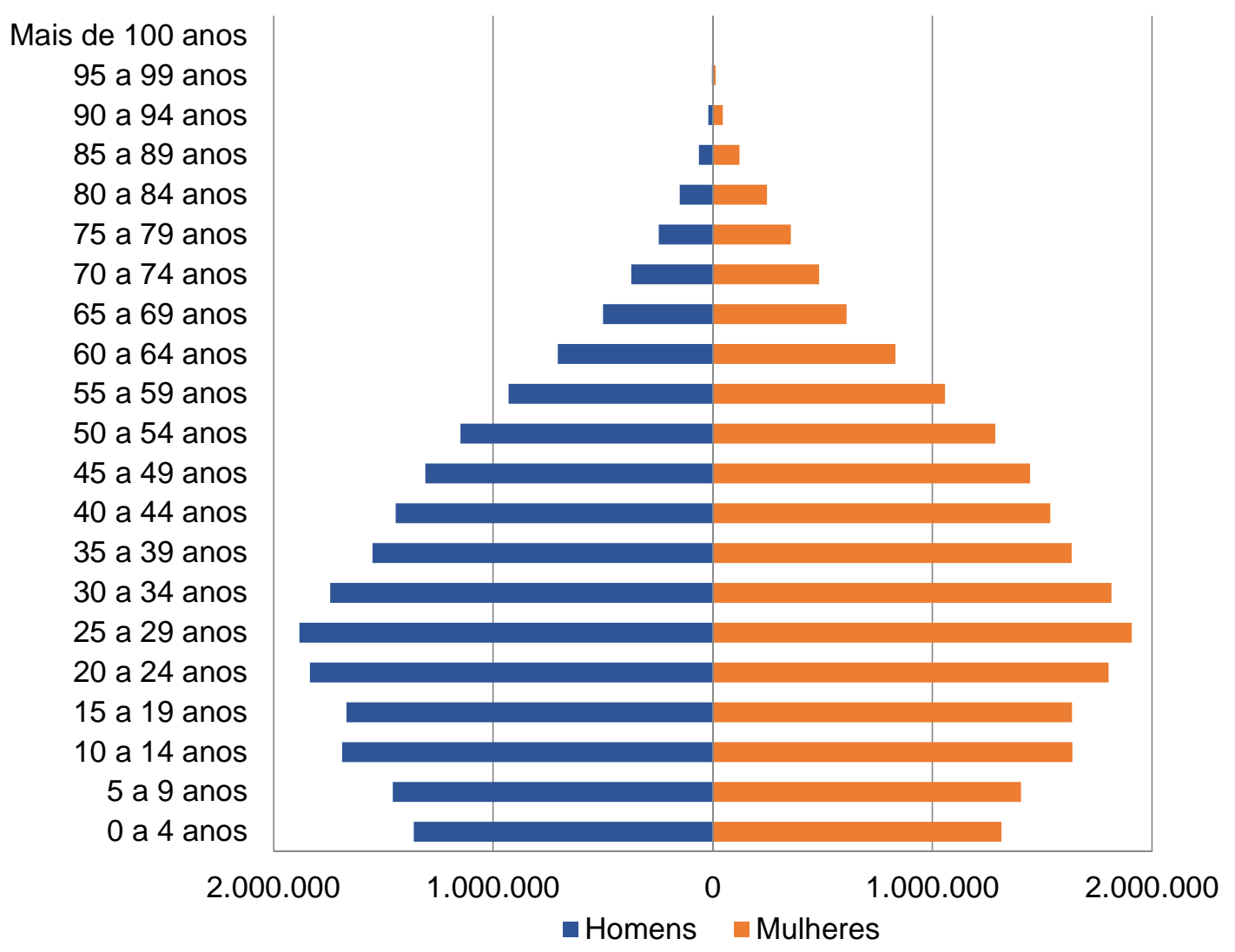

Fonte: São Paulo, 2012.

A partir da análise do gráfico 1 é possível evidenciar a pirâmide etária no formato de gota, a qual demonstra a presença de transição demográfica, por meio do envelhecimento populacional e da redução da taxa de natalidade, bem 
como o quantitativo superior de mulheres em relação aos homens, o que envolve a necessidade do desenvolvimento de ações intersetoriais que oportunizem à mulher manter-se ativa socialmente ao longo de sua vida. Além disso, a redução de jovens dos 15 aos 19 anos é observada, o que sugere a mortalidade devido aos agravos emergentes ou às causas externas, relacionados, por exemplo, à violência urbana.

\subsubsection{PERFIL EPIDEMIOLÓGICO}

As causas de mortalidade no estado de São Paulo são apresentadas utilizando-se da Classificação Internacional de Doenças - versão 10 (CID -10), entre as quais destacaram-se as doenças crônico-degenerativas, representadas pelas doenças do aparelho circulatório e neoplasias, e as causas externas (Tabela 2). 
Tabela 2 - Causas de mortalidade no estado de São Paulo, segundo a CID - 10 e o sexo. São Paulo, 2017 (adaptado).

\begin{tabular}{|c|c|c|c|c|c|c|}
\hline \multirow[t]{3}{*}{ Causas } & \multicolumn{4}{|c|}{ Sexo } & \multirow{2}{*}{\multicolumn{2}{|c|}{ Total }} \\
\hline & \multicolumn{2}{|c|}{ Masculino } & \multicolumn{2}{|c|}{ Feminino } & & \\
\hline & $\mathrm{N}$ & $\%$ & $\mathrm{~N}$ & $\%$ & $\mathrm{~N}$ & $\%$ \\
\hline IX. Doenças do aparelho circulatório & 38.139 & 26,9 & 34.232 & 35,6 & 72.371 & 30,4 \\
\hline II. Neoplasias & 19.516 & 13,8 & 15.857 & 16,5 & 35.383 & 14,9 \\
\hline XX. Causas externas & 28.759 & 20,3 & 4.742 & 4,9 & 33.501 & 14,1 \\
\hline X. Doenças do aparelho respiratório & 14.054 & 9,9 & 10.922 & 11,4 & 24.976 & 10,5 \\
\hline $\begin{array}{l}\text { XVIII. Sintomas, sinais e achados anormais em exames } \\
\text { clínicos e laboratoriais }\end{array}$ & 9.432 & 6,7 & 6.210 & 6,5 & 15.642 & 6,6 \\
\hline XI. Doenças do aparelho digestivo & 8.634 & 6,1 & 4,397 & 4,6 & 13.031 & 5,5 \\
\hline IV. Doenças endócrinas nutricionais e metabólicas & 4.977 & 3,5 & 6.251 & 6,5 & 11.228 & 4,7 \\
\hline I. Algumas doenças infecciosas e parasitárias & 7.077 & 5,0 & 4.000 & 4,2 & 11.077 & 4,7 \\
\hline XVI. Algumas afecções originadas no período perinatal & 3.849 & 2,7 & 2.927 & 3,0 & 6.776 & 2,9 \\
\hline XIV. Doenças do aparelho geniturinário & 1.984 & 1,4 & 1.815 & 1,9 & 3.799 & 1,6 \\
\hline VI. Doenças do sistema nervoso & 1.840 & 1,3 & 1.573 & 1,6 & 3.413 & 1,4 \\
\hline Todas as demais causas & 3.434 & 2,4 & 3.093 & 3,2 & 6.529 & 2,7 \\
\hline Total & 141.695 & 100 & 96.029 & 100 & 237.726 & 100 \\
\hline
\end{tabular}

Fonte: São Paulo, 2012. 
A tabela 2 demonstra o registro de 6,6\% (15.642) das causas de morte no estado de São Paulo sob o Capítulo XVIII - Sintomas, sinais e achados anormais em exames clínicos e laboratoriais da CID - 10, o que sugere a possibilidade da reduzida qualidade nos registros dos bancos de dados estaduais, bem como a baixa capacitação profissional para atribuição do diagnóstico médico nestas situações.

Além disso, é evidenciada a carga tripla de doenças, por meio da ocorrência das doenças crônico-degenerativas, conjuntamente, às doenças infectocontagiosas e aos eventos decorrentes das causas externas, o que por sua vez denota a necessidade da implantação de ações direcionadas para a promoção à saúde e prevenção de agravos.

Neste sentido, a tabela 3 mostra a mortalidade no estado de São Paulo de acordo com os tipos de causas externas, o que remete à ideia da necessidade do desenvolvimento de métodos para a identificação de grupos sociais vulneráveis com maior predisposição a estes eventos, bem como a proposição de ações intersetoriais que minimizem essas causas de morte.

Tabela 3 - Mortalidade, em 2009, segundo os tipos de causas externas e sexo. São Paulo, 2017 (adaptado).

\begin{tabular}{lcccccc}
\hline Causas & \multicolumn{3}{c}{ Sexo } & \multicolumn{3}{c}{ Total } \\
\cline { 2 - 5 } & \multicolumn{2}{c}{ Masculino } & \multicolumn{2}{c}{ Feminino } & & \\
\cline { 2 - 5 } Acidente de transporte & 4.866 & 24,1 & 1.055 & 20,0 & 5.924 & 23,2 \\
Homicídios & 4.913 & 24,4 & 568 & 10,8 & 5.487 & 21,5 \\
Suicídios & 1.490 & 7,4 & 323 & 6,1 & 1.814 & 7,1 \\
Quedas & 1.047 & 5,2 & 402 & 7,6 & 1.449 & 5,7 \\
Demais lesões & 7.875 & 39,0 & 2.928 & 55,5 & 10.812 & 42,4 \\
\hline Total & 20.191 & 100 & 5.276 & 100 & 25.486 & 100 \\
\hline
\end{tabular}

Fonte: São Paulo, 2012. 
A análise da tabela 3 permite visualizar a pertinência do desenvolvimento de ações direcionadas para homens e mulheres, visto que os homens em comparação às mulheres têm maior predisposição às causas externas, principalmente, quanto aos acidentes de trânsito, homicídios e suicídios. Entretanto, as quedas e demais causas se destacam entre as mulheres, o que deve ser alvo de investigação aprofundada para a compreensão da ocorrência desses eventos e elaboração de ações intersetoriais efetivas.

Já o gráfico 2 mostra a redução do coeficiente de mortalidade infantil, pós-neonatal e neonatal do estado de São Paulo, no período de 2000 a 2009.

Gráfico 2 - Coeficiente de mortalidade infantil, pós-neonatal e neonatal do estado de São Paulo, segundo os anos. São Paulo, 2017 (adaptado).

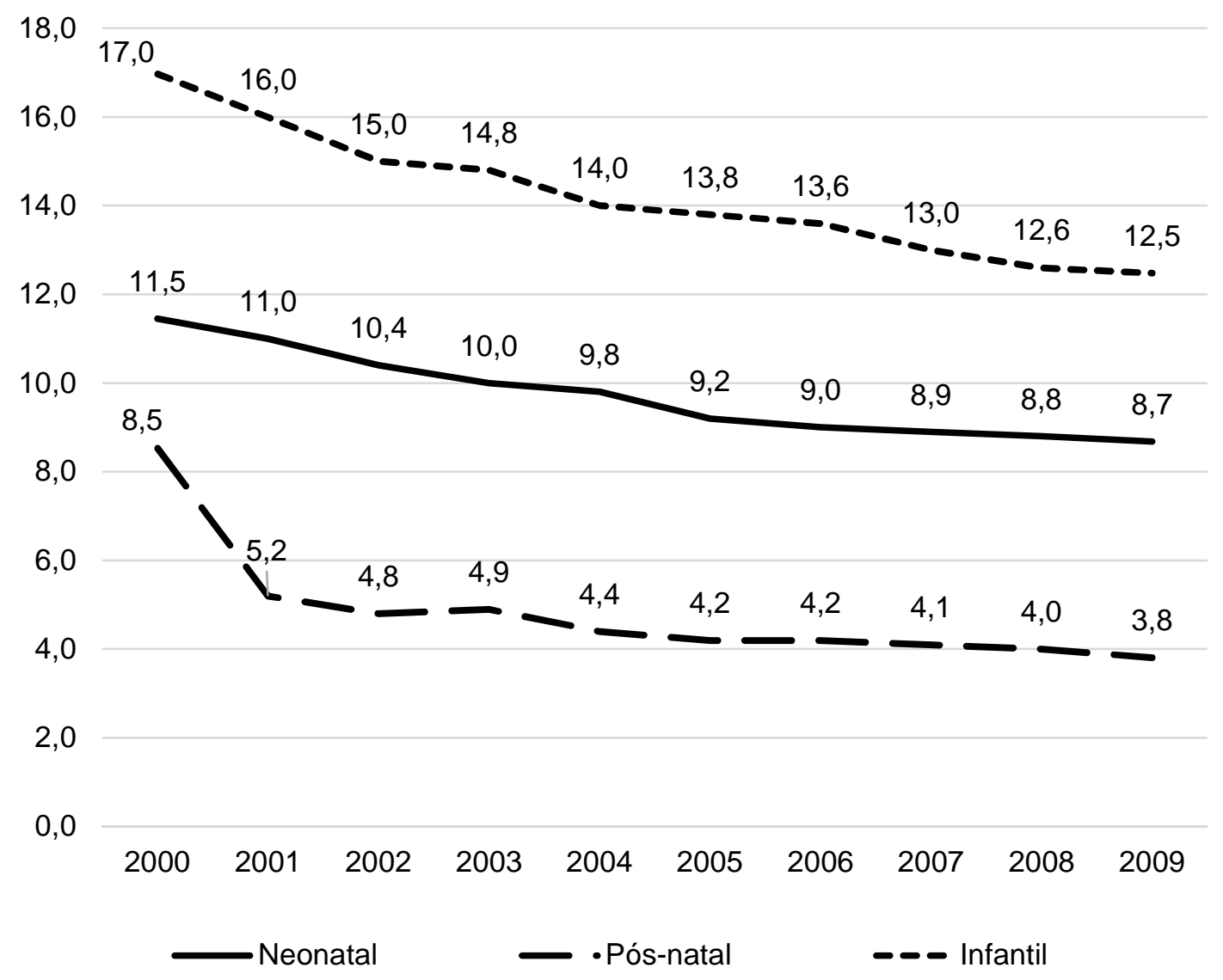

Fonte: São Paulo, 2012. 
O PES apontou as afecções do período perinatal (57\%), seguidas das malformações congênitas, deformidades e anomalias cromossômicas (22\%) como as principais causas de óbito em menores de um ano (São Paulo, 2012). Estas evidências denotam a importância das ações pré e perinatais, embasadas na promoção à saúde e prevenção de doenças, as quais têm potencialidade para reduzir agravos e óbitos, por meio de estratégias de educação em saúde, empoderamento de grupos sociais vulneráveis e apoio às famílias.

Já a análise específica do coeficiente de mortalidade infantil comparando-se os anos 2000 e 2009 (Tabela 4), demonstrou que apesar da redução de óbitos em menores de um ano no estado de São Paulo ter ocorrido, este resultado não atendeu ao preconizado pela Organização Mundial da Saúde (OMS), que estabelece a proporção máxima de 10:1.000 nascidos vivos (IPEA, 2014), tampouco, os resultados praticados em países desenvolvidos, nos quais a mortalidade infantil é registrada utilizando-se um dígito para cada 1.000 nascidos vivos (São Paulo, 2012).

Isto denota a urgência na identificação de grupos sociais com maior vulnerabilidade à mortalidade infantil no estado de São Paulo, bem como a elaboração, implantação e monitoramento de ações que respondam de forma efetiva contribuindo para a sobrevida das crianças paulistas, em especial, por exemplo, aquelas residentes em DRSs que tiveram maior ocorrência de óbitos em 2009, como: Baixada Santista (18,83\%), Franca $(15,35 \%)$ e Sorocaba $(14,26 \%)$, bem como aquelas de DRSs que obtiveram uma significativa melhora neste indicador, mas que necessitam de ações de manutenção e monitoramento, como o DRS de Barretos que reduziu a mortalidade infantil em $41,7 \%$, ou seja, de $16,80 \%$ em 2000 para $9,80 \%$ em 2009 , e Registro que a reduziu em $38,6 \%$, ou seja, de 19,75 em 2000 para 12,14 em 2009 (Tabela 4). 
Tabela 4 - Variação percentual do coeficiente de mortalidade infantil no estado de São Paulo, entre os anos de 2000 e 2009, segundo os DRSs. São Paulo, 2017 (adaptado).

\begin{tabular}{lccc}
\hline $\begin{array}{l}\text { Departamentos Regionais } \\
\text { de Saúde }\end{array}$ & 2000 & 2009 & $\begin{array}{c}\text { Anoriação percentual, } \\
\text { entre 2000 e 2009 }\end{array}$ \\
\hline Araçatuba & 16,30 & 12,35 & $-24,2$ \\
Araraquara & 14,08 & 12,32 & $-12,5$ \\
Baixada Santista & 22,19 & 18,83 & $-15,2$ \\
Barretos & 16,80 & 9,80 & $-41,7$ \\
Bauru & 17,99 & 12,20 & $-32,2$ \\
Campinas & 14,78 & 11,19 & $-24,3$ \\
Franca & 19,14 & 15,35 & $-19,8$ \\
Grande São Paulo & 16,90 & 12,34 & $-27,0$ \\
Marília & 17,30 & 11,26 & $-34,9$ \\
Piracicaba & 14,30 & 10,67 & $-25,3$ \\
Presidente Prudente & 17,76 & 12,42 & $-30,1$ \\
Registro & 19,75 & 12,14 & $-38,6$ \\
Ribeirão Preto & 13,67 & 9,87 & $-27,8$ \\
São João da Boa Vista & 16,11 & 11,77 & $-27,0$ \\
São José do Rio Preto & 12,45 & 11,28 & $-9,4$ \\
Sorocaba & 19,34 & 14,26 & $-26,3$ \\
Taubaté & 16,78 & 13,32 & $-20,7$ \\
\hline Estado de São Paulo & 16,97 & 12,48 & $-26,4$ \\
\hline
\end{tabular}

Fonte: São Paulo, 2012.

Quanto à mortalidade materna, entre os anos de 1980 e 2000, verificouse redução de, aproximadamente, $63,6 \%$, bem como manutenção do seu padrão 
ao longo dos últimos anos, entre 30 e 35 mortes para cada 100.000 nascidos vivos (Gráfico 3), o que se afasta do preconizado pela OMS, que estabeleceu no 5 o Objetivo do Desenvolvimento do Milênio a redução em $75 \%$ da mortalidade materna até 2015 no Brasil (IPEA, 2014).

Gráfico 3 - Coeficiente de mortalidade materna no estado de São Paulo, segundo os anos. São Paulo, 2017 (adaptado).

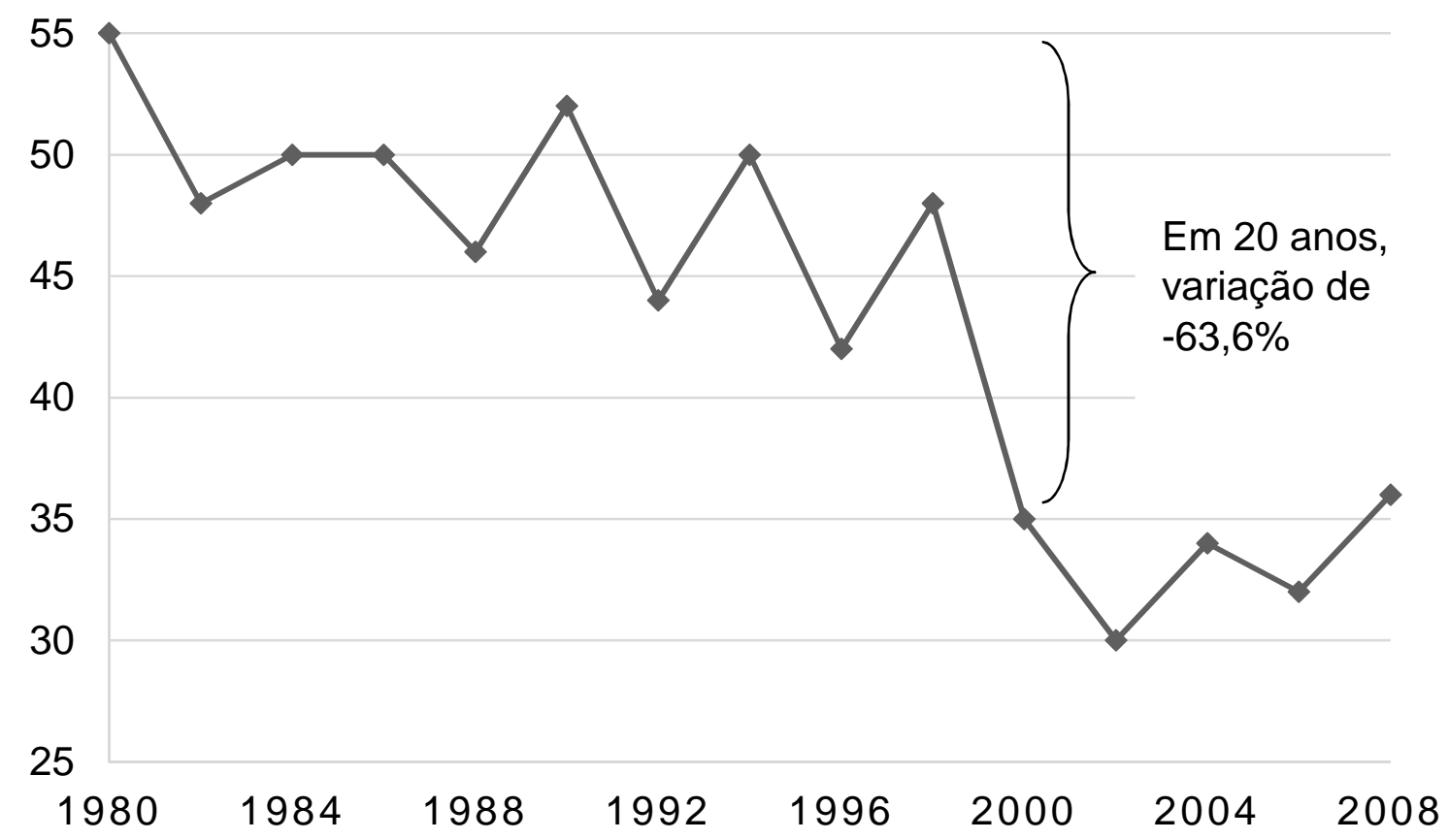

Fonte: São Paulo, 2012.

A tabela 5 mostra as causas mortalidade materna, no ano de 2009, entre as quais $58,2 \%$ se referiram à hipertensão arterial e eclampsia ( $27,8 \%)$, às outras doenças por complicação de gravidez e parto $(20,7 \%)$ e às complicações no trabalho de parto e parto $(9,7 \%)$. As demais causas de morte, não menos importantes, somaram $41,8 \%$ e também demandam por atenção da gestão pública municipal, como, por exemplo, por meio do estabelecido pelo $5^{\circ}$ Objetivo do Desenvolvimento do Milênio, relacionado ao cuidado à gestante, para o qual o governo federal desenvolveu programas com atenção voltada ao pré-natal; parto e nascimento; puerpério e atenção integral à saúde da criança; e sistema logístico (IPEA, 2014). 
Tabela 5 - Causas de mortalidade materna no estado de São Paulo, em 2009, segundo a CID - 10. São Paulo, 2017 (adaptado).

\begin{tabular}{|c|c|c|}
\hline Causas & $\mathrm{N}$ & $\%$ \\
\hline Hipertensão arterial / Eclampsia & 63 & 27,8 \\
\hline $\begin{array}{l}\text { Outras doenças por complicação } \\
\text { de gravidez e parto }\end{array}$ & 47 & 20,7 \\
\hline Complicações no trabalho de parto e parto & 22 & 9,7 \\
\hline Hemorragia pós-parto & 14 & 6,2 \\
\hline $\begin{array}{l}\text { Aborto não especificado e } \\
\text { falha na tentativa de aborto }\end{array}$ & 13 & 5,7 \\
\hline Embolia de origem obstétrica & 11 & 4,8 \\
\hline Infecção puerperal & 9 & 4,0 \\
\hline Outras infecções puerperais & 6 & 2,6 \\
\hline Infecção do trato geniturinário na gravidez & 5 & 2,2 \\
\hline Deslocamento prematuro da placenta & 5 & 2,2 \\
\hline Outras causas & 32 & 14,1 \\
\hline Total & 227 & 100 \\
\hline
\end{tabular}

Fonte: São Paulo, 2012. 
Tabela 6 - Variação percentual das internações hospitalares no estado de São Paulo, nos anos de 2001 e 2010, segundo a CID 10. São Paulo, 2016 (adaptado).

\begin{tabular}{|c|c|c|c|c|c|}
\hline \multirow{3}{*}{ Causas das internações hospitalares } & \multicolumn{4}{|c|}{ Anos } & \multirow{3}{*}{$\begin{array}{c}\text { Variação } \\
\text { percentual, } \\
\text { entre } 2001 \text { e } 2010\end{array}$} \\
\hline & \multicolumn{2}{|c|}{2001} & \multicolumn{2}{|c|}{2010} & \\
\hline & $\mathrm{N}$ & $\%$ & $\mathrm{~N}$ & $\%$ & \\
\hline V. Transtornos mentais e comportamentais & 102.635 & 4,76 & 75.861 & 3,25 & $-26,09$ \\
\hline $\begin{array}{l}\text { IV. Doenças nutricionais endócrinas e } \\
\text { metabólicas }\end{array}$ & 64.272 & 2,98 & 54.006 & 2,31 & $-15,97$ \\
\hline XV. Gravidez, parto e puerpério & 486.566 & 22,56 & 442.030 & 18,94 & $-9,15$ \\
\hline $\begin{array}{l}\text { VIII. Doenças do ouvido e da apófise e } \\
\text { mastoide }\end{array}$ & 7.843 & 0,36 & 7.259 & 0,31 & $-7,45$ \\
\hline $\begin{array}{l}\text { XIII. Doenças do sistema osteomuscular e } \\
\text { tecido conjuntivo }\end{array}$ & 55.123 & 2,56 & 51.378 & 2,20 & $-6,79$ \\
\hline X. Doenças do aparelho respiratório & 266.733 & 12,37 & 254.216 & 10,89 & $-4,69$ \\
\hline $\begin{array}{l}\text { XVIII. Sintomas, sinais e achados anormais } \\
\text { em exames clínicos e laboratoriais }\end{array}$ & 43.985 & 2,04 & 42.995 & 1,84 & $-2,25$ \\
\hline VI. Doenças do sistema nervoso & 46.887 & 2,17 & 45.972 & 1,97 & $-1,95$ \\
\hline I. Algumas doenças infecciosas e parasitárias & 101.229 & 4,69 & 108.759 & 4,66 & 7,44 \\
\hline IX. Doenças do aparelho circulatório & 237.162 & 11,00 & 264.459 & 11,33 & 11,51 \\
\hline
\end{tabular}




\begin{tabular}{|c|c|c|c|c|c|}
\hline \multirow{3}{*}{ Causas das internações hospitalares } & \multicolumn{4}{|c|}{ Anos } & \multirow{3}{*}{$\begin{array}{c}\text { Variação } \\
\text { percentual, entre } \\
2001 \text { e } 2010\end{array}$} \\
\hline & \multirow{2}{*}{$\begin{array}{c}2001 \\
N\end{array}$} & \multicolumn{3}{|c|}{2010} & \\
\hline & & $\%$ & $\mathrm{~N}$ & $\%$ & \\
\hline $\begin{array}{l}\mathrm{XVI} \text {. Algumas afecções originadas no período } \\
\text { perinatal }\end{array}$ & 44.832 & 2,08 & 51.348 & 2,20 & 14,53 \\
\hline $\begin{array}{l}\text { XVII. Malformações congênitas, } \\
\text { deformidades e anomalias cromossômicas }\end{array}$ & 18.728 & 0,87 & 21.804 & 0,93 & 16,42 \\
\hline $\begin{array}{l}\text { III. Doenças do sangue, órgãos } \\
\text { hematopoiéticos e transtornos imunitários }\end{array}$ & 14.523 & 0,67 & 17.066 & 0,73 & 17,51 \\
\hline XI. Doenças do aparelho digestivo & 193.900 & 8,99 & 231.234 & 9,91 & 19,25 \\
\hline XIV. Doenças do aparelho geniturinário & 132.876 & 6,16 & 167.603 & 7,18 & 26,13 \\
\hline VII. Doenças do olho e anexos & 19.598 & 0,91 & 24.951 & 1,07 & 27,31 \\
\hline $\begin{array}{l}\text { XIX. Lesões, envenenamento e algumas } \\
\text { outras consequências de causas externas }\end{array}$ & 162.478 & 7,53 & 224.384 & 9,59 & 38,10 \\
\hline XXI. Contatos com serviços de saúde & 43.106 & 2,00 & 60.342 & 2,59 & 39,99 \\
\hline II. Neoplasias & 87.420 & 4,05 & 141.580 & 6,07 & 61,95 \\
\hline XII. Doenças da pele e do tecido subcutâneo & 26.637 & 1,24 & 46.454 & 1,99 & 74,40 \\
\hline Total & 2.156 .523 & 100 & 2.333 .701 & 100 & 8,22 \\
\hline
\end{tabular}

Fonte: São Paulo, 2012. 
A tabela 6 demonstra as causas de internação hospitalar no estado de São Paulo, comparando-se os anos de 2001 e 2010. A sua análise evidencia que, apesar da redução de internações hospitalares devido aos transtornos mentais e comportamentais $(-26,09 \%)$, bem como das doenças nutricionais, endócrinas e metabólicas $(-15,97 \%)$ e das doenças do ouvido, apófise e mastoide $(-7,45)$, em linhas gerais, houve aumento em maior ou menor proporção das internações hospitalares, o que denota a relevância da compreensão dessas causas de adoecimento a partir da identificação de grupos sociais vulneráveis e com perfil de produção e reprodução social que os predisponham a esses agravos.

\subsubsection{REDE DE ATENÇÃo À SAÚDE}

A RAS do estado de São Paulo é organizada a partir de 17 DRSs (Figura 1), sendo estes compostos por uma grande diversidade de equipamentos de saúde para atender às necessidades em saúde da população (Tabela 7).

Figura 1 - Redes de atenção à saúde do estado de São Paulo, segundo os DRSs. São Paulo, 2017 (adaptado).

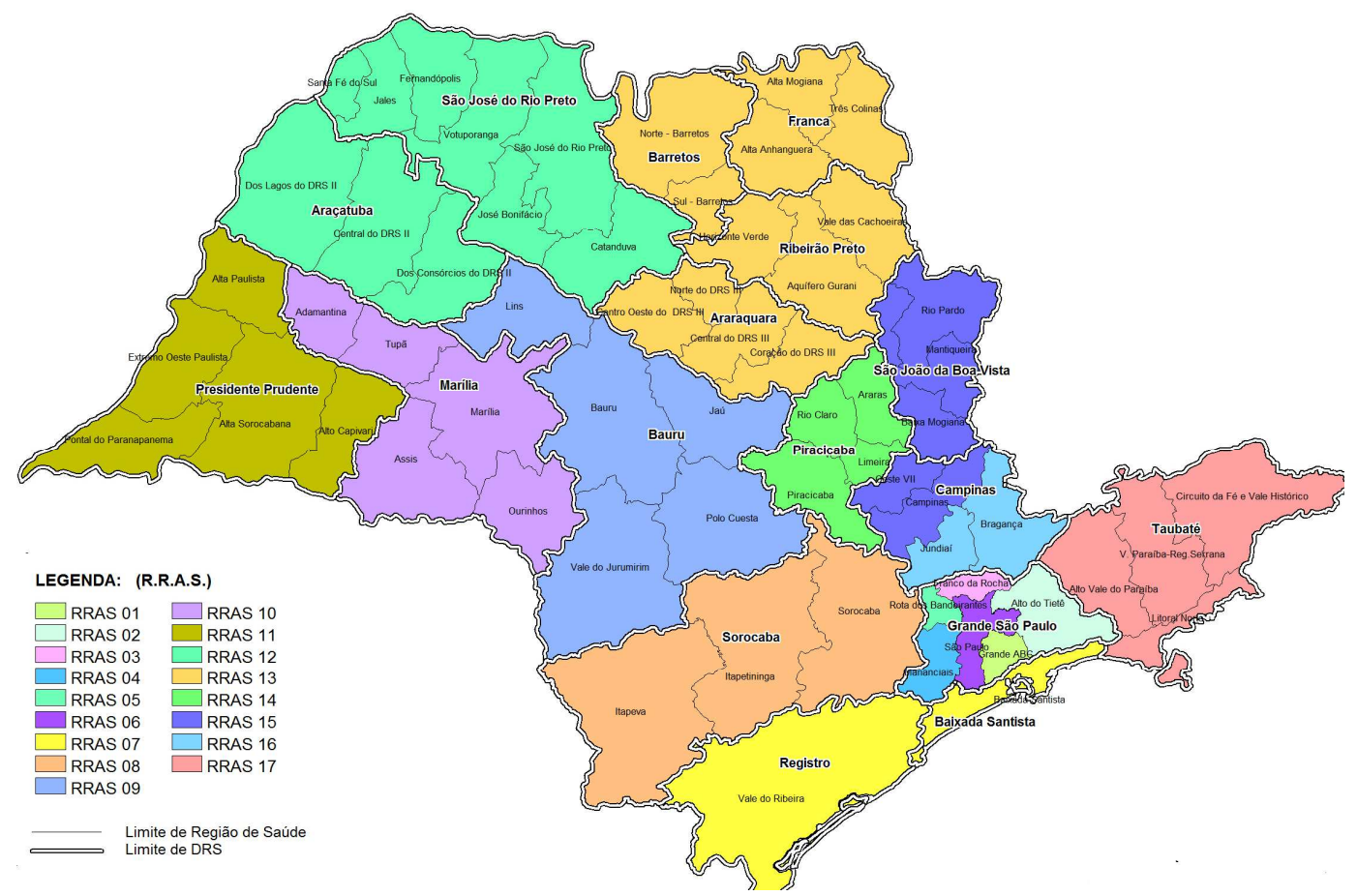

Fonte: São Paulo, 2012. 
Tabela 7 - Equipamentos de saúde, em 2010, no estado de São Paulo, segundo os DRSs. São Paulo, 2017 (adaptado).

\begin{tabular}{|c|c|c|c|c|c|c|}
\hline \multirow[b]{2}{*}{$\begin{array}{l}\text { Departamentos regionais } \\
\text { de saúde }\end{array}$} & \multicolumn{6}{|c|}{ Equipamentos de saúde } \\
\hline & $\begin{array}{l}\text { Unidade Básica } \\
\text { de Saúde }\end{array}$ & $\begin{array}{c}\text { Centro de } \\
\text { Atenção } \\
\text { Psicossocial }\end{array}$ & $\begin{array}{l}\text { Ambulatório de } \\
\text { Especialidade }\end{array}$ & Unidade Mista & Hospital Dia & Hospital \\
\hline Grande São Paulo & 1.106 & 104 & 397 & 6 & 5 & 149 \\
\hline Araçatuba & 119 & 3 & 37 & 1 & - & 23 \\
\hline Araraquara & 154 & 6 & 47 & 1 & - & 20 \\
\hline Baixada Santista & 151 & 21 & 78 & - & 3 & 15 \\
\hline Barretos & 87 & 3 & 31 & 4 & 1 & 12 \\
\hline Bauru & 291 & 13 & 84 & - & 2 & 50 \\
\hline Campinas & 447 & 37 & 164 & 2 & 5 & 49 \\
\hline Franca & 115 & 3 & 44 & - & - & 13 \\
\hline Marília & 267 & 12 & 51 & - & - & 42 \\
\hline Piracicaba & 210 & 10 & 83 & 2 & - & 16 \\
\hline Presidente Prudente & 189 & 7 & 22 & - & - & 22 \\
\hline Registro & 82 & - & 2 & 1 & - & 6 \\
\hline Ribeirão Preto & 171 & 9 & 86 & 2 & - & 25 \\
\hline São João da Boa Vista & 120 & 11 & 55 & - & - & 24 \\
\hline São José do Rio Preto & 306 & 10 & 79 & - & 1 & 44 \\
\hline Sorocaba & 350 & 20 & 118 & - & - & 38 \\
\hline Taubaté & 352 & 18 & 91 & 7 & 3 & 34 \\
\hline Total & 4.517 & 287 & 1.469 & 26 & 20 & 582 \\
\hline
\end{tabular}


O gráfico 4 demonstra que no período de 1998 a 2010 houve expansão no número de equipes da Estratégia Saúde da Família (ESF), o que denota um grande avanço, visto que reforça a consolidação da APS como articuladora e coordenadora da gestão em saúde municipal, na qual a ESF tem papel imprescindível.

Gráfico 4 - Número de equipes da ESF no estado de São Paulo, segundo o ano. São Paulo, 2017 (adaptado).

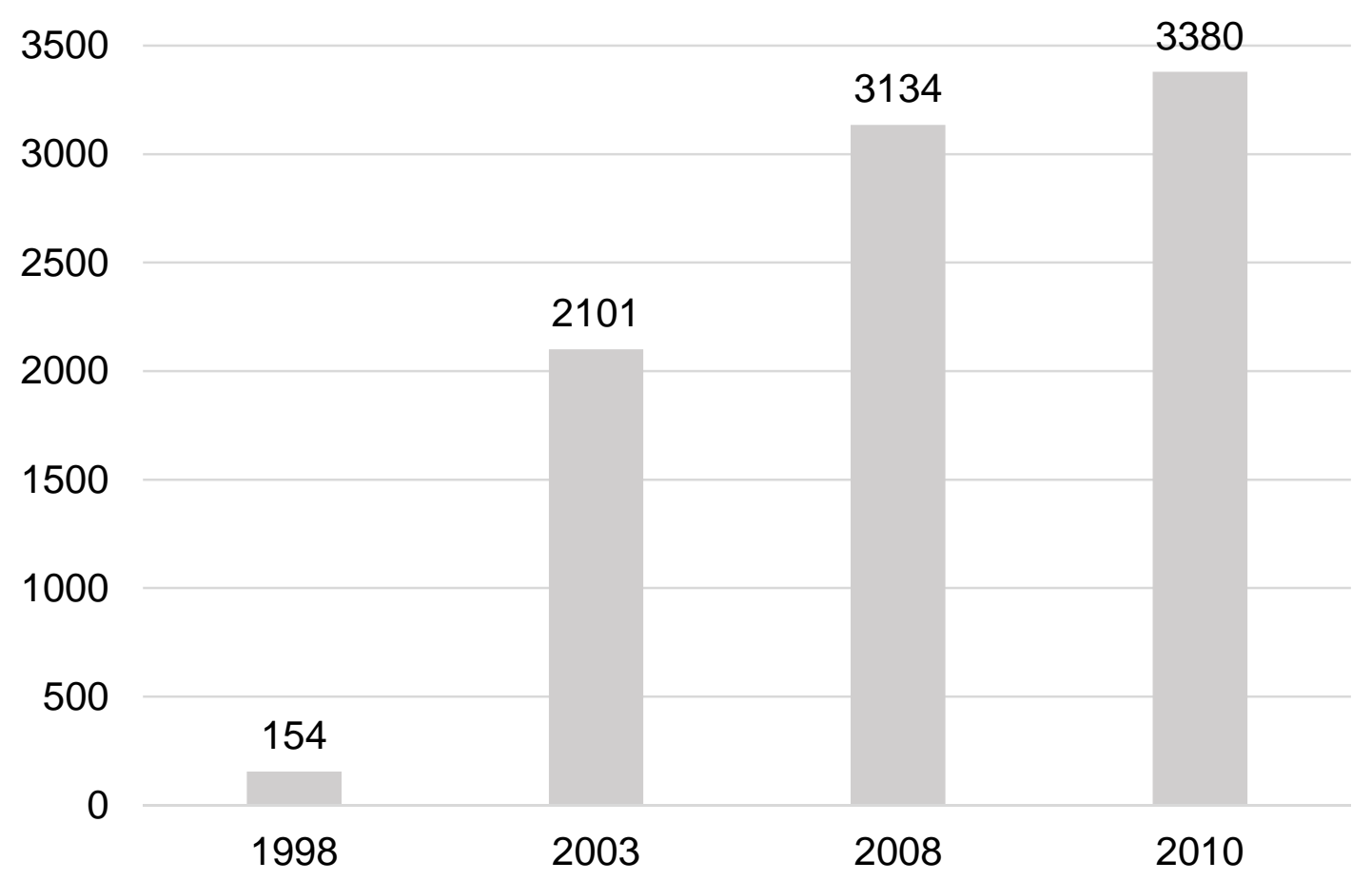

Fonte: São Paulo, 2012.

A tabela 8 mostra que, comparando-se os anos 2001 e 2010, houve aumento na cobertura das famílias residentes em todos os DRSs do estado de São Paulo pela ESF.

Entretanto, vale relativizar que, em linhas gerais, esta cobertura (em 2010) foi de apenas, aproximadamente, $28 \%$ das famílias do estado de São Paulo, apesar da Política Nacional de Atenção Básica preconizar que a ESF seja adotada pelos municípios como estratégia prioritária para a articulação, consolidação e qualificação da APS (Brasil, 2012c). 
Tabela 8 - Cobertura estimada da população do estado de São Paulo, pelas equipes da ESF, segundo os DRSs. São Paulo, 2017 (adaptado).

\begin{tabular}{|c|c|c|c|c|c|c|}
\hline \multirow[b]{2}{*}{$\begin{array}{l}\text { Departamentos regionais de } \\
\text { saúde }\end{array}$} & \multicolumn{3}{|c|}{ Ano de 2001} & \multicolumn{3}{|c|}{ Ano de 2010} \\
\hline & $\begin{array}{c}\text { ESF } \\
\text { Implantado }\end{array}$ & $\begin{array}{l}\text { Número de } \\
\text { habitantes }\end{array}$ & $\begin{array}{c}\text { Estimativa } \\
\text { percentual de } \\
\text { acompanhados }\end{array}$ & $\begin{array}{c}\text { ESF } \\
\text { Implantado }\end{array}$ & $\begin{array}{l}\text { Número de } \\
\text { habitantes }\end{array}$ & $\begin{array}{c}\text { Estimativa } \\
\text { percentual de } \\
\text { acompanhado }\end{array}$ \\
\hline Grande São Paulo & 280 & 18.128 .061 & 5,33 & 1.355 & 19.683 .975 & 23,75 \\
\hline Araçatuba & 89 & 664.089 & 46,24 & 145 & 719.323 & 69,54 \\
\hline Araraquara & 14 & 838.247 & 5,76 & 75 & 920.257 & 28,12 \\
\hline Baixada Santista & 22 & 1.505 .898 & 5,04 & 132 & 1.664 .136 & 27,37 \\
\hline Barretos & 10 & 392.241 & 8,80 & 52 & 411.690 & 43,58 \\
\hline Bauru & 32 & 1.490 .971 & 7,40 & 137 & 1.624 .623 & 29,09 \\
\hline Campinas & 117 & 3.464 .825 & 11,65 & 267 & 4.031 .910 & 22,85 \\
\hline Franca & 15 & 600.194 & 8,62 & 61 & 649.807 & 32,39 \\
\hline Marília & 83 & 1.020 .225 & 28,07 & 163 & 1.068 .408 & 52,63 \\
\hline Piracicaba & 54 & 1.273 .441 & 14,63 & 117 & 1.412 .584 & 28,58 \\
\hline $\begin{array}{l}\text { Presidente Prudente } \\
\text { Registro }\end{array}$ & $\begin{array}{l}99 \\
36\end{array}$ & $\begin{array}{l}689.580 \\
274.066\end{array}$ & $\begin{array}{l}49.53 \\
45,32\end{array}$ & $\begin{array}{c}150 \\
57\end{array}$ & $\begin{array}{l}722.781 \\
273.566\end{array}$ & $\begin{array}{l}71.66 \\
71,88\end{array}$ \\
\hline Ribeirão Preto & 31 & 1.156 .019 & 9,25 & 68 & 1.327 .989 & 17,67 \\
\hline São João da Boa Vista & 26 & 738.731 & 12,14 & 53 & 773.781 & 23,63 \\
\hline São José do Rio Preto & 68 & 1.349 .933 & 17,38 & 166 & 1.470 .348 & 38.95 \\
\hline Sorocaba & 99 & 2.012 .364 & 16,97 & 156 & 2.243 .016 & 23,99 \\
\hline Taubaté & 100 & 2.031 .220 & 16,98 & 226 & 2.264 .594 & 34,43 \\
\hline Total & 1.175 & 37.630 .105 & 10,77 & 3.380 & 41.262 .199 & 28,26 \\
\hline
\end{tabular}

Fonte: São Paulo, 2012. 


\subsection{FONTES E ANÁLISE DOS DADOS EMPÍRICOS}

A fonte dos dados empíricos será de natureza secundária, uma vez que foi realizada a consulta aos PMSs e RAGMs no Sistema de Apoio à Construção do Relatório de Gestão (SARG-SUS), disponíveis e emitidos a partir de 2000, quando da publicação da Emenda Constitucional (EC) № 29/2000, que estabeleceu a responsabilidade de estados e municípios quanto ao investimento percentual mínimo de, respectivamente, $12 \%$ e $15 \%$ de suas receitas em saúde (Brasil, 2000).

Paralelamente, foi realizada uma consulta junto às páginas eletrônicas das prefeituras do estado de São Paulo, a fim de verificar a disponibilidade desses documentos em canal público, seja por meio da secretaria de saúde municipal ou da secretaria executiva dos Conselhos Municipais de Saúde (CMS). Os CMSs configuram-se como responsáveis pela guarda de tais documentos, haja vista a obrigatoriedade de comprovação dos investimentos em saúde pelos municípios, conforme determinado pela EC nำ29/2000, a qual, posteriormente, ganhou força de lei em 2012, por meio da Lei Complementar no 141 (Brasil, 2012a).

Entretanto, nessa consulta, constatou-se que nenhum dos 645 municípios do estado de São Paulo apresentou a totalidade dos PMSs e RAGMs, a partir de 2000, em canal de domínio público. Apenas 1,9\% (12) municípios disponibilizaram alguns destes documentos do período proposto para análise.

Para a coleta dos dados, optou-se pela amostragem probabilística de alguns municípios do estado de São Paulo, sendo os participantes desta pesquisa: Araraquara, Santos, Valinhos e Vinhedo, cujo método adotado para a seleção está explicitado na figura 2. 
Figura 2 - Método de seleção dos municípios participantes. São Paulo, 2017.

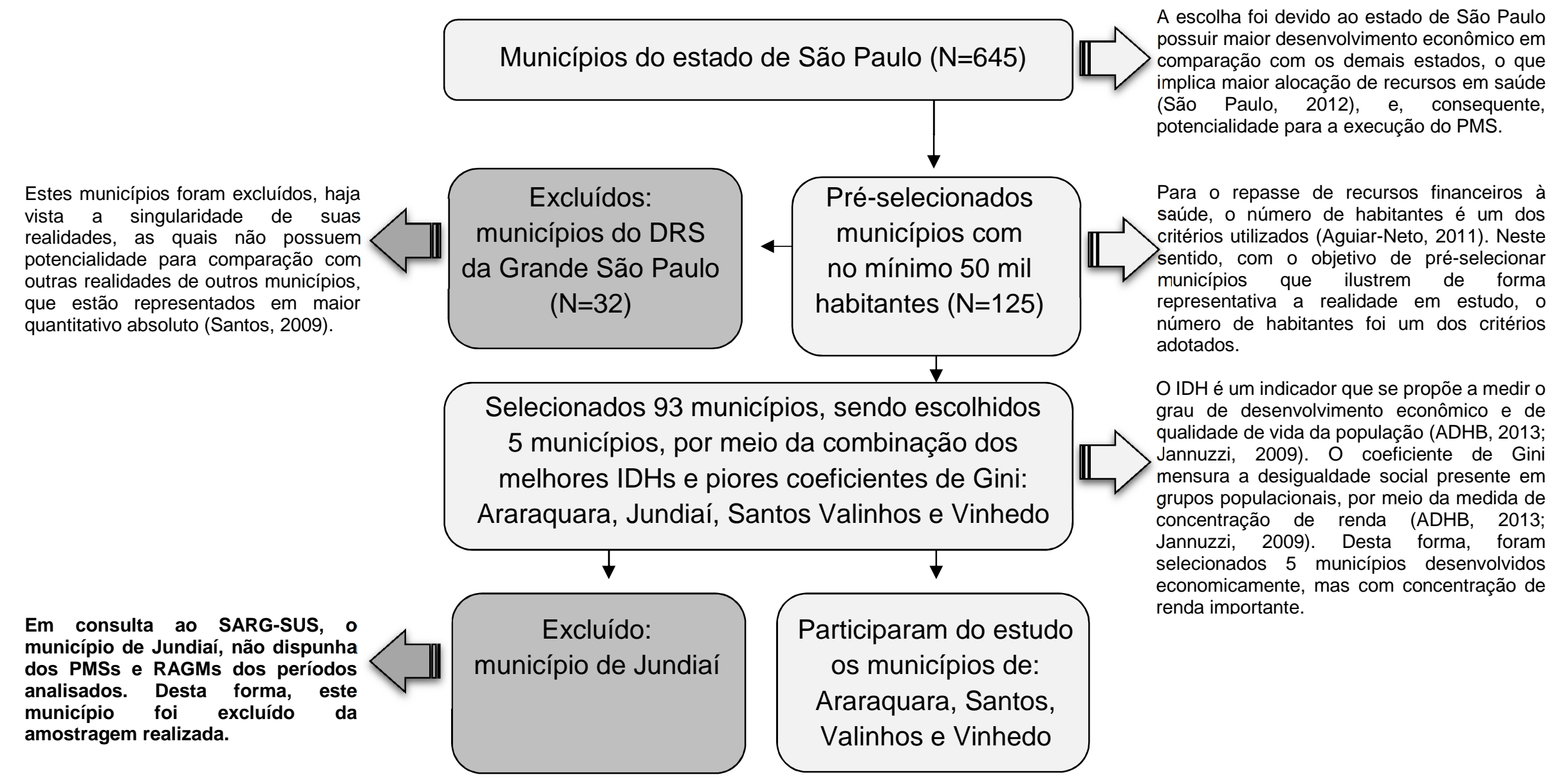


A opção por selecionar os municípios considerando o IDH e o coeficiente de Gini ocorreu devido a estes indicadores sociais serem utilizados em larga escala, além de consagrados internacionalmente (Jannuzzi, 2009), permitindo a replicabilidade da metodologia deste estudo em outras realidades.

O IDH é produto do Programa das Nações Unidas para 0 Desenvolvimento (PNUD), o qual foi proposto, em 1990, como desdobramento do primeiro Relatório do Desenvolvido Humano publicado em Londres (Machado, Pamplona, 2008).

O IDH é formado por 3 elementos essenciais: longevidade, em que se utiliza o indicador de expectativa de vida ao nascer; conhecimento, o qual é analisado por meio da taxa de alfabetização e a média dos anos de escolaridade da população; e padrão de vida, em que o PIB per capita é analisado ajustado pela paridade do poder aquisitivo (Jannuzzi, 2009; Machado, Pamplona, 2008).

A análise do IDH é realizada por meio de faixas de desenvolvimento humano (Tabela 9).

Tabela 9 - Faixas de desenvolvimento humano, segundo o IDH. São Paulo, 2017.

\begin{tabular}{cc}
\hline IDH & Interpretação \\
\hline $0,800+1,000$ & Muito Alto \\
$0,700+0,800$ & Alto \\
$0,700+0,600$ & Médio \\
$0,600+0,500$ & Baixo \\
$0,500+0,000$ & Muito Baixo \\
\hline
\end{tabular}

Fonte: ADHB, 2013

Entretanto, a análise do desenvolvimento humano extrapola a mensuração do IDH, sendo necessária a conjugação com outros indicadores de desenvolvimento, como, por exemplo, o coeficiente de Gini, que se propõe a 
mensurar a desigualdade social, por meio da medida de concentração de renda (ADHB, 2013; Jannuzzi, 2009; Machado, Pamplona, 2008).

Desta forma, optou-se pela utilização destes dois indicadores sociais para a seleção final dos municípios participantes, os quais em seguida foram analisados a fim de verificar há presença ou não de diferenças estatisticamente significante quanto ao IDH e ao coeficiente de Gini.

Esse método de seleção dos municípios partiu da necessidade de se estabelecer critérios de elegibilidade para composição da amostra, visto a inviabilidade de análise da totalidade dos municípios brasileiros ou do estado de São Paulo, bem como diante da possibilidade de imutabilidade dos resultados alcançados no estudo, já que eles independem da representatividade da amostra utilizada, tampouco da obrigatoriedade de estudo da totalidade da realidade brasileira. Isto porque os PMSs e os RAGMs são normalizados pela área de planejamento do Ministério da Saúde e sua metodologia replicada nas realidades locais dos municípios brasileiros (Brasil, 2009b; Brasil, 2013b; Brasil, 2016).

Assim, o que propõe este estudo é compreender a dinâmica metodológica de planejamento e relatório de gestão municipal de saúde, por meio de instrumentos normativos oriundos da esfera federal. Para que pudesse haver uma base mínima de homogeneidade em termos de características demográficas e sociais entre os territórios, sendo escolhidos os municípios de acordo com alto IDH - portanto, municípios com capacidade econômica de autogerir os recursos existentes - e acrescido do coeficiente de Gini, municípios que apesar de alto potencial econômico comparativo, mostraram alta desigualdade de distribuição de renda.

É importante destacar que os municípios escolhidos não são amostras representativas, mas assemelhados em termos de características demográficas e sociais mensuráveis por meio do IDH e do coeficiente de Gini.

Findada a etapa de seleção dos PMSs e os RAGMs, esses foram organizados e sistematizados por meio de planilhas do software Microsoft Exce ${ }^{\circledR}$ com o auxílio do Instrumento de Coleta de Dados (Apêndice A), o qual foi desenvolvido especificamente para este estudo e estruturado em duas partes: a primeira com a caracterização do município quanto ao seu nome, número de habitantes, DRS, IDH e coeficiente de Gini; e a segunda com a compreensão 
dos conteúdos dos PMSs e dos RAGMs quanto às seguintes categorias de análise: limites dos PMSs e dos RAGMs; potencialidades dos PMSs e RAGMs; e contradições e proposição para a transformação da realidade.

Os dados foram analisados utilizando-se da primeira e segunda etapas preconizadas pela TIPESC, ou seja, captação e interpretação da realidade objetiva do fenômeno deste estudo (Egry, 1996), pois que se realizou a articulação entre os aspectos de produção e reprodução social referentes ao processo saúde-doença presentes nos PMSs e RAGMs considerando-se a realidade dos municípios estudados.

Neste sentido, foi realizada a análise de conteúdo textual dos PMSs e dos RAGMs, com o auxílio do software WebQDA ${ }^{\circledR}$.

Para a análise dos conteúdos selecionados, foi utilizada a metodologia preconizada por Bardin (1977), com o arcabouço teórico da hermenêutica crítica, a partir da qual se realizou o exercício de compreensão dos textos dos PMSs e RAGMs, buscando-se identificar os significados quanto aos limites e potencialidades de ambos os documentos.

Este processo exigiu abstração e imparcialidade para a compreensão do fenômeno sob análise, com vistas a iluminar e organizar as ideias presentes nos documentos analisados.

A partir da compreensão dos conteúdos dos PMSs e dos RAGMs foram identificadas as contradições e, em seguida, foram elaboradas as proposições para a transformação da realidade.

\subsection{ASPECTOS RELATIVOS À ÉTICA EM PESQUISA}

Esta pesquisa tomará como base de dados aqueles de natureza secundária, o que dispensa a apreciação deste estudo por um Comitê de Ética em Pesquisa, como preconizado pela Resolução do Conselho Nacional de Saúde ํo 466 de 2012, que regulamenta a realização de pesquisas científicas com seres humanos (Brasil, 2012b).

Entretanto, visando garantir a lisura da intenção dos pesquisadores envolvidos neste estudo, destaca-se que os resultados deste estudo, 
proveniente de dados de domínio público, serão disponibilizados formalmente por meio de relatório aos secretários de saúde municipais, bem como durante um seminário de pesquisa a ser organizado ao término da pesquisa. 
5 RESULTADOS 


\section{RESULTADOS}

Os resultados serão apresentados mantendo o anonimato dos municípios estudados, que passarão a ser denominados: A, B, C e D.

Para responder ao problema de pesquisa os resultados foram apresentados considerando os limites e potencialidades dos PMSs e dos RAGMs, bem como as suas contradições na realidade (Figura 3).

Figura 3 - Ilustração da apresentação dos resultados. São Paulo, 2017.
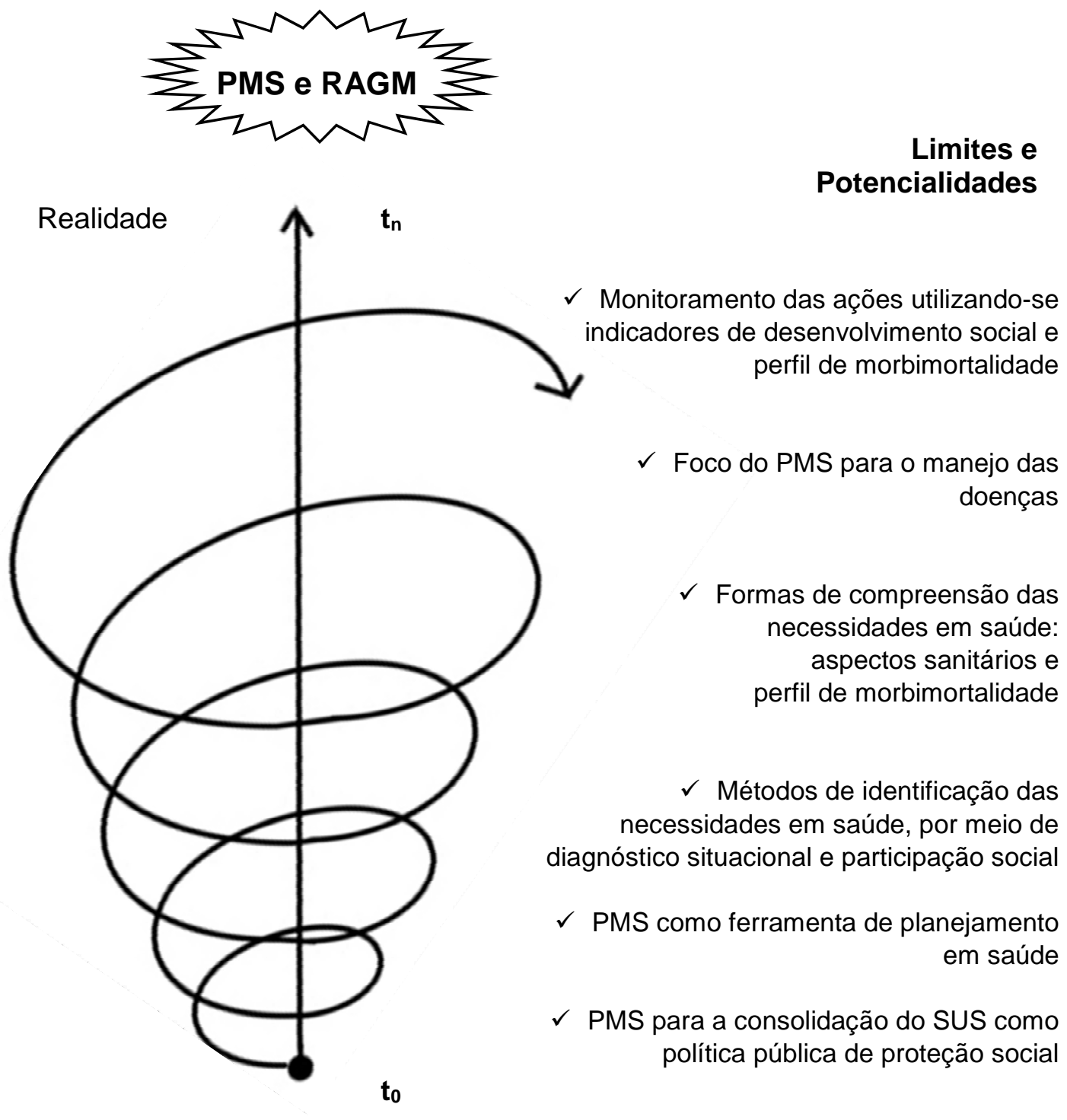

Monitoramento das ações utilizando-se indicadores de desenvolvimento social e perfil de morbimortalidade

\section{Potencialidades}

PMS e RAGM 


\section{$5.1 \quad$ LIMITES E POTENCIALIDADES}

Para compreensão da realidade em que os PMSs e RAGMs foram concebidos os resultados serão apresentados problematizando, inicialmente, os limites e potencialidades de ambos documentos.

A partir da análise dos objetivos dos PMSs destacou-se como potencialidade a consolidação do SUS como política pública de proteção social, o que pode ser evidenciados como:

C (2010-2013): [...] reconhecimento da norma constitucional à saúde, como dever do Estado e direito do cidadão [...] implementação e otimização do Sistema Único de Saúde [...].

D (2014-2017): [...] Fortalecer o Sistema Único de Saúde no município [...].

Além disso, a compreensão dos PMSs como ferramenta de planejamento em saúde se destacou como:

A (2010-2013): [...] base para a execução, o acompanhamento, a avaliação e a gestão do sistema de saúde [...] mecanismo de gestão que visa dar direcionalidade ao processo de consolidação do SUS. [...] resultados, expressos em diretrizes, objetivos, e metas a serem buscados [...] definição das políticas de saúde na esfera de gestão municipal $[\ldots]$.

B (2014-2017): [...] eixo balizador para delinear as prioridades e os investimentos a serem executados [...].

C (2010-2013): [...] a viabilização do atendimento à população [...] propicia serviços resolutivos e de qualidade [...].

C (2014-2017): [...] compromete-se com a qualidade na assistência $[\ldots]$.

D (2010-2013): [...] implementando as políticas de saúde necessárias à manutenção e melhoria da saúde da população [...]. 
D (2014-2017): [...] compromisso de garantir qualidade de vida e melhores condições de saúde à população [...] ações e serviços de promoção de saúde, prevenção de doenças e cuidados assistenciais resolutivos, com participação social e humanização [...].

\section{Ao se analisar os métodos de identificação das necessidades em} saúde utilizados entre os PMSs estudados evidenciou-se que as formas adotadas para este fim avançaram, tanto que o diagnóstico situacional e o envolvimento da comunidade na gestão do SUS se destacaram, como demonstrado em:

A (2010-2013): [...] Diagnóstico Situacional que engloba a análise da situação geral do município, sendo este dividido em dados territoriais, geográficos, demográficos, sociais, econômicos e indicadores de saúde, com análise do perfil epidemiológico, incluindo a análise de algumas doenças endêmicas e epidêmicas e outros fatores de risco que afetam o município. Além disso, realizou-se uma descrição da oferta e produção de serviços de saúde, contextualizada dentro dos diversos setores da estrutura organizacional da rede de saúde municipal. Destaca-se, ainda, a incorporação das contribuições da VII Conferência Municipal de Saúde realizada nos dias 18, 19 e 24/9/2009. [...] (grifo nosso)

B (2014-2017): [...] uma análise situacional das condições de saúde da população santista, abordando os aspectos sócio econômicos, as condições de vida, trabalho e ambiente, bem como os perfis demográfico e epidemiológico. Também demonstra como a rede de saúde está composta e organizada no município e como os recursos financeiros estão destinados para o seu custeio e financiamento. [...] (grifo nosso)

D (2010-2013): [...] Realizamos pesquisa e análise do perfil epidemiológico, das realizações dos anos anteriores, dos principais problemas e necessidades de saúde da população, aliados ao plano de governo da atual administração municipal, bem como ao orçamento em vigor. Através do planejamento estratégico e situacional realizado no 1 9rimestre de 2010 [...]. (grifo noss o)

D (2014-2017): [...] Análise Situacional: identificação, formulação e priorização de problemas dentro da realidade do município. [...] 0 município [...] participou, através dos fóruns regionais, da elaboração do Mapa de Saúde da Região [...], que identificou o perfil, a estrutura e as necessidades de saúde de 11(onze) municípios da Região Metropolitana [...] (RMC) em 2012 [...]. (grifo nosso) 
Apesar do avanço quanto aos modelos de identificação das necessidades em saúde, utilizando-se do diagnóstico situacional e da participação social, observou-se que estes métodos partiram de uma macroanálise do território sanitário, o que pode implicar na adoção de políticas públicas municipais que, eventualmente, não atendam às necessidades da população, em especial, de grupos sociais vulneráveis.

Esta evidência foi reforçada pela forma de compreensão das necessidades em saúde a partir de aspectos multicausais, como aqueles relacionados à descrição das características de saneamento básico e moradia, como demonstrado nos seguintes trechos:

B (2014-2017): [...] Os assentamentos precários concentram-se em áreas bem demarcadas no município, notadamente nos morros, na região central e na Zona Noroeste da cidade, com ocorrências isoladas em outras áreas. Nas áreas periféricas e inundáveis da cidade foi a alternativa de habitação para a população pobre e excluída, tendo o seu agravamento nas décadas que se seguiram. Outra forma de ocupação precária do solo são as palafitas com suas construções em madeira suspensas nas áreas alagadiças. São ocupações encontradas em assentamentos [...]. Neste tipo de ocupação a infraestrutura é quase inexistente e os acessos se dão através de vielas construídas com tábuas de madeira. Os moradores estão sujeitos às intempéries e oscilações das marés, onde muitas vezes são surpreendidos pelas inundações e corrosões das fundações acelerando o processo de degradação ambiental local. As famílias convivem ainda com a umidade, a insalubridade e os riscos à saúde. Um dos problemas mais graves decorrente deste tipo de ocupação é a ausência de rede coletora de esgoto, que faz com que o mesmo seja lançado in natura ao rio, constituindo-se um grave fator de poluição. Outro tipo de habitação predominante no município é ocupação em morros e encostas identificadas como áreas de risco, sujeitas a escorregamentos. As construções se localizam no topo e no pé dos morros e são construções de alvenaria e de madeira, erguidas precariamente. Muitas delas possuem abastecimento de água, pavimentação e energia elétrica, porém registram a falta de esgotamento sanitário. Vale ressaltar que a ocupação dos morros é antiga e com o passar dos anos, e a pressão dos ocupantes, o poder público acabou levando infraestrutura a estas áreas e vários morros vieram a ser urbanizados. Porém, as ocupações em áreas sujeitas a escorregamentos são alarmantes e constituem-se num dos principais problemas habitacionais do município. Segundo dados do Plano Municipal de Redução de Riscos elaborado pelo IPT, em 2005, foram identificados 79 setores de risco em B que abrigam cerca de 1009 moradias [...] (grifo nosso)

C (2010-2013): [...] estação de tratamento de esgotos iniciou sua operação no mês de março/2005, e terá tratamento gradativo até ser atingida a porcentagem de $100 \%$ dos esgotos coletados, ainda no corrente exercício. [...] (grifo nosso) 
D (2014-2017): [...] No que se refere ao abastecimento de água, o município tem quase $100 \%$, tendo avançado de 2000 a 2010, sem, no entanto, conseguir ultrapassar o nível de abastecimento [...]. A coleta de lixo também ocorre em quase $100 \%$ do município, seguindo o estado e Região Metropolitana [...], acrescentando a coleta seletiva (de recicláveis) que ocorre em todos os bairros da cidade. [...] $O$ esgotamento sanitário em D atingiu $82,96 \%$ em 2010, abaixo do estado de São Paulo, que era de $89,75 \%$ e da Região Metropolitana [...] que chegou a $86,99 \%$. Cabe esclarecer que todo o esgoto coletado é tratado em usinas de tratamento no município. [...] (grifo nosso)

Estes resultados denotaram a compreensão das necessidades em saúde de forma meramente descritiva, por exemplo, quanto aos aspectos sanitários que têm a sua importância, porém limitada quando não compreendidos conjuntamente a aspectos sociais de determinação do processo saúde e doença.

Neste sentido, questiona-se a potencialidade destes indicadores para traduzir as necessidades em saúde da totalidade da população.

Outra forma de compreensão das necessidades em saúde da população baseou-se em indicadores de morbimortalidade, como taxa de internações hospitalares por causas diversas, bem como causas de óbitos entre a população. Essas ideias estiveram contidas em:

A (2010-2013): [...] A série histórica das taxas de internações por doenças diarreicas agudas em menores de 5 anos para o município de A no período 2005-2008 revela baixos índices de internação por esse agravo, com diminuição relevante após o ano de 2006 que pode estar relacionada à introdução da Vacina contra o Rotavírus Humano no calendário Básico de Vacinação. A taxa de internações por Acidentes Vasculares Cerebrais no município de A é uma das menores de toda a regional e apresenta comportamento decrescente de 2005 a 2007, com acréscimo em 2008, mantendo-se abaixo da meta mínima estabelecida para o estado de São Paulo que é de 27,5 por 10.000 habitantes. Isso pode indicar uma boa qualidade de resposta do sistema para o controle da doença hipertensiva no município através de ações de promoção, prevenção, diagnóstico precoce e tratamento adequado. [...] $O$ indicador de Internações por Complicações do Diabetes Mellitus objetiva avaliar a disponibilidade de ações básicas de prevenção e controle das doenças crônicodegenerativas, através do diagnóstico precoce, tratamento adequado e ações de promoção e educação em saúde [...] No caso das meningites é fundamental que se conheça a etiologia para o desencadeamento de ações específicas [...] casos confirmados de Rubéola e tendência flutuante no período, indicando aqui a necessidade, com já avaliado, de se intensificar essa vacinação no 
município [...] a distribuição dos óbitos infantis ocorridos no município cuja assistência à gestação está vinculada às Unidades Básicas de Saúde municipais. Observa-se também, a relação óbitos/nascimentos nas mesmas áreas onde houve ocorrências de óbitos. As fontes são do Sistema de Informação sobre Mortalidade e Sistema de Informação sobre Nascidos Vivos de base local e considera óbitos ocorridos somente no município de residência. Ao se analisar a ocorrência dos óbitos infantis na rede SUS e Privada, percebe-se maior concentração da mortalidade na rede pública com ocorrência de 24 óbitos num universo de 1.240 nascidos vivos vinculados ao serviço público, enquanto na rede privada houve ocorrência de 5 óbitos em relação a 1.133 nascidos vivos. Vale lembrar que a mesma análise realizada em anos anteriores a 2006 a concentração de óbitos em ambos os sistemas era quase de igualdade com discreto aumento na parcela vinculada à rede pública. Essa relação hoje apresentada sugere falhas relativas ao Sistema Municipal de Saúde. [...] Ao se analisar os dados de acordo com critérios de evitabilidade utilizados pelo Comitê Municipal de Mortalidade Materno Infantil, que utiliza instrumento padronizado pela Secretaria Estadual de Saúde para esse estudo, identifica-se que $58,6 \%$ dos óbitos são passíveis de redução por Adequado Controle na Gravidez, 27,6\% redutíveis por Diagnóstico e Intervenção Precoce e 13,8\% classificados como inevitáveis. A série histórica dos Coeficientes de Mortalidade Materna no Município de A apresenta ainda índices elevados, com inexistência do fenômeno em 2005 e 2007 e várias flutuações no período [...]. A série indicada pode denotar ações incipientes na Assistência ao Pré-Natal e ao Parto no âmbito da rede básica e hospitalar no município, uma vez que os decréscimos das taxas de mortalidade infantil e materna estão diretamente relacionados ao acompanhamento de saúde da gestante e melhoria da qualidade de assistência à mulher, tendo como focos principais a redução da gestação em adolescentes, das taxas de cesáreas, do baixo peso ao nascer, da mortalidade neonatal precoce, da sífilis congênita e de causas diretamente relacionadas à gestação e parto passíveis de redução por diagnóstico e intervenção precoce, evitando complicações à saúde da mãe e da criança. Para tanto é fundamental a reorganização da atenção básica, a manutenção e ampliação das atividades do Comitê Municipal para a Redução da Mortalidade Materna que deve avaliar permanentemente a qualidade da assistência prestada, dar visibilidade às intervenções que se façam necessárias e direção às ações a serem priorizadas em todos os níveis de atenção à gestante. [...] $O$ indicador de sete ou mais consultas pré-natais realizadas, [...] apesar de apontar índices melhores do que a meta estabelecida para o estado São Paulo em todos os anos analisados, apresenta tendência de queda, de $90 \%$ no início da década para $84,75 \%$ em 2008. Cabe aqui avaliar acesso e qualidade das ações educativas que visam maior adesão ao pré-natal no município. [...] Os indicadores são de Base Local (SINASC) e revelam o alto índice de cesáreas no município. Por outro lado, a série histórica do percentual de partos em mulheres com idade inferior a 19 anos apresenta tendência decrescente. Esse indicador pode sugerir a resolubilidade das ações preventivas realizadas no município pela rede básica, através de projetos e parcerias desenvolvidas ao longo da última década pelo Centro Referência do Jovem e Adolescente. [...]. No município de $A$ as ações preventivas, focadas no combate ao vetor $e$ na vigilância de suspeitos, permitiram que a doença atingisse índices anuais baixos, bem inferiores aos do estado e país [...] porém no ano de 2007, a circulação viral foi mantida mesmo nos meses de outono e inverno, fazendo com que o município registrasse a primeira epidemia da doença no primeiro semestre de 2008. Neste ano, o município se destacou com a maior incidência de casos do estado, com o pico de 
incidência no mês de março (semana 13/08). Não há registros de óbito pela doença no município, porém em 2006 foram confirmados um caso de Febre Hemorrágica da Dengue e um caso de Dengue com Complicação. [...] No que diz respeito aos casos notificados de AIDS no município [...] observa-se tendência crescente de 1988 a 1998, provavelmente associado à melhora da informação, tendo 1998 o maior número de notificações e a partir daí tendência decrescente do número de notificações até o ano de 2008. Nesse sentido, A apresenta comportamento semelhante ao do estado de São Paulo que apresenta crescimento da epidemia com aumento do número de casos e taxa de incidência por ano de diagnóstico até 1998 e após esse ano decréscimo progressivo no número de casos notificados [...] Quando analisada a mesma série histórica por sexo, verifica-se o crescimento do número de mulheres infectadas. Tanto para o sexo masculino como para o feminino o maior número de notificação ocorreu no ano de 1998. A partir de 1995 verifica-se o processo de feminização da epidemia com aumento progressivo dos casos entre mulheres, permanecendo desde então numa razão 2/1, ou seja, para cada dois casos de AIDS notificados em homens é notificado um caso em mulher. [...] A série histórica dos casos novos de tuberculose para o período 2002 a 2008, demonstrada [...] como vem sendo desenvolvido o Programa no município, apresentando a detecção, o percentual de cura, de óbitos e de abandono de tratamento no município de A. A taxa de incidência de Tuberculose Pulmonar no município demonstrada na série histórica 2002 a 2008, indica tendência flutuante com taxas decrescentes a partir de 2006.0 município apresenta número de casos novos e coeficientes de detecção que demonstram a necessidade de se dar continuidade à execução de atividades que impactem a transmissão da doença [...]". O perfil de mortalidade do município de A segue 0 processo de transição que vem ocorrendo com intensidade no Brasil e no estado, mais particularmente a partir da década de 1940, quando houve significativa redução das mortes por doenças infecciosas e parasitárias e aumento das mortes por doenças crônico-degenerativas, dentro de um contexto de avanços sócio econômicos, desenvolvimento tecnológico, melhora nas condições de habitação, saneamento e melhora de acesso aos serviços de saúde. Hoje no município, há predomínio de óbitos por doenças do aparelho circulatório, neoplasias, doenças respiratórias, digestivas, além das causas externas. Apesar da redução dos óbitos provocados por doenças infecciosas e parasitárias, devem ser ressaltadas as doenças pelo vírus da imunodeficiência adquirida (HIV), que a partir da revisão da Classificação Internacional de Doenças passaram a ser classificadas no capítulo referente às doenças infecciosas e parasitárias e são, atualmente, responsáveis por grande parte dos óbitos por estas causas. [...] A taxa de mortalidade por AIDS vem decrescendo no município, seguindo a tendência do estado de São Paulo e Brasil. Uma das razões para a queda da mortalidade entre os pacientes HIV positivos é a introdução dos antiretrovirais mais potentes ocorrida no país em 1996. [...] No município de A, conforme já evidenciado e aqui destacado, as Doenças do Aparelho Circulatório somadas às Neoplasias, respondem por $48 \%$ do total das mortes. [...] A mortalidade por doenças alcoólicas do fígado no município, vem apresentando tendência de crescimento e prevalência no sexo masculino e também tendência crescente no sexo feminino aos usuários do álcool. [...] a série histórica dos Coeficientes de mortalidade por câncer de mama no município de A referente ao período 2005 a 2008 demonstra tendência de crescimento da doença nos anos mais recentes. Inversamente ao câncer de mama, a mortalidade por câncer do colo do útero mostrou, para o estado de São Paulo, uma tendência de queda. O município de A para o 
quadriênio 2005 a 2008 apresenta flutuação nos coeficientes que podem denotar tanto a melhora na informação através da investigação das causas básicas de óbito, como também um aumento na incidência da doença, uma vez que o município vem apresentando baixas coberturas do exame de citologia oncótica, cujo método utilizado é o de papanicolau, que vem se mostrando até o presente como o meio mais efetivo de detecção de lesões precursoras de carcinoma do colo uterino em estádios iniciais. Estudos vêm demonstrando que se efetuando rastreamento de mulheres de risco em intervalos apropriados, pode-se observar uma redução de 40 a 70\% na incidência e na mortalidade por este tipo de câncer [...]". No Brasil, o coeficiente de mortalidade padronizado por idade passou de 5,1 por 100.000 homens em 1980 para 7,8 em 1996. A mesma tendência se observa no estado de São Paulo, cujos coeficientes passaram de 8,3 por 100.000 homens em 1970/71 para 12,6 em 1991/92. Esta tendência crescente e o aumento da possibilidade de cura do câncer de próstata através do diagnóstico e tratamento precoces mostram a sua relevância para a saúde pública. Diversos estudos epidemiológicos buscaram estabelecer os fatores de risco para o câncer de próstata. Todavia, só foram observadas associações consistentes com a idade e a existência de antecedentes familiares. A eficácia de medidas preventivas e de controle populacional, como o rastreamento sobre a mortalidade tem sido questionada. No entanto, o Instituto Nacional do Câncer, ao considerar que a evolução do câncer de próstata ocorre de forma lenta, podendo levar anos até surgirem os primeiros sintomas clínicos, recomenda a realização periódica de exames para o diagnóstico precoce que incluem o toque retal e dosagem de substâncias produzidas pela próstata. Avaliando que o diagnóstico e tratamento precoces elevam as possibilidades de cura, o Instituto Nacional do Câncer recomenda que os exames sejam realizados a partir dos 50 anos, mesmo na ausência de sintomas, com início aos 40 anos se existirem antecedentes familiares. Há que se fazer um parêntese aqui para lembrar as doenças específicas da população feminina, que por não se expressarem em indicadores de mortalidade, escapam no mais das vezes da definição de prioridades de saúde, incluindo-se aí as vulvovaginites, de transmissão sexual, na maioria dos casos, as miomatoses e endometrioses, essas particularmente com atendimentos represados em função da dificuldade de acesso à média complexidade. Ao se analisar a série histórica dos Coeficientes de Mortalidade por Câncer de Próstata no município de A, quadriênio 2005 a 2008, observa-se variação na tendência, com quadro significativamente decrescente no triênio 2005/2007. Porém, esse indicador, a exemplo dos demais, como taxa de mortalidade por doenças cérebro vasculares e doenças alcoólicas do fígado apontam para a necessidade de se priorizar um Programa que contemple a Saúde do Homem no município. No município de $A$ as causas externas de mortalidade na última década alternam-se entre o quarto e quinto lugar de causas de mortalidade. [...] Quando se analisam as causas externas separadamente por acidentes de trânsito, homicídios e suicídios evidenciam-se indicadores crescentes e maiores para os acidentes de trânsito, notadamente acidentes por motocicletas que se configuram como o grande problema do trânsito de A. A redução desses óbitos demanda ações intersetoriais, pois, essas mortes, além de implicarem em grande ônus para a saúde não somente com gastos elevados, refletem um grande impacto social com o grande número de óbitos e de incapacidade na população jovem no município. [...] Os óbitos por causas externas prevalecem na população masculina nesta faixa etária. Destaca-se que para a população de 15 a 19 anos no sexo masculino as agressões são responsáveis por $50 \%$ dos óbitos, seguindo-se os óbitos por acidentes de trânsito, que 
correspondem a $30 \%$ dos óbitos. Para o sexo feminino, acidentes de trânsito, agressões, suicídios e outros acidentes dividem igualmente a segunda posição de causa de óbito com $17 \%$ dos óbitos respectivamente, sendo a primeira posição ocupada por causas naturais de óbito, com $33 \%$ dos óbitos. A série histórica 2005-2008 referente aos coeficientes de mortalidade por agressões [...] indica tendência decrescente de 2005 a 2007, com grande queda em 2007, voltando a um indicador elevado em 2008. Mais uma vez aqui, ressaltase a necessidade de fortalecer parcerias com os outros setores no sentido de conter a marcha da violência urbana que vem associada ao desenvolvimento da cidade. No que tange aos suicídios, o município também apresenta tendência crescente, particularmente no ano de 2008 quando apresenta coeficiente significativamente maior que os anos anteriores na série histórica 2005-2008. Mais uma vez, ressaltase o impacto desse indicador na população adolescente e adulta jovem. [...] A mortalidade por quedas na população de 60 anos e mais no município apresenta altos índices e flutuação no indicador, o que pode denotar ausência de políticas públicas abrangentes no nível básico de atenção voltadas para a promoção do envelhecimento saudável e prevenção de riscos pertinentes às faixas etárias acima dos 60 anos. [...] (grifo nosso)

B (2014-2017): [...] o número total de internações [...] pelo SUS teve uma redução de 2011 para 2012, passando de 18.646 para 18.074 [...]. A maior causa de internação ainda é por gravidez, parto e puerpério $(17,89 \%)$, seguida pelas doenças do aparelho circulatório $(12,05 \%)$, doenças do aparelho respiratório $(10,30 \%)$ e, subindo ao quarto lugar neste ano, pelas Lesões, envenenamentos e algumas outras por causas externas (10,23\%). As internações que sofreram aumento em 2012, em números absolutos, foram as causadas por neoplasias seguidas pelas causadas por contatos com serviços de saúde e as Doenças Endócrinas nutricionais e metabólicas. Com relação à faixa etária as ocorrências aumentaram nas faixas de 15-19, 30-39 e acima de 60 anos [...] os indicadores do Pacto da Atenção Básica, para 0 ano de 2012, relacionados às doenças infectocontagiosas, B apresentou resultados superiores aos municípios da [...] no: percentual de cura dos casos novos de hanseníase (100\%); percentual de água tratada (96,32\%); percentual de qualidade de tratamento de água por cloro $(98,53 \%)$ e por flúor $(99,57 \%)$. Porém, [...], B apresentou valores abaixo da média da região da [...], quais sejam: cura de casos novos de tuberculose pulmonar bacilífera $(76,27 \%)$ e percentual de cobertura vacinal tetravalente $(90,86 \%)$. Ainda segundo a mesma fonte, a cobertura de primeira consulta odontológica programática em $B$ foi de 3,4\% - inferior à média da [...] cujo valor foi de $5,0 \%$. Em relação ao indicador pactuado para as doenças crônicas, 0 percentual de exames citopatológicos em mulheres de 25 a 64 anos, o município de $B$ [...] foi de $12,1 \%$. [...] o número de óbitos gerais e a taxa de mortalidade geral apresentaram uma queda em 2011, subindo novamente em 2012. Alguns fatores exercem influência sobre a taxa de $\mathrm{B}$, em especial o envelhecimento da população santista, onde $19,16 \%$ da população têm idade acima de 60 anos, enquanto que esta mesma faixa etária da população no estado de São Paulo representa $11,55 \%$ (SEADE) e no Brasil 10,14\% (DATASUS 2009). Comparando-se os óbitos de 2010 e 2012, por faixa etária, confirmamos a maior ocorrência acima dos 60 anos de idade $(77,07 \%$ em 2010 e 77,97\% em 2012), distribuindo-se o restante entre as demais faixas. As três primeiras causas de óbitos permaneceram as 
mesmas nos dois anos, quais sejam: em primeiro lugar as doenças do aparelho circulatório com $32.67 \%$ em 2012 contra 33,09\% em 2010. Em segundo lugar estão as neoplasias com 20,33\% em 2012 contra $18,52 \%$ em 2010, observando-se um aumento da ocorrência dos óbitos por neoplasias. Em terceiro lugar permanecem as Doenças do Aparelho Respiratório com 13,21\% em 2012 e 13,90\% em 2010.15,4\%. As Doenças Endócrinas Nutricionais e Metabólicas ficaram em 4ㅇ lugar em 2010 com 6,27\% dos óbitos, mas em 2012 esse lugar foi ocupado pelas Causas Externas de Morbidade e Mortalidade com 5,68\% dos óbitos. As causas externas apresentam uma curva ascendente nos últimos anos como causa de óbito. As faixas etárias mais atingidas são de 15 a 49 anos. [...] (grifo nosso)

C (2010-2013): [...] Em 2007, houve 18 óbitos de crianças menores de 1 ano, e destas, 14 crianças morreram por prematuridade extrema. $O$ peso destas crianças ao nascer variou de $550 \mathrm{~g}$ a $1.605 \mathrm{~g}$. Sabemos que a redução de mortes ao nascer está diretamente relacionada com o peso. O coeficiente de mortalidade neonatal foi de 12,73 óbitos/1000 nascidos vivos. Sua fração tardia foi de 1,59 . As outras crianças que foram a óbito nasceram a termo e com peso compatível, mas com anomalias congênitas. Uma criança teve óbito por causa não especificada, e duas por Insuficiência Respiratória Aguda e Broncoaspiração. [...] Na Campanha da Pólio são vacinadas as crianças de 0 a 4 anos, 11 meses e 29 dias (incluindo os recém-nascidos) e mesmo aquelas que apresentam o esquema básico de vacinação completo, pois a vacinação durante a campanha é indiscriminada com o objetivo de disseminar o vírus no ambiente. [...] Numa tendência crescente os óbitos por doenças cardiovasculares apresentam a primeira posição quanto ao número de óbitos, seguida por doenças do aparelho respiratório, causas mal definidas e doenças do aparelho digestivo. [...] (grifo nosso)

D (2010-2013): [...] A mortalidade em adolescentes e adultos jovens teve pequena variação para cima entre 2008 e 2011, passando de 86,37 para 111,61. Em 2008 era a menor em comparação com estado de São Paulo e região, mas em 2011 D superou a mortalidade na faixa etária de 15 a 34 anos na Região Metropolitana [...]. O total de óbitos em 2013 (405) foi ligeiramente maior ao total de 2012 (339) e dos anos anteriores, sendo 2010=349 óbitos e 2011=368 óbitos. Em $2013,74 \%$ dos óbitos ocorreram em pessoas com 60 anos e mais, $57 \%$ deles nas faixas etárias mais avançadas (80 anos e mais), sendo que em 2012 foram 70\% dos óbitos em idosos. Houve uma pequena diminuição no percentual de mortes na faixa etária de 50 a 59 anos, comparando-se 2013 , onde $11,3 \%$ dos óbitos ocorreram nessa faixa etária, a 2012, quando $14,2 \%$ dos óbitos ocorreram entre pessoas de 50 a 59 anos. As principais causas de óbitos continuam sendo as doenças do aparelho circulatório (capítulo IX da CID), que em 2013 representaram $35 \%$ dos óbitos ocorridos em residentes de D. A segunda causa foi representada pelas Neoplasias (capítulo II da CID) com 19\%, e a terceira causa pelas Doenças do Aparelho Respiratório (capítulo X da CID) correspondendo a 16\% dos óbitos, distribuição causal que vem seguindo o mesmo padrão no município desde 2009. As Causas Externas (capítulo XX da CID) representaram $6 \%$ dos óbitos no ano de 2013 (24 óbitos), com número absoluto ligeiramente menor ao de 2012 (29 óbitos) [...] (grifo nosso) 
D (2014-2017): [...] As três primeiras causas de internações hospitalares foram a Gravidez, parto e puerpério (249), as Doenças do aparelho gênito urinário (201) e as Doenças do Aparelho Respiratório (199). Tanto a primeira quanto a terceira causas coincidem com a análise de morbidade hospitalar SUS de residentes em $D$ de 2012 [...] A gestação na adolescência tem sido um desafio para as equipes de saúde e sua prevenção uma prioridade. A gestação na adolescência tem de mantido em torno dos $10 \%$ no período de 2009 a 2013. O parto cesáreo representa mais de $70 \%$ dos partos de residentes. Teve leve tendência de queda no período de 2009 a 2012, revertida em 2013, quando correspondeu a $73,84 \%$ dos mesmos. $O$ Baixo peso ao nascer representou em 2013 7,96\% dos nascidos vivos, percentual maior que em 2011 e 2012. Em relação à prematuridade verifica-se, desde 2010 , uma tendência de aumento no número de nascidos vivos prematuros, sendo em 2013 atingido o maior percentual do período analisado (13,34\%) [...]. A Mortalidade Infantil (menores de 1 ano) em D é menor que a do estado de São Paulo e Região Metropolitana [...], segundo dados de 2012. Em relação à Mortalidade na Infância (maiores de 1 ano) o município também apresenta melhores indicadores em comparação ao Estado e região (2011). No período de 2009 a 2013, exceto pelo ano de 2010, quando houve um aumento no Coeficiente de Mortalidade Infantil, mantivemos certa estabilização no indicador. No último ano tivemos mais 1(um) óbito de menor de 1 ano em relação à 2012 [...]. O levantamento epidemiológico realizado ao final de 2013, demonstra claramente índices melhores em $\mathrm{D}$, comparativamente ao município de São Paulo, região Sudeste e Brasil [...] (grifo nosso)

\section{Diante do apresentado os PMSs têm centrado as suas ações no manejo}

das doenças e, aparentemente, não na compreensão das formas de produzir e reproduzir dos grupos sociais, cujos aspectos podem impactar na demanda por serviços de saúde.

Os trechos a seguir reforçam o foco nas doenças em detrimento da compreensão do processo saúde-doença socialmente determinado:

A (2010-2013): [...] conclui-se que o município de A tem tido êxito nas ações de campanha de vacinação com uma cobertura vacinal satisfatória. A análise mais detalhada indica a Cobertura Vacinal das Campanhas Nacionais de Vacinação Contra a Poliomielite, no município, série Histórica 2005 a 2009 e mostra os indicadores oficiais do Programa Nacional de Imunização e a cobertura do mesmo período segundo base de dados da População < de 05 anos de acordo com estimativa do IBGE. De acordo com a população estimada IBGE, A atinge meta para todos os anos analisados, com exceção da segunda etapa do ano 2008. O Programa Nacional de Imunização utiliza como base populacional o SINASC (Sistema de Informação sobre Nascidos Vivos). A baixa cobertura vacinal em 2008, parece estar relacionada ao número excessivo de campanhas de vacinação neste período, bem como à ocorrência de evento adverso fatal durante a campanha de vacinação contra a febre amarela no município. [...] A nunca registrou casos de óbito por Dengue, porém alguns casos necessitaram de internação ao longo destes anos. Segundo dados colhidos no $\mathrm{SIH}$, Sistema de Informações Hospitalares, em 2008, registram-se 2 
internações em virtude da Dengue. Ressalta-se que tal informação deve ser tratada com cautela, uma vez que as internações dos suspeitos de Dengue são muitas vezes justificadas como febre a esclarecer por ainda não ter comprovação sorológica. Não há como avaliar a demanda por leitos de observação em virtude da falta de registro apropriado desta ação durante os surtos e principalmente durante a epidemia de 2008. [...] Embora o município de A não registre nenhum caso de Febre Amarela, em abril e maio de 2008, ocorreram na região dois casos autóctones de Febre amarela Silvestre que foram a óbito: um residente na zona rural de São Carlos (Próximo ao município de Rincão e Rio Mogi) e outro residente em Cravinhos que se infectou na zona rural do município de Luís Antonio. Nos dois casos, os locais prováveis de infecção estão próximos à reserva ecológica de Jataí, onde foram encontrados vetores contaminados com o vírus da Febre Amarela. Após a confirmação dos casos foi realizada vacinação de bloqueio na população da região de São Carlos e A e a imunização contra a Febre Amarela tornou-se obrigatória no calendário vacinal de todos os municípios da região. O município de $A$ não apresenta casos de Leishmaniose Visceral Americana, mas existe ocorrência de casos de Leishmaniose Cutânea registrados em residentes em A. [...] Alguns indicadores do Programa de Ações Prioritárias em Vigilância em Saúde, referentes ao ano de 2008 [...] apontam a atuação da Vigilância Sanitária nos âmbitos de alimentos, produtos para a saúde, prevenção de riscos de agravos por terapêutica transfusional, terapia renal substitutiva, maternidade e UTI neonatal, intervenção em fatores de risco ambiental, ambiente de trabalho e processos em geral, vigilância de populações expostas a áreas com solo contaminado, vigilância de saúde do setor canavieiro, vigilância da qualidade da água para consumo humano. [...] (grifo nosso)

B (2014-2017): [...] Ao analisar o perfil das internações por condições sensíveis à atenção básica, $B$ apresenta um percentual de $19,69 \%$, o maior valor dentre os municípios da [...] e superior à média de $14,94 \%$. Isto significa que, ao melhorar o acesso e qualidade da Atenção Básica do município poderiam ser disponibilizados mais leitos para internações de acordo com as necessidades de saúde da população. [...] (grifo nosso)

C (2010-2013): [...] Em 2007, foram realizados $\mathbf{5 7 . 9 7 5}$ procedimentos coletivos (aplicação de flúor, palestras, higiene bucal supervisionada e levantamento epidemiológico) e em 2008, foram 61.362 procedimentos, revelando um aumento de $5,51 \%$. [...] Campanha de Prevenção ao Câncer Bucal realizada durante a Campanha de Vacinação do Idoso avaliou a saúde bucal dos idosos acima de 60 anos, além de promover orientações sobre lesões bucais, próteses dentárias e higiene bucal. [...] (grifo nosso)

C (2014-2017): [...] Portadores de lesões vasculares atendidos na sala de curativos no ano de 2012/2013. Pronto atendimento Municipal de $C$ realiza aproximadamente 13.000 atendimentos mês. [...] (grifo nosso) 
D (2014-2017): [...] No período analisado, tivemos aumento significativo no acesso ao atendimento médico em todos os níveis de atenção. Chama atenção de 2010 a 2012, o crescimento na atenção básica (clínicas básicas) e em especializadas. Em 2013 ocorre manutenção e leve queda no atendimento básico e especializado, bem como um aumento significativo no atendimento de urgência e emergência. Destaca-se que a partir de junho de 2013 a UPA 24 h constituiu-se a única porta de pronto atendimento e pronto socorro do município, inclusive para usuários de convênios médicos. [...] (grifo nosso)

As evidências ilustraram os avanços na tentativa de captação das necessidades em saúde da população, o que é de extrema importância para o planejamento das ações em saúde.

Entretanto, esse modelo de captação possui limitações quando se tenta compreender 0 processo saúde-doença a partir dos padrões de morbimortalidade e do quantitativo de procedimentos realizados de forma desarticulada das formas de produção e reprodução, bem como das vulnerabilidades sociais que contribuem para o adoecimento e morte das pessoas.

Dessa forma, ao longo dos anos de implantação dos RAGMs, estes sofreram alterações em sua estrutura, com o objetivo de contribuir para 0 monitoramento efetivo das ações em saúde planejadas nos PMSs.

$\mathrm{Na}$ figura 4 demonstra-se a evolução dos RAGMs considerando-se os instrumentos de gestão que foram desenvolvidos, incorporados e readequados no período de 2011 a 2015, visando contribuir para as ações de monitoramento. 
Figura 4 - Evolução do RAGM no período de 2011 a 2015. São Paulo, 2017.

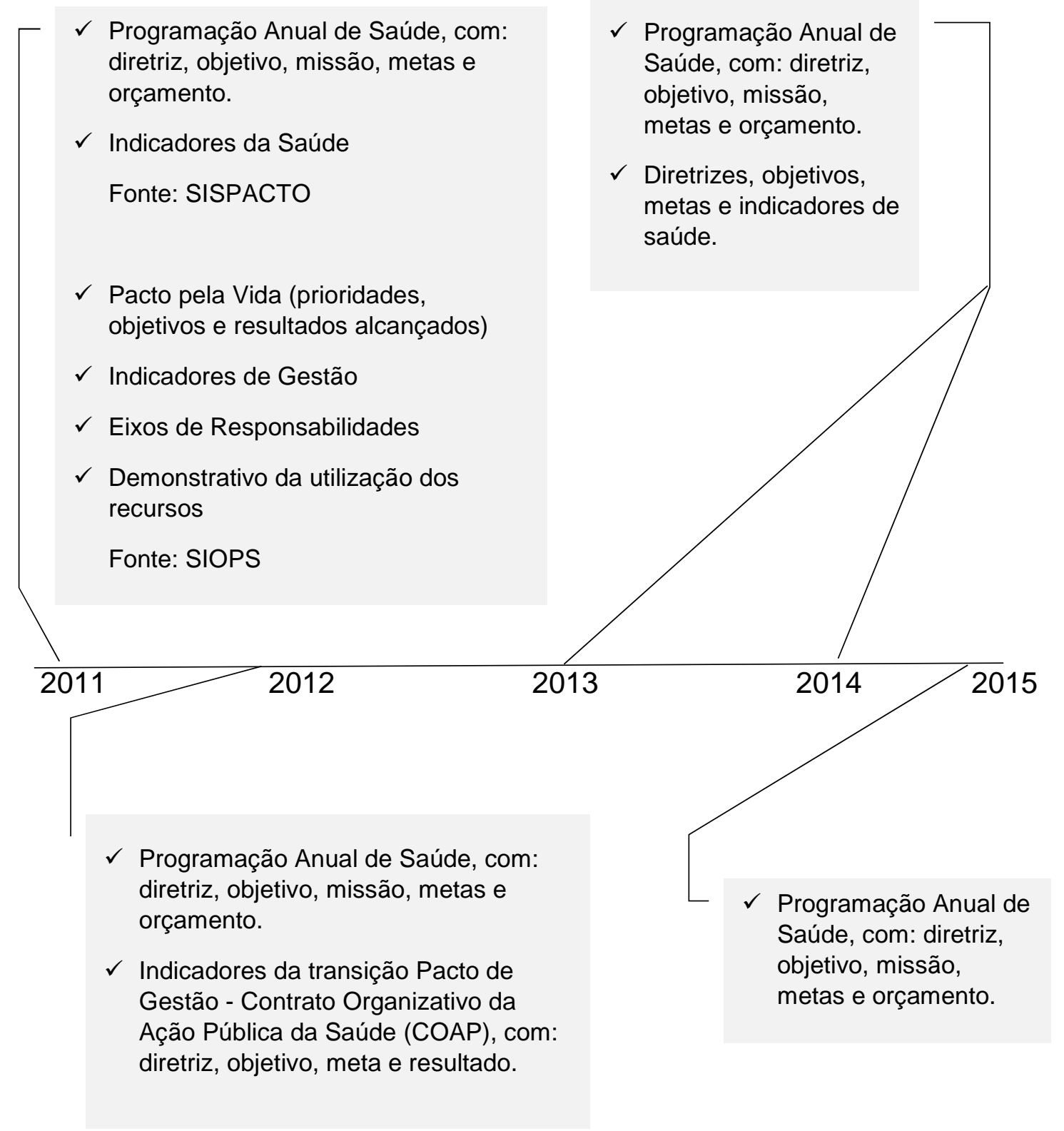

Apesar dos avanços no monitoramento das ações em saúde, por meio da sistematização dos RAGMs, evidenciou-se que, em linhas gerais, eles não se ocupam em identificar os grupos sociais vulneráveis com menor autonomia, visto que esses instrumentos de gestão municipal não clarificaram o referencial teórico utilizado para compreender o processo saúde-doença atinente aos grupos sociais específicos, no sentido de identificar as necessidades em saúde para articular ações com outros setores da sociedade. 
Assim, denota-se a urgência de nova readequação dos RAGMs no sentido de que eles se aproximem da concepção de saúde socialmente determinada, a fim de identificarem e monitorarem os grupos sociais vulneráveis, bem como as suas formas de adoecer e morrer determinadas pelas formas de produção e reprodução social, as quais também devem ser mapeadas e monitoradas sistematicamente pelos gestores municipais em saúde.

\subsection{CONTRADIÇÕES}

Apesar dos avanços na gestão do SUS, por meio da implantação dos PMSs e RAGMs, estes instrumentos da administração pública parecem ter limitações na captação da realidade, já que os indicadores de monitoramento das ações em saúde propostos no PMS, a despeito de suas modificações ao longo dos anos, continuam não contemplando as formas de produção e reprodução social que impactam o adoecimento e a morte da população, em especial, de grupos sociais vulneráveis.

Esses indicadores foram implantados durante 0 processo de amadurecimento das ações gerenciais de planejamento em nível local, seja com o auxílio dos PMSs ou dos RAGMs.

O monitoramento das ações propostas se referiu basicamente ao acompanhamento do desenvolvimento social e do perfil de morbimortalidade.

Quando analisados os indicadores de desenvolvimento social dos municípios, ou seja, perfil etário, esperança de vida ao nascer, educação, renda per capita, vínculo empregatício, índice de envelhecimento, IDH, Índice Paulista de Responsabilidade Social, taxa de natalidade e taxa de fecundidade observouse que os PMSs os descreveram ou destacaram os resultados positivos alcançados, como evidenciado em:

A (2010-2013): [...] O Indicador Esperança de Vida ao nascer mede a probabilidade de tempo de vida médio da população residente em determinado espaço geográfico, num ano determinado. $O$ aumento neste indicador demonstra melhoria nas condições de vida e de saúde da população. Em A, se considerarmos os indicadores de 1991 e 2000 da Fundação Sistema Estadual de Análise de Dados (SEADE), observa-se aumento progressivo da expectativa de vida, a partir do ano 2000, superando os índices do Estado. Os indicadores de esperança 
de vida ao nascer para A para os anos 1991, 2004 e 2005, são respectivamente: 1991 - 70,36; 2000 - 71,86 e 2004 - 75. Comparando os dados entre 1991 e 2005, o número médio de anos de vida cresceu $6,2 \%$. [...] Os indicadores relativos ao quesito educação [...] são dados da Fundação SEADE relativos ao ano 2000. Comparativamente aos indicadores regionais e do estado de São Paulo, o município já apresentava tendência melhor que ambas as instâncias em todos os indicadores apontados. [...] Os indicadores da Fundação SEADE [...] apontam a renda per capita (em salários mínimos), percentual de domicílios com renda per capita até $1 / 4$ do salário mínimo e percentual de domicílios com renda per capita até $1 / 2$ salário mínimo para o ano 2000, nas instâncias municipal, regional e estadual. Nestes quesitos, 0 município apresenta já no ano analisado indicadores melhores que as outras duas instâncias. [...] participação dos vínculos empregatícios da indústria no total de vínculos representa $26,44 \%$ no município [...]. Já, a construção civil participa com $4,17 \%$ do total de vínculos [...] Este indicador representa a razão de dependência entre o segmento etário da população definido como economicamente dependente, quer sejam os menores de 15 anos e os maiores de 65 anos e o segmento economicamente ativo, ou seja, a parcela de 15 a 64 anos na população residente em determinado espaço, no ano considerado, mensurando a participação relativa do contingente populacional potencialmente inativo, que deveria ser sustentado pela parcela da população produtiva [...] $O$ índice de envelhecimento do município para o ano de 2009, segundo a Fundação SEADE é de $71,67 \%$ significativamente maior que os indicadores da regional e do estado que são respectivamente $59,34 \%$ e $46,65 \%$. [...] Índice de Desenvolvimento Humano do Município de A cresceu 6,15\% no período 1991/2000, passando de 0,789 em 1991 para 0,830 em 2000, o que representou um crescimento quase $1 \%$ maior do que o do Estado de São Paulo. [...] O Índice Paulista de Responsabilidade Social construído pela Fundação SEADE a partir do ano 2000, por incumbência da Assembleia Legislativa do Estado de São Paulo permite o acompanhamento e a aferição dos desempenhos sociais e econômicos dos diferentes municípios paulistas e destina-se a subsidiar a formulação e avaliação das políticas públicas na esfera municipal. Para melhor entendimento, destaca-se que o Índice Paulista de Responsabilidade Social é composto de três dimensões que revelam níveis distintos de desempenho dos municípios quanto à riqueza, longevidade e educação. [...] o desempenho do município nos anos 2004/2006, nas três dimensões, destacando-se um aumento de $6,25 \%$ na dimensão riqueza e $20 \%$ na dimensão escolaridade, permanecendo sem crescimento a dimensão longevidade [...] $O$ traçado do perfil populacional através das pirâmides populacionais é de extrema importância para o planejamento das ações de saúde, uma vez que possibilita visualizar não somente o número total de habitantes como também o número de habitantes por sexo e faixa etária, o que pode mudar significativamente o rumo das priorizações de saúde. [...] Quando se analisam as duas pirâmides apresentadas percebe-se que tanto a pirâmide que representa a população de 1990 quanto a de 2009 estão evoluindo para um formato de barril, mostrando o avanço do nível de desenvolvimento do município. Esses formatos de pirâmides, segundo a classificação de Thompson, podem ser considerados como formas de transição entre uma forma piramidal (menor nível de desenvolvimento) e de barril (elevado nível de desenvolvimento). A pirâmide populacional de 2009 apresenta menor proporção de habitantes na faixa de 0 a 5 anos e maior proporção de habitantes acima de 60 anos do que a de 1990, demonstrando que o município hoje atinge um grau de desenvolvimento maior com taxas menores de natalidade, baixa mortalidade infantil e maior expectativa de vida, o que 
implica em necessidades específicas voltadas ao preparo para o envelhecimento dessa população. As taxas de natalidade vêm decrescendo no município, chegando em 2007, segundo a Fundação SEADE a 12,00 nascimentos por mil habitantes, o que reafirma o estreitamento da base da pirâmide populacional comparativamente aos anos analisados (1990 e 2009). [...] A taxa de fecundidade geral é a relação entre o número de nascidos vivos ocorridos numa determinada unidade geográfica, num período de tempo, e a população feminina em idade fértil ( 15 a 49 anos) residente na mesma unidade estimada para o meio do período. Para o ano de 2007, essa relação é de 41,94/1.000 mulheres em idade fértil. $A$ taxa de fecundidade total mensura o número médio de filhos nascidos vivos, tidos por mulher ao final do seu período reprodutivo, em determinado espaço geográfico. Representa a condição reprodutiva média de mulheres, sendo este o principal indicador da dinâmica demográfica. Em termos técnicos, expressa a condição reprodutiva de uma mulher pertencente a uma coorte hipotética, sujeita às taxas específicas de fecundidade por idade, observadas na população em estudo, supondo-se a ausência de mortalidade nessa coorte. Taxas inferiores a 2,1 indicam fecundidade insuficiente para assegurar a reposição populacional [...]. (grifo nosso)

B (2014-2017): [...] O gráfico do Produto Interno Bruto mostra que o município possui grande relevância econômica, [...]; e polo turístico de lazer e negócios. [...] Reforçando a constatação da importância econômica do município, é possível perceber o peso relativo do município em relação à Região de Governo e ao estado de São Paulo. Em 2010, o Produto Interno Bruto representa 58,38\% do Produto Interno Bruto da sua região de governo, e o Produto Interno Bruto per capita é superior tanto dos demais municípios da Baixada, quanto do estado como um todo (SEADE, 2010). A renda média domiciliar per capita é superior da Região Metropolitana da [...] e do estado de São Paulo nos três últimos anos censitários. De 1991 a 2010 a renda média domiciliar per capita mais do que duplicou, passando de $\mathrm{R} \$ 813$ para $\mathrm{R} \$$ 1.651.Na proporção de pessoas com renda per capita de até $1 / 2$ salário mínimo, isto é, medida aproximada da magnitude da pobreza da população, constata-se que a cidade diminuiu fortemente o contingente dessa população. [...] Em 1991, o município abrigava $23,27 \%$ da sua população com renda per capita de até $1 / 2$ salário mínimo e em 2010 este era de $10,21 \%$ da população, indicando uma redução de mais de 50\%. [...] A Taxa de Desemprego no município tem uma trajetória muito semelhante ao do estado de São Paulo e se destaca da Região Metropolitana da [...] com dados de desemprego inferiores [...] O município, assim como os outros que compõem a Região Metropolitana da [...], apresenta um desequilíbrio social na distribuição da população em seu território, onde sua organização espacial apresenta nítidos contornos e limites socioeconômicos, com a clara divisão da cidade por faixas de renda. Este desequilíbrio aponta a classe social de média e alta renda habitando áreas valorizadas, privilegiada pela presença satisfatória de infraestrutura urbana, enquanto a classe de baixa renda distribui-se em áreas periféricas, onde a presença de infraestrutura é precária. [...] B se destaca dos outros municípios da [...] no setor educacional, pois apresenta indicadores que evidenciam bom nível da educação. [...] A Taxa de Analfabetismo é a porcentagem de pessoas com 15 anos ou mais que não sabem ler e escrever pelo menos um bilhete simples. [...] B possui, em relação aos outros municípios da [...], o menor percentual $(9,73 \%)$ de pessoas sem instrução ou com o 1 - ciclo fundamental incompleto, 
bem como o de pessoas com $1^{\circ}$ ciclo fundamental completo ou $2^{\circ}$ ciclo incompleto $(11,49 \%)$. Para o ensino fundamental completo ou mais, B é o município da Região que se destaca com $78,78 \%$ da população com este nível de escolaridade. [...] É bastante evidente, a redução no percentual das faixas etárias de 0 a 4,5 a 9 e 10 a 14 anos - 0 chamado estreitamento da base, com um crescimento nas faixas intermediárias, e finalmente, em 2010, aumento claro nas faixas etárias acima de 60 anos. Há nos dois anos censitários predominância de homens nas faixas etárias até 40 anos e a inversão acima desta. $O$ perfil etário do município reflete uma população mais envelhecida do que a do estado de São Paulo como um todo: apenas $16,8 \%$ da sua população têm menos de 15 anos, contra $21,5 \%$ no estado. Já a população com mais de 60 anos é de $19,2 \%$, para $11,5 \%$ no estado. [...] (grifo nosso)

C (2010-2013): [...] O indicador sintético de riqueza municipal consiste na combinação de quatro variáveis: consumo anual de energia elétrica residencial por ligação; consumo anual de energia elétrica na agricultura, no comércio e nos serviços por ligação; valor adicionado fiscal per capita; e remuneração média dos empregados com carteira assinada e do setor público. O indicador varia de 0 a 100, em que 0 representa a pior situação no indicador e 100, a melhor. O indicador sintético de longevidade compõe-se da combinação de quatro taxas de mortalidade: mortalidade perinatal, infantil, de pessoas de 15 a 39 anos e de pessoas de 60 anos ou mais. $O$ indicador varia de 0 a 100, em que 0 representa a pior situação no indicador e 100, a melhor. 0 indicador sintético de escolaridade resulta da combinação de quatro variáveis: porcentual de jovens de 15 a 17 anos com ensino fundamental completo, porcentual de jovens de 18 a 19 anos com ensino médio completo, porcentual de jovens de 15 a 17 anos com pelo menos quatro anos de estudo, porcentual de crianças de 5 a 6 anos que frequentam a pré-escola. $O$ indicador varia de 0 a 100 , em que 0 representa a pior situação no indicador e 100, a melhor [...] Estes indicadores mostraram-se melhores no município em comparação ao período anterior [...]. (grifo nosso)

D (2010-2013): [...] As parcelas da população com menos de 15 anos e com mais de 60 anos, são semelhantes às do estado e região, sendo o Índice de Envelhecimento maior em D, se comparado ao do estado e região [...]. (grifo nosso)

D (2014-2017): [...] A renda per capita da região [...] é maior que a do estado de São Paulo, seja representada em salários mínimos (2000) como em reais (2010). O município apresenta renda per capita ainda maior que a Região Metropolitana [...], sendo em 2010 igual a $\mathrm{R} \$ 1.308,22$. Para colaborar com a situação privilegiada do município em relação à renda familiar, D apresentou em 2010 menor percentual de domicílios particulares com renda per capita de até $1 / 4$ do salário mínimo (4,43\%), comparativamente ao Estado de São Paulo, que teve $7,42 \%$ e a RMC que teve $5,51 \%$ de domicílios nessa situação. [...] $\mathrm{Na}$ dimensão longevidade, o município de $\mathrm{D}$ também aparece à frente do estado, sendo de 78 em 2010. Na dimensão escolaridade, D apresentava em 2010 indicador 60, também maior que o do estado de São Paulo. [...] A taxa de analfabetismo na população de 15 anos e 
mais, em 1991 era de 9,5\%, maior que da Região Metropolitana [...] $(8,9 \%)$ e ligeiramente maior que do estado de São Paulo no mesmo período $(9,7 \%)$. A partir do ano 2000 até 2010 , assim como na Região Metropolitana [...] e estado de São, houve melhora significativa nesse indicador, e D passou a ter em 2010 a menor taxa de analfabetismo entre a população de 15 anos e mais, comparativamente à Região Metropolitana [...] e ao estado de São Paulo $(2,8)$. [...] a maior participação nos empregos formais no município está nos empregos formais da indústria, enquanto no estado e Região Metropolitana [...] está em serviços. Em relação ao rendimento, o da indústria é o menor em comparação com estado e Região Metropolitana [...], ao contrário do comércio, que tem rendimento maior que estado e Região Metropolitana [...]. O rendimento médio de serviços também é menor que da Região Metropolitana [...] e do estado, assim como o de construção e agricultura, sendo o rendimento médio do total de empregos formais no município, menor em comparação com estado e Região Metropolitana [...] o município acompanha a tendência de envelhecimento populacional que ocorre no país, sendo que a população com 60 anos e mais que correspondia a $11,18 \%$ da população total em 2010, em 2013 correspondia a 12,30\% da mesma, sendo semelhantes e ligeiramente superiores ao estado e região em 2010 e ligeiramente inferior ao estado em 2013. Quanto ao Índice de Envelhecimento, foi de $55,73 \%$ em 2010 e teve aumento significativo em 2013 , sendo de $65 \%$, seguindo a tendência do estado e região, ainda superando esses últimos, que ficaram em $61,55 \%$ e $61,93 \%$, respectivamente. Índice de envelhecimento da população com menos de 15 anos, por outro lado, vem diminuindo percentualmente em relação à população total, representando 20,06\% em 2010 e em 2013 $18,92 \%$, sendo menor comparativamente ao estado de São Paulo e Região Metropolitana [...], que também apresentam tendência de queda no percentual de menores de 15 anos na população [...] $\mathrm{O}$ Índice de Desenvolvimento Humano é um indicador usado mundialmente que é composto por três indicadores de desenvolvimento humano: vida longa e saudável (longevidade), acesso ao conhecimento (educação) e padrão de vida (renda). O Brasil como um todo progrediu muito nesse índice, passando de "muito baixo" $(0,493)$ em 1991, para "médio" $(0,612)$ em 2000 e em 2010 para "alto desenvolvimento humano" $(0,727)$. As regiões sul e sudeste, onde se encontra o estado de São Paulo, concentram a maior parte dos municípios com "alto desenvolvimento humano. O município de $D$, que no ano 2000 já tinha Índice de Desenvolvimento Humano com "muito alto desenvolvimento humano", em 2013 ocupou a 13ª posição no país, com Índice de Desenvolvimento Humano 0,817, a frente do município [...], da capital São Paulo e de outras capitais, como Porto Alegre e Belo Horizonte [...]. O Índice Paulista de Responsabilidade Social que acompanha o Índice de Desenvolvimento Humano, avalia as condições de vida, através da renda, escolaridade e longevidade, especificamente para o estado de São Paulo. Na dimensão riqueza, o município de $D$ apresenta indicador mais alto que do estado, ficando em 53 no ano de 2010 [...]. A Distribuição da População por Faixa Etária mostra que em 2012, $11,73 \%$ se encontrava na faixa etária com 60 anos e mais, enquanto $19,87 \%$ na faixa etária menor que 15 anos [...]. (grifo nosso)

A análise destes conteúdos reflete a compreensão dos PMSs quanto à utilização de indicadores de desenvolvimento social como métricas de acompanhamento das ações em saúde. Apesar dessa forma de mensuração 
denotar avanço na gestão municipal em saúde, ao ser apresentada de forma descritiva dificulta a comparação longitudinal e entre cenários similares, bem como pouco se aproxima da identificação das vulnerabilidades de grupos sociais específicos.

O mesmo ocorre quando se verifica o quantitativo populacional nos RAGMs no período de 2011 a 2015. No município A houve crescimento da população, em torno de $0,92 \%$, com mínimas diferenças entre algumas faixas etárias, as quais em sua totalidade apresentaram variação populacional positiva entre $0,90 \%$ e $0,97 \%$ a depender do estrato etário e do sexo analisado.

No município $C$ a variação foi positiva e de 3,37\%, também com mínimas diferenças entre algumas faixas etárias, as quais em sua totalidade apresentaram variação populacional positiva entre 3,34\% e 3,42\% a depender do estrato etário e do sexo analisado.

No município $D$ houve crescimento na ordem de $4 \%$ para a população masculina e de $3 \%$ para a população feminina. Entretanto, ao analisar os estratos etários identificou-se regressão no número de crianças de 5 a 9 anos, sendo de $-7 \%$ para os meninos e de $-8 \%$ para as meninas. Além disso, entre as mulheres na faixa etária dos 70 aos 79 anos foi observada a regressão de -66\% neste quantitativo, entre os homens houve incremento de $5 \%$ neste estrato etário.

Esse perfil populacional entre as idosas de 70 a 79 anos, no município $D$, pode ter relação com algum evento de morbimortalidade ou mesmo inconsistência nos dados disponíveis, o que por sua vez implica dificuldade de análise do perfil populacional e epidemiológico do município.

Quanto ao município $B$, não foi possível realizar a análise de perfil populacional e de morbimortalidade, devido à indisponibilidade dos RAGMs referentes aos anos de 2013, 2014 e 2015, apesar da obrigatoriedade legal destes documentos para o monitoramento das ações em saúde propostas no PMS, bem como da acessível disponibilização de instruções para a sua realização e divulgação.

Esse fato faz com que se vislumbre uma contradição teórico-prática clássica, em que, apesar da presença de normativas instrucionais e da 
obrigatoriedade de elaboração e divulgação dos RAGMs, esses não foram elaborados ou divulgados por meio do SARG-SUS, o que implica uma realidade dialetizada à medida que essa elaboração e divulgação são um meio, inclusive, para a garantia do repasse de recursos para o financiamento de saúde e sustentabilidade das contas públicas municipais.

Portanto, a análise do quantitativo populacional dos municípios é importante, no sentido de se aproximar do perfil etário e das políticas públicas relevantes para cada grupo. Porém, para isso, é fundamental que a compreensão da realidade se dê de forma aprofundada, buscando por inconsistências nos dados, razões pelas quais houve expressivo aumento ou redução em determinados estratos etários, sejam eles estudados conjuntamente, por sexo, etnia ou classe social, visando identificar vulnerabilidades e direcionar ações em saúde coerentes e efetivas à população.

Para contribuir para a análise da realidade, as pirâmides etárias se configuram como um instrumental de gestão imprescindível. No entanto, aquelas disponíveis nos RAGMs evidenciaram que nesse documento de gestão municipal não foi utilizada a metodologia preconizada pelo Instituto Brasileiro de Geografia e Estatística (IBGE) para a sua elaboração, a qual descreve quantitativamente os estratos a cada cinco anos até os cem anos de vida ou mais (IBGE, s.d.).

Ao desconsiderar a metodologia estabelecida pelo IBGE, as pirâmides etárias não têm potencialidade para demonstrar situações de saúde presentes em estratos populacionais específicos que possam ser alvo de investigação minuciosa da realidade e proposição de ações, como agravos emergentes decorrentes de doenças infectocontagiosas, como: Dengue, Zika, Meningites, Chikungunya, HIV, entre outras; de doenças crônico-degenerativas, como: Alzheimer, Neoplasias, Depressão; de eventos relacionados à gravidez, parto e puerpério, como a Microcefalia em bebês de mulheres infectadas pela Zika, por exemplo; ou mesmo de eventos referentes às causas externas, como aqueles ocorridos em virtude da violência urbana, catástrofes, desastres ambientais, entre outros.

Diante disso, os gráficos 5, 6 e 7 comparam as pirâmides etárias disponíveis nos RAGMs de 2015 dos municípios A, C e D com os dados 
populacionais destes municípios referentes ao censo de 2010, disponíveis eletronicamente pelo IBGE (IBGE, 2010).

Essa comparação confirmou que as pirâmides etárias presentes nos RAGMs pouco agregam para a gestão municipal em saúde, isto porque elas não permitem a visualização da redução do quantitativo populacional entre os jovens e adultos-jovens, os quais podem, por exemplo, terem sido vítimas da violência urbana ou de agravos à saúde emergentes, mascarando possíveis aspectos relacionados à determinação social e aos grupos sociais vulneráveis.

Além disso, o formato da pirâmide etária utilizando-se da metodologia do IBGE permite identificar que os municípios analisados vivenciam 0 envelhecimento populacional, inclusive, com o quantitativo superior de mulheres em relação aos homens, em idades avançadas.

Assim, seria possível verificar a necessidade de desenvolvimento, implantação e monitoramento de políticas públicas específicas para as mulheres, as quais devem abranger o acesso à saúde, à educação, ao trabalho, à renda, ao lazer, entre outros, visando dessa forma oportunizar condições para que essas mulheres se mantenham ativas e produtivas socialmente ao longo dos anos. 
Gráfico 5 - Comparativo das pirâmides etárias do município A, segundo os dados do RAGM de 2015 e do IBGE de 2010. São Paulo, 2017.

Dados do RAGM de 2015

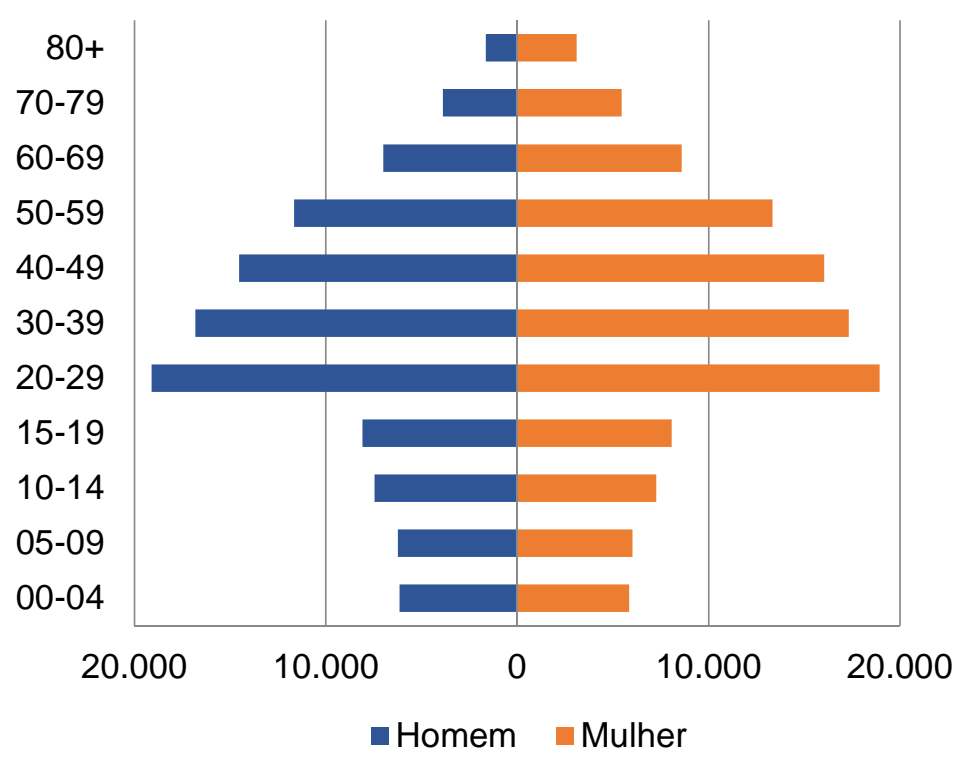

Dados do IBGE de 2010

100 anos ou mais de idade 95 a 99 anos de idade 90 a 94 anos de idade 85 a 89 anos de idade 80 a 84 anos de idade 75 a 79 anos de idade 70 a 74 anos de idade 65 a 69 anos de idade 60 a 64 anos de idade 55 a 59 anos de idade 50 a 54 anos de idade 45 a 49 anos de idade 40 a 44 anos de idade 35 a 39 anos de idade 30 a 34 anos de idade 25 a 29 anos de idade 20 a 24 anos de idade 15 a 19 anos de idade 10 a 14 anos de idade 5 a 9 anos de idade 0 a 4 anos de idade

$\begin{array}{ccrrr}10.000 & 5.000 & 0 & 5.000 & 10.000 \\ & & & \\ & & \text { Homem } & & \end{array}$


Gráfico 6 - Comparativo das pirâmides etárias do município C, segundo os dados do RAGM de 2015 e do IBGE de 2010. São Paulo, 2017.

Dados do RAGM de 2015

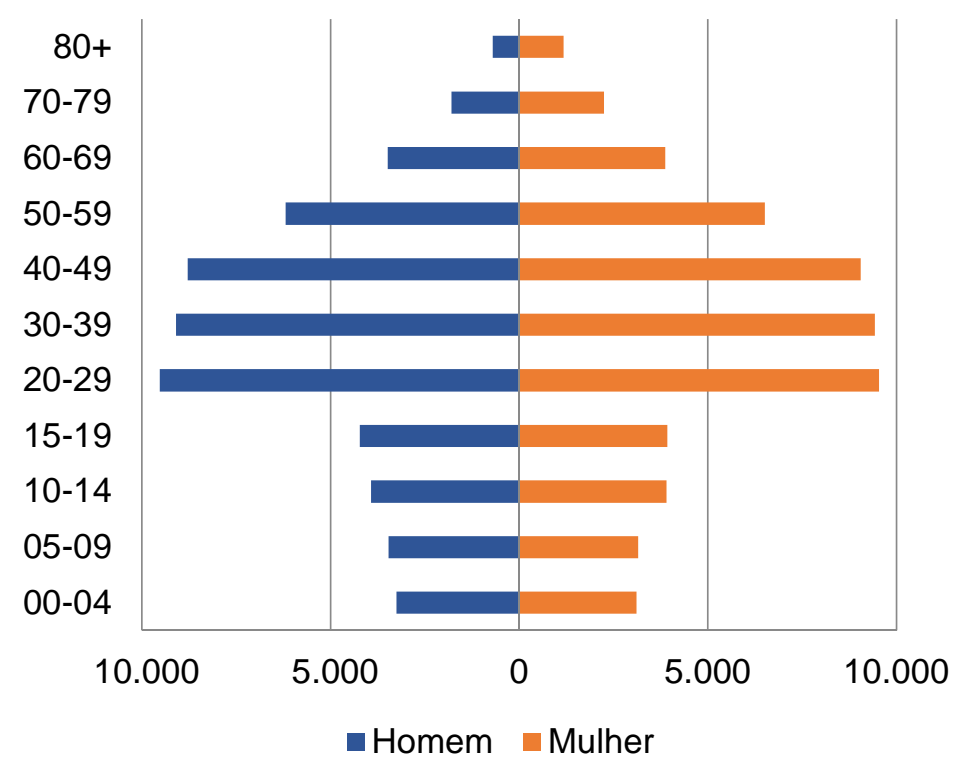

Dados do IBGE de 2010

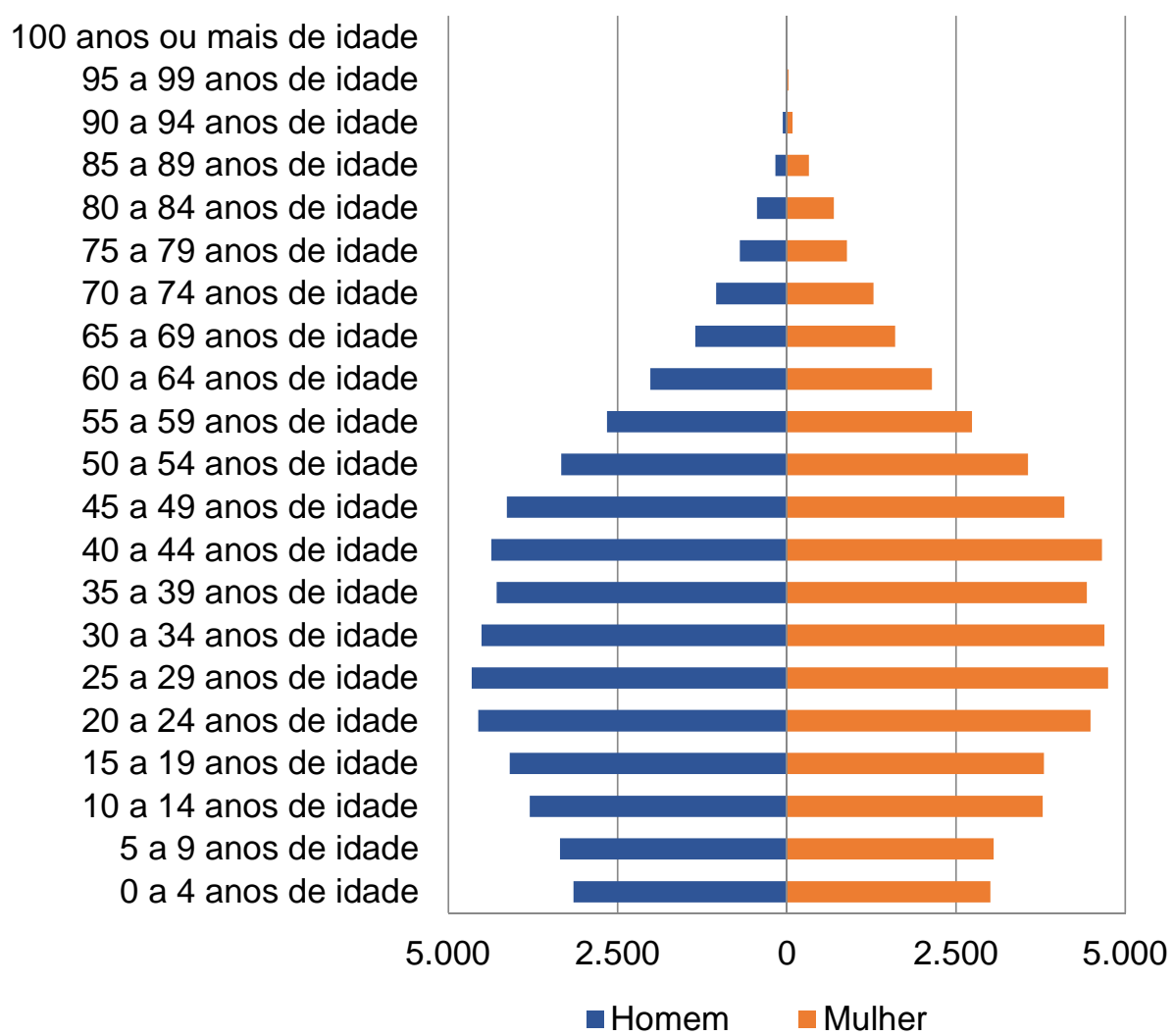


Gráfico 7 - Comparativo das pirâmides etárias do município D, segundo os dados do RAGM de 2015 e do IBGE de 2010. São Paulo, 2017.

Dados do RAGM de 2015

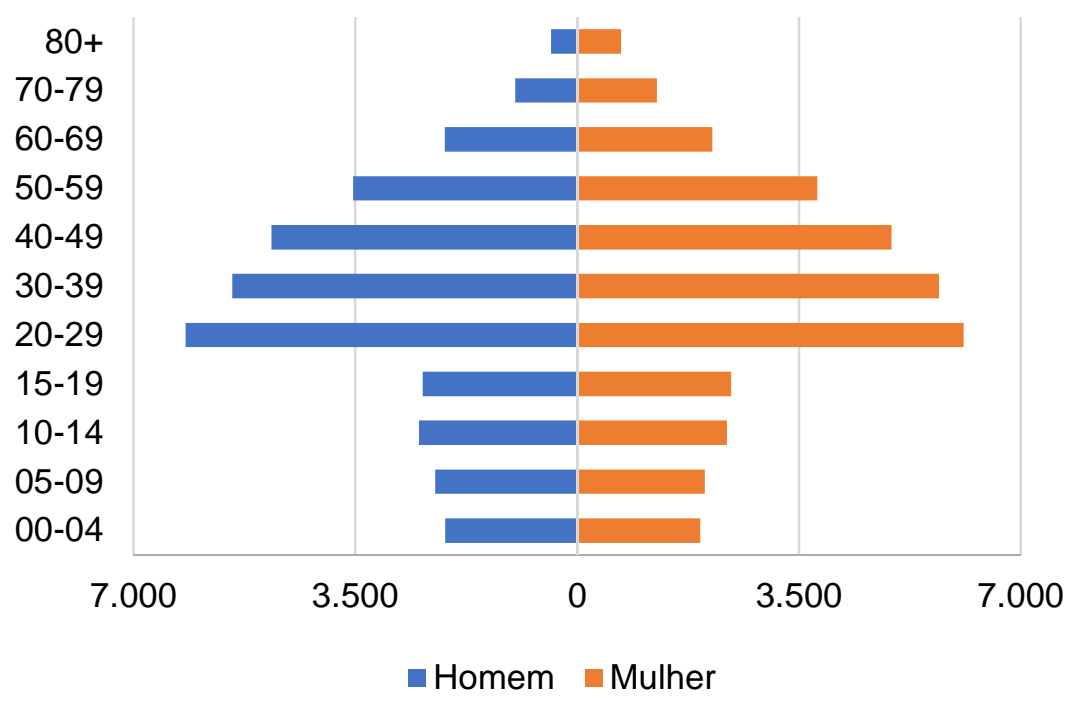

100 anos ou mais de idade 95 a 99 anos de idade 90 a 94 anos de idade 85 a 89 anos de idade 80 a 84 anos de idade 75 a 79 anos de idade 70 a 74 anos de idade 65 a 69 anos de idade 60 a 64 anos de idade 55 a 59 anos de idade 50 a 54 anos de idade 45 a 49 anos de idade 40 a 44 anos de idade 35 a 39 anos de idade 30 a 34 anos de idade 25 a 29 anos de idade 20 a 24 anos de idade 15 a 19 anos de idade 10 a 14 anos de idade 5 a 9 anos de idade 0 a 4 anos de idade

4.000
Dados do IBGE de 2010

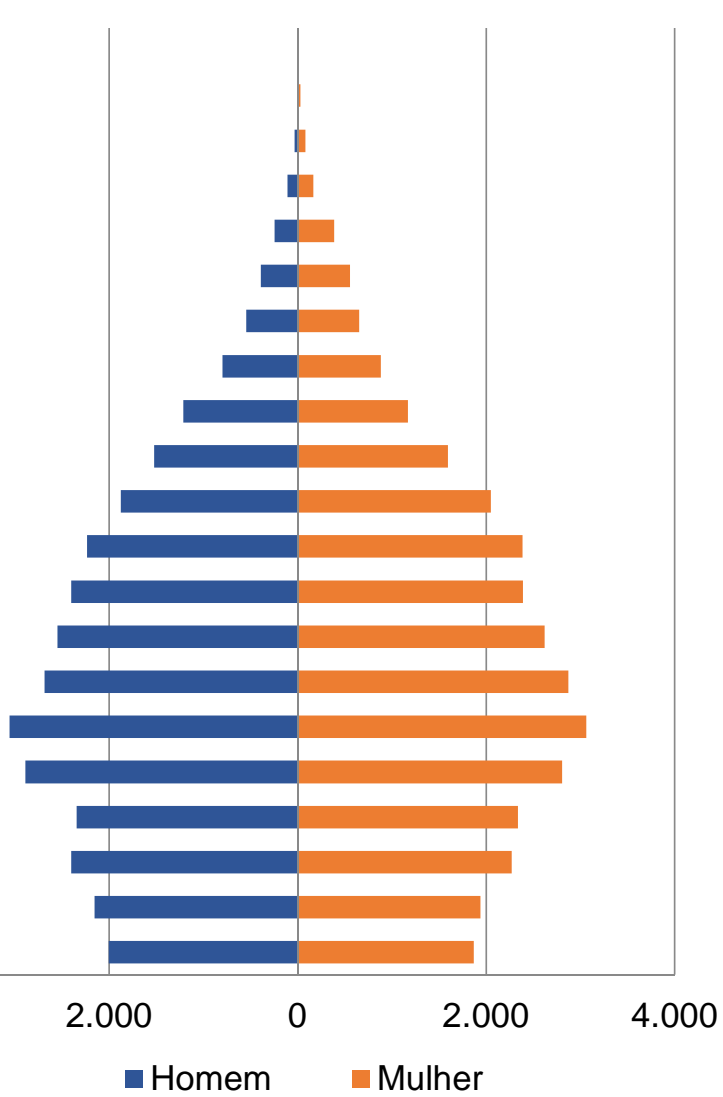


Para o monitoramento do perfil de morbimortalidade os RAGMs utilizaram-se da CID-10, sendo que a análise do perfil de mortalidade deflagrou a manutenção de algumas causas entre os municípios analisados, como, por exemplo, aquelas relacionadas às causas externas que, apesar da redução ao longo dos anos nos municípios estudados, continuam latentes, das doenças do aparelho respiratório que aumentaram entre os municípios analisados (Gráfico 8, Gráfico 9, Gráfico 10), das doenças do aparelho circulatório no município C (Gráfico 9), das neoplasias no município D (Gráfico 10) e dos transtornos mentais e comportamentais nos municípios C e D (Gráfico 9 e Gráfico 10).

Em linhas gerais, o perfil descrito reforça os aspectos da tripla carga de doença, que se caracteriza pela maior ocorrência de agravos por doenças crônico-degenerativas, como as causas relacionadas às doenças circulatórias e neoplasias; da persistência de doenças infectocontagiosas, as quais podem ser denotadas pela mortalidade por doenças respiratórias, entre as quais se destacam as pneumonias e os diversos tipos de gripes, por exemplo; bem como pela ocorrência da mortalidade materna e devido às causas externas, relacionadas, principalmente, à violência urbana.

As más-formações congênitas, as doenças da pele e tecido subcutâneo, doenças do sangue e órgãos hematopoiéticos, os transtornos mentais e comportamentais e as mortes em decorrência da gravidez, parto e puerpério destacaram-se como causas que reforçam a ocorrência de agravos relacionados às formas socialmente determinadas de adoecer e morrer, no que se refere, por exemplo, ao acesso a determinados tipos de alimentos, aos serviços de saúde e tipos de trabalho que podem envolver exposição solar ou a outros agentes nocivos, bem como às condições laborais desfavoráveis e à restrição de acesso ao lazer, à cultura e à educação que podem contribuir para a ocorrência de doenças mentais.

Além disso, as mortes registradas sob o Capítulo XVIII da CID-10 Sinais e Achados Anormais em Exames Clínicos e Laboratoriais - diminuíram ao longo dos anos nos municípios analisados, o que pode ser em decorrência da maior capacidade de atribuição de diagnóstico médico aos agravos, bem como da melhor qualidade do registro e da divulgação dos dados nos sistemas de informação municipais. 
Gráfico 8 - Perfil de mortalidade descrito nos RAGMs do município A, segundo o ano e a CID-10. São Paulo, 2017.

Capítulo XX Causas externas de morbidade e mortalidade Capitulo XIX Lesoes, envenenamento e algumas outras consequencias de...

Capítulo XVIII Sint sinais e achad anorm ex clín e laborat Capítulo XVII Malf cong deformid e anomalias cromossômicas

Capítulo XVI Algumas afec originadas no período perinatal

Capitulo XV Gravidez, parto e puerperio

Capítulo XIV Doenças do aparelho geniturinário

Capítulo XIII Doenças sist osteomuscular e tec conjuntivo

Capítulo XII Doenças da pele e do tecido subcutâneo

Capítulo XI Doenças do aparelho digestivo

Capítulo X Doenças do aparelho respiratório

Capítulo IX Doenças do aparelho circulatório

Capitulo VIII Doencas do ouvido e da apofise mastoide

Capitulo VII Doencas do olho e anexos

Capítulo VI Doenças do sistema nervoso

Capítulo V Transtornos mentais e comportamentais

Capítulo IV Doenças endócrinas nutricionais e metabólicas

Capítulo III Doenças sangue órgãos hemat e transt imunitár

Capítulo II Neoplasias (tumores)

Capítulo I Algumas doenças infecciosas e parasitárias

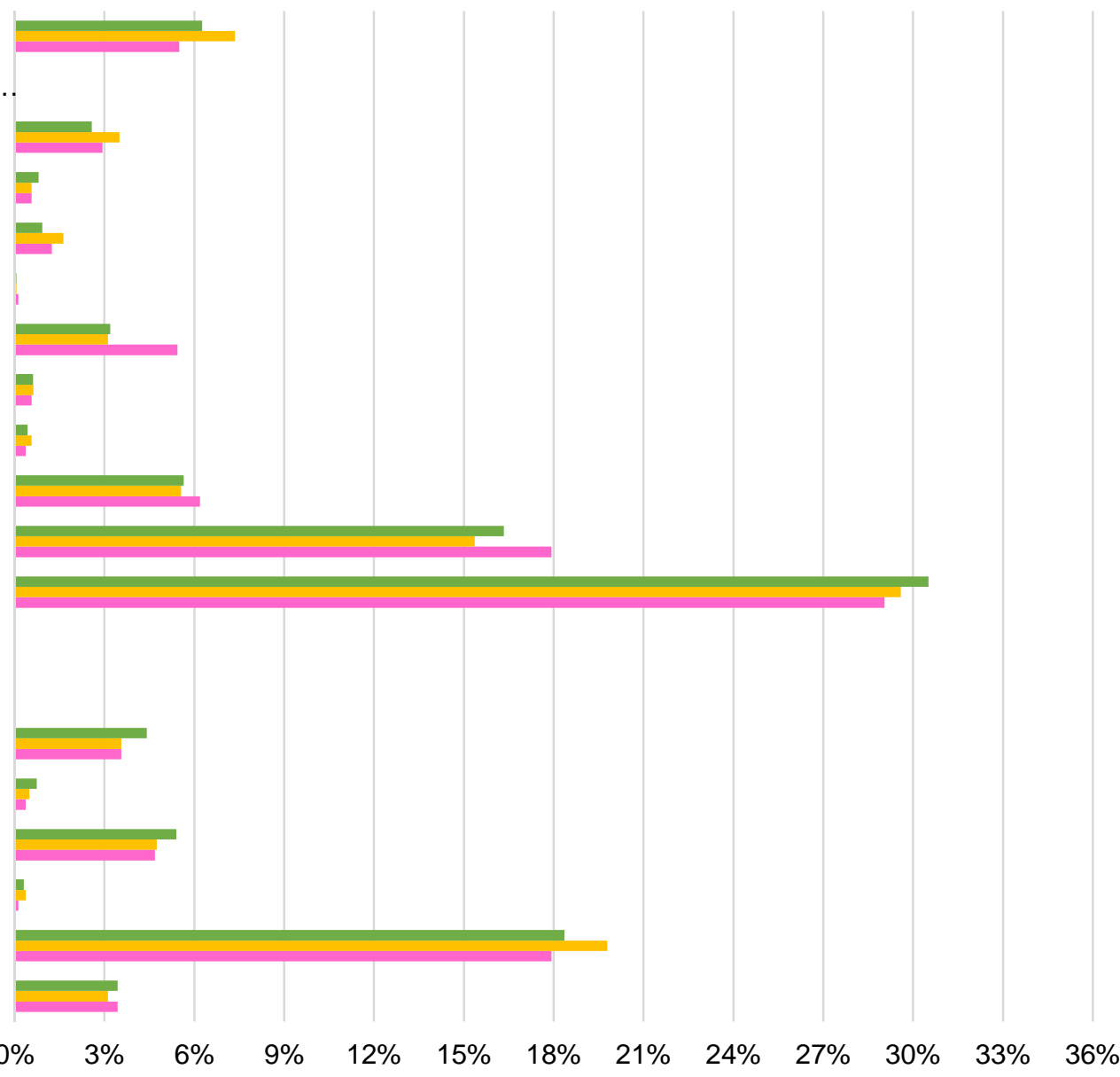

$\because 2013 \square 2014 \square 2015$

Mortalidade

2013: $N=1629 ; 2014: N=1602 ; 2015: N=1601$ 
Gráfico 9 - Perfil de mortalidade descrito nos RAGMs do município C, segundo o ano e a CID-10. São Paulo, 2017.

Capítulo XX Causas externas de morbidade e mortalidade Capítulo XIX Lesões enven e alg out conseq causas externas

Capítulo XVIII Sint sinais e achad anorm ex clín e laborat Capítulo XVII Malf cong deformid e anomalias cromossômicas

Capítulo XVI Algumas afec originadas no período perinatal Capitulo XV Gravidez, parto e puerperio Capítulo XIV Doenças do aparelho geniturinário Capítulo XIII Doenças sist osteomuscular e tec conjuntivo

Capítulo XII Doenças da pele e do tecido subcutâneo

Capítulo XI Doenças do aparelho digestivo

Capítulo X Doenças do aparelho respiratório

Capítulo IX Doenças do aparelho circulatório

Capítulo VIII Doenças do ouvido e da apófise mastóide

Capítulo VII Doenças do olho e anexos

Capítulo VI Doenças do sistema nervoso

Capítulo V Transtornos mentais e comportamentais

Capítulo IV Doenças endócrinas nutricionais e metabólicas

Capítulo III Doenças sangue órgãos hemat e transt imunitár

Capítulo II Neoplasias (tumores)

Capítulo I Algumas doenças infecciosas e parasitárias
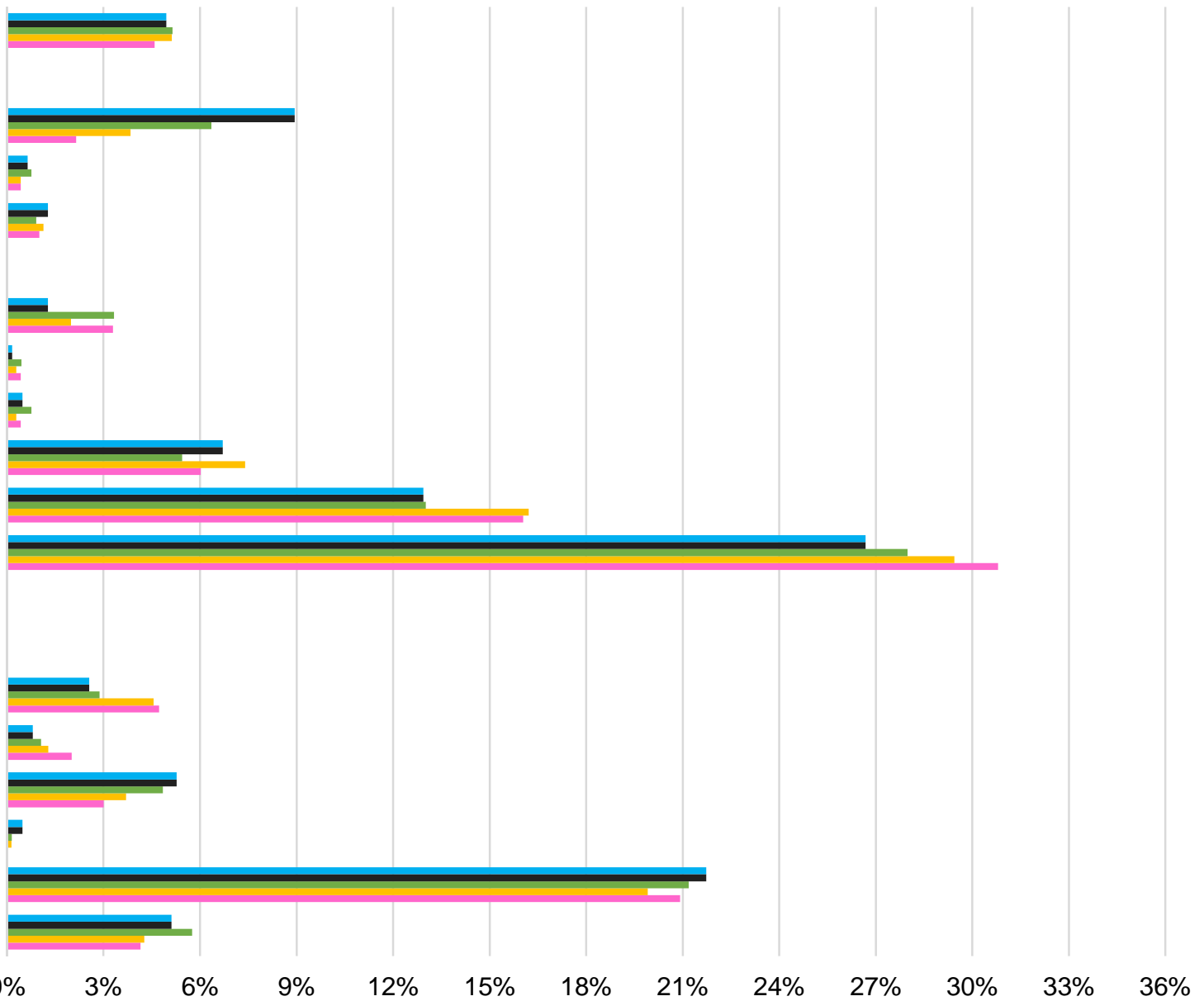

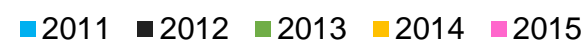

Mortalidade 
Gráfico 10 - Perfil de mortalidade descrito nos RAGMs do município D, segundo o ano e a CID-10. São Paulo, 2017.

Capítulo XX Causas externas de morbidade e mortalidade Capítulo XIX Lesões enven e alg out conseq causas externas

Capítulo XVIII Sint sinais e achad anorm ex clín e laborat

Capítulo XVII Malf cong deformid e anomalias cromossômicas

Capítulo XVI Algumas afec originadas no período perinatal

Capítulo XV Gravidez parto e puerpério

Capítulo XIV Doenças do aparelho geniturinário

Capítulo XIII Doenças sist osteomuscular e tec conjuntivo

Capítulo XII Doenças da pele e do tecido subcutâneo

Capítulo XI Doenças do aparelho digestivo

Capítulo X Doenças do aparelho respiratório

Capítulo IX Doenças do aparelho circulatório

Capítulo VIII Doenças do ouvido e da apófise mastóide

Capítulo VII Doenças do olho e anexos

Capítulo VI Doenças do sistema nervoso

Capítulo V Transtornos mentais e comportamentais

Capítulo IV Doenças endócrinas nutricionais e metabólicas

Capítulo III Doenças sangue órgãos hemat e transt imunitár

Capítulo II Neoplasias (tumores)

Capítulo I Algumas doenças infecciosas e parasitárias

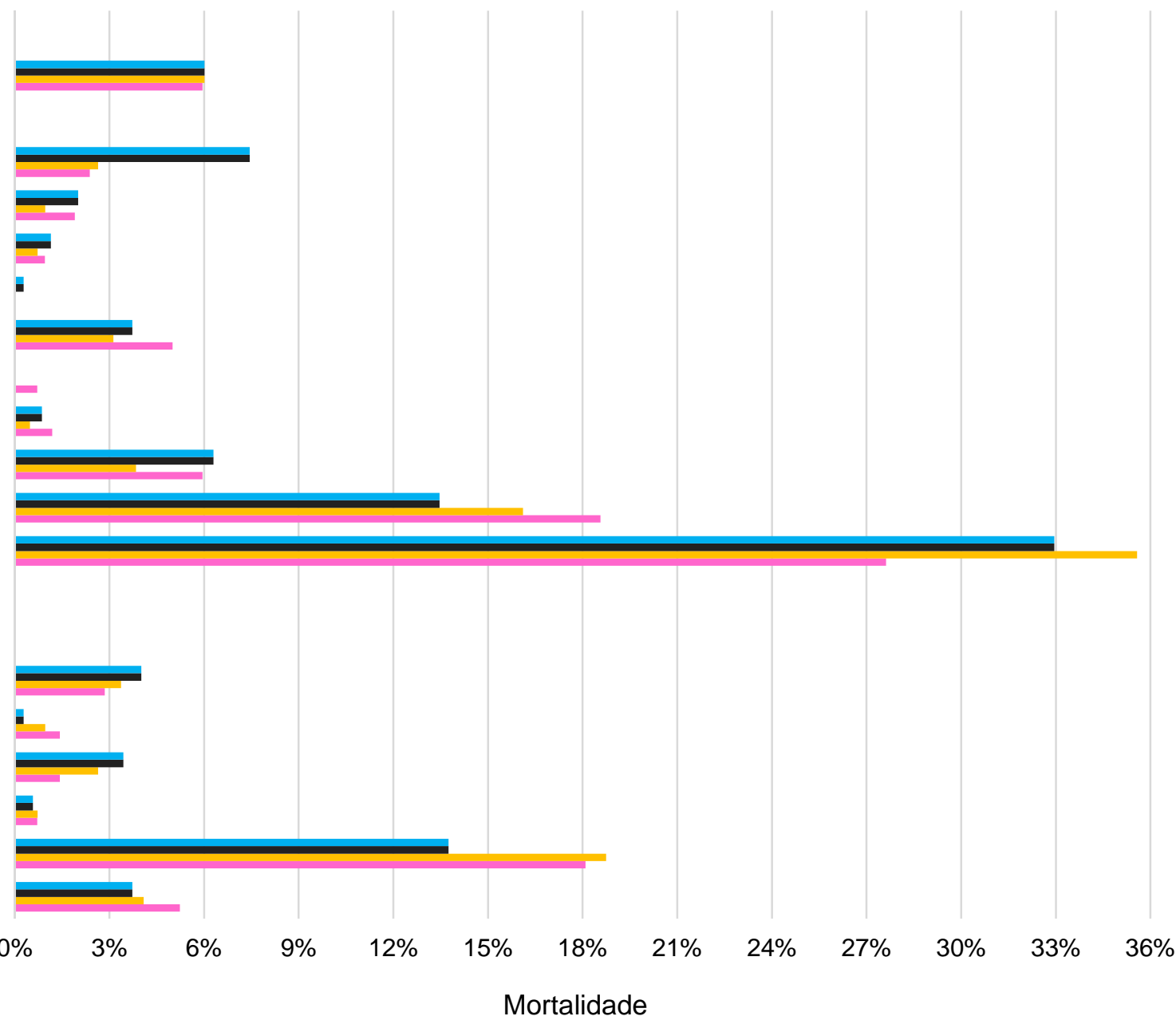

$\square 2011 \square 2012 \square 2014 \square 2015$

Mortalidade

2011: $N=349 ; 2012: \mathrm{N}=349 ; 2014: \mathrm{N}=416 ; 2015: \mathrm{N}=420$ 
Quanto ao perfil de morbidade, houve a manutenção do padrão para algumas causas, como, por exemplo, para aquelas relacionadas às másformações congênitas; às afecções do período perinatal; às doenças do sistema osteomuscular e do tecido conjuntivo; às doenças da pele e tecido subcutâneo; às doenças do ouvido e apófise mastoide; e às doenças do sangue e órgãos hematopoiéticos (Gráfico 11, Gráfico 12 e Gráfico 13).

Enquanto outras causas de adoecimento aumentaram, como: as do aparelho circulatório no município A (Gráfico 11); as doenças infecciosas e parasitárias no município C (Gráfico 12); e as doenças respiratórias e os transtornos mentais e comportamentais no município D (Gráfico 13).

Destacam-se os registros sob o Capítulo XVIII da CID -10, Sinais e Achados Anormais em Exames Clínicos e Laboratoriais, que reforçam a necessidade de investir na atribuição do diagnóstico médico aos agravos, bem como na qualidade do registro e da divulgação, que devem ser consistentes com os dados nos sistemas de informação municipais, com vistas a contribuir para a tomada de decisão e gestão municipal de saúde.

O perfil de morbidade apresentado pelos municípios estudados reforça a necessidade do desenvolvimento de métodos para identificação, mapeamento, intervenção e monitoramento de ações em grupos sociais vulneráveis, haja vista a alta carga de determinação social para as formas de adoecimento identificadas entre os RAGMs analisados. 
Gráfico 11 - Perfil de morbidade descrito nos RAGMs do município A, segundo o ano e a CID-10. São Paulo, 2017.

Capítulo XX Causas externas de morbidade e mortalidade

Capitulo XIX Lesoes, envenenamento e algumas outras.

Capítulo XVIII Sint sinais e achad anorm ex clín e laborat Capítulo XVII Malf cong deformid e anomalias cromossômicas

Capitulo XVI Algumas afeccoes originadas no periodo perinatal

Capitulo XV Gravidez, parto e puerperio

Capitulo XIV Doencas do aparelho geniturinario

Capitulo XIII Doencas do sistema osteomuscular e do tecido conjuntivo

Capitulo XII Doencas da pele e do tecido subcutaneo

Capitulo XI Doencas do aparelho digestivo

Capitulo $X$ Doencas do aparelho respiratorio

Capitulo IX Doencas do aparelho circulatorio

Capitulo VIII Doencas do ouvido e da apofise mastoide

Capitulo VII Doencas do olho e anexos

Capitulo VI Doencas do sistema nervoso

Capitulo V Transtornos mentais e comportamentais

Capitulo IV Doencas endocrinas, nutricionais e metabolicas Capitulo III Doencas do sangue e dos orgaos hematopoeticos e..

Capitulo II Neoplasias [tumores]

Capitulo I Algumas doencas infecciosas e parasitarias

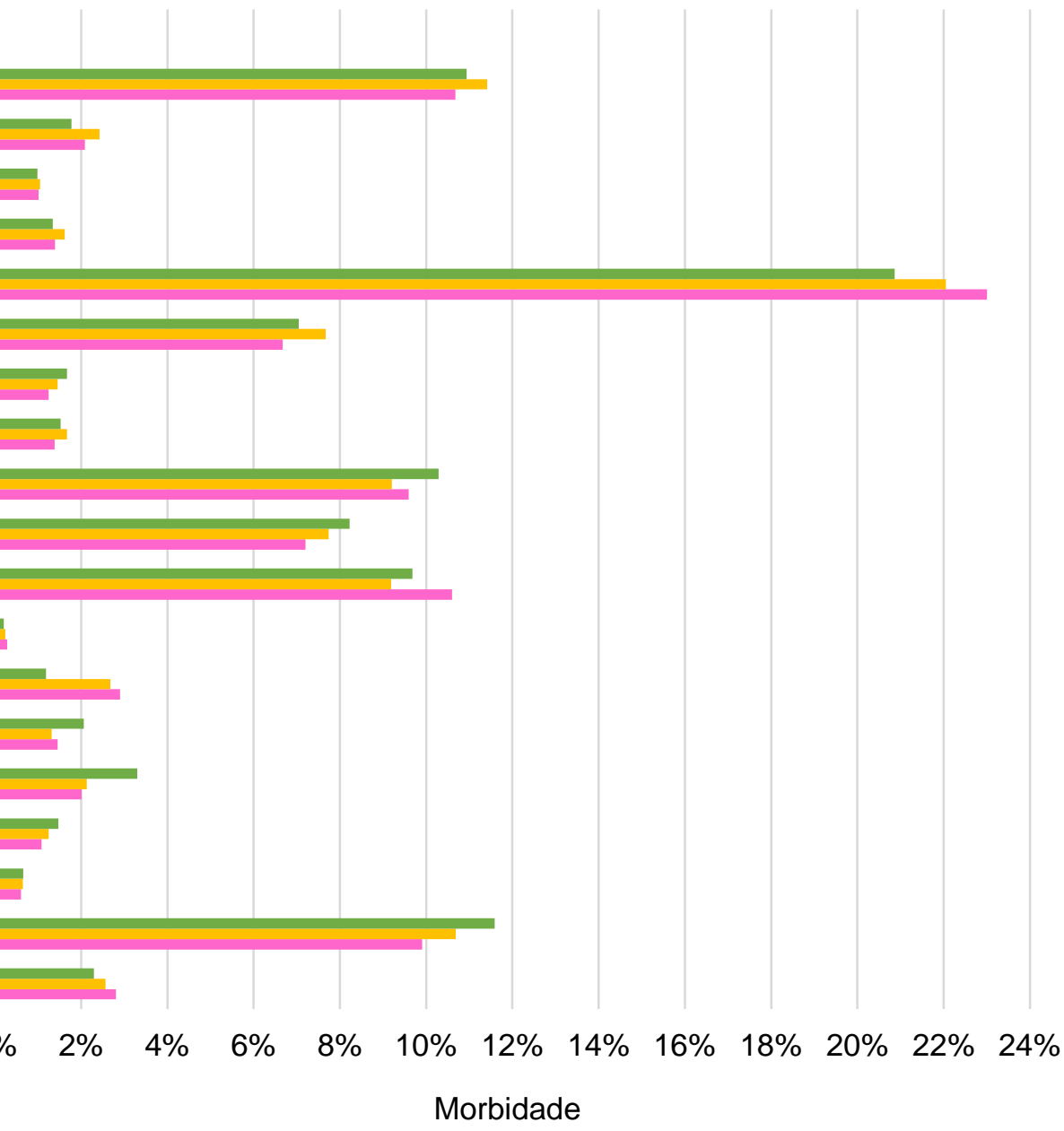

$\square 2013 \square 2014 \square 2015$

2013: $N=8844 ; 2014: N=8668 ; 2015: N=9471$ 
Gráfico 12 - Perfil de morbidade descrito nos RAGMs do município C, segundo o ano e a CID-10. São Paulo, 2017.

Capítulo XX Causas externas de morbidade e mortalidade Capítulo XIX Lesões enven e alg out conseq causas externas

Capítulo XVIII Sint sinais e achad anorm ex clín e laborat Capítulo XVII Malf cong deformid e anomalias cromossômicas

Capítulo XVI Algumas afec originadas no período perinatal

Capítulo XV Gravidez parto e puerpério

Capítulo XIV Doenças do aparelho geniturinário

Capítulo XIII Doenças sist osteomuscular e tec conjuntivo

Capítulo XII Doenças da pele e do tecido subcutâneo

Capítulo XI Doenças do aparelho digestivo

Capítulo X Doenças do aparelho respiratório

Capítulo IX Doenças do aparelho circulatório

Capítulo VIII Doenças do ouvido e da apófise mastóide

Capítulo VII Doenças do olho e anexos

Capítulo VI Doenças do sistema nervoso

Capítulo V Transtornos mentais e comportamentais

Capítulo IV Doenças endócrinas nutricionais e metabólicas

Capítulo III Doenças sangue órgãos hemat e transt imunitár

Capítulo II Neoplasias (tumores)

Capítulo I Algumas doenças infecciosas e parasitárias 
Gráfico 13 - Perfil de morbidade descrito nos RAGMs do município D, segundo o ano e a CID-10. São Paulo, 2017.

Capítulo XX Causas externas de morbidade e mortalidade Capítulo XIX Lesões enven e alg out conseq causas externas

Capítulo XVIII Sint sinais e achad anorm ex clín e laborat Capítulo XVII Malf cong deformid e anomalias cromossômicas

Capítulo XVI Algumas afec originadas no período perinatal

Capítulo XV Gravidez parto e puerpério

Capítulo XIV Doenças do aparelho geniturinário

Capítulo XIII Doenças sist osteomuscular e tec conjuntivo

Capítulo XII Doenças da pele e do tecido subcutâneo

Capítulo XI Doenças do aparelho digestivo

Capítulo $X$ Doenças do aparelho respiratório

Capítulo IX Doenças do aparelho circulatório

Capítulo VIII Doenças do ouvido e da apófise mastóide

Capítulo VII Doenças do olho e anexos

Capítulo VI Doenças do sistema nervoso

Capítulo V Transtornos mentais e comportamentais

Capítulo IV Doenças endócrinas nutricionais e metabólicas

Capítulo III Doenças sangue órgãos hemat e transt imunitár

Capítulo II Neoplasias (tumores)

Capítulo I Algumas doenças infecciosas e parasitárias

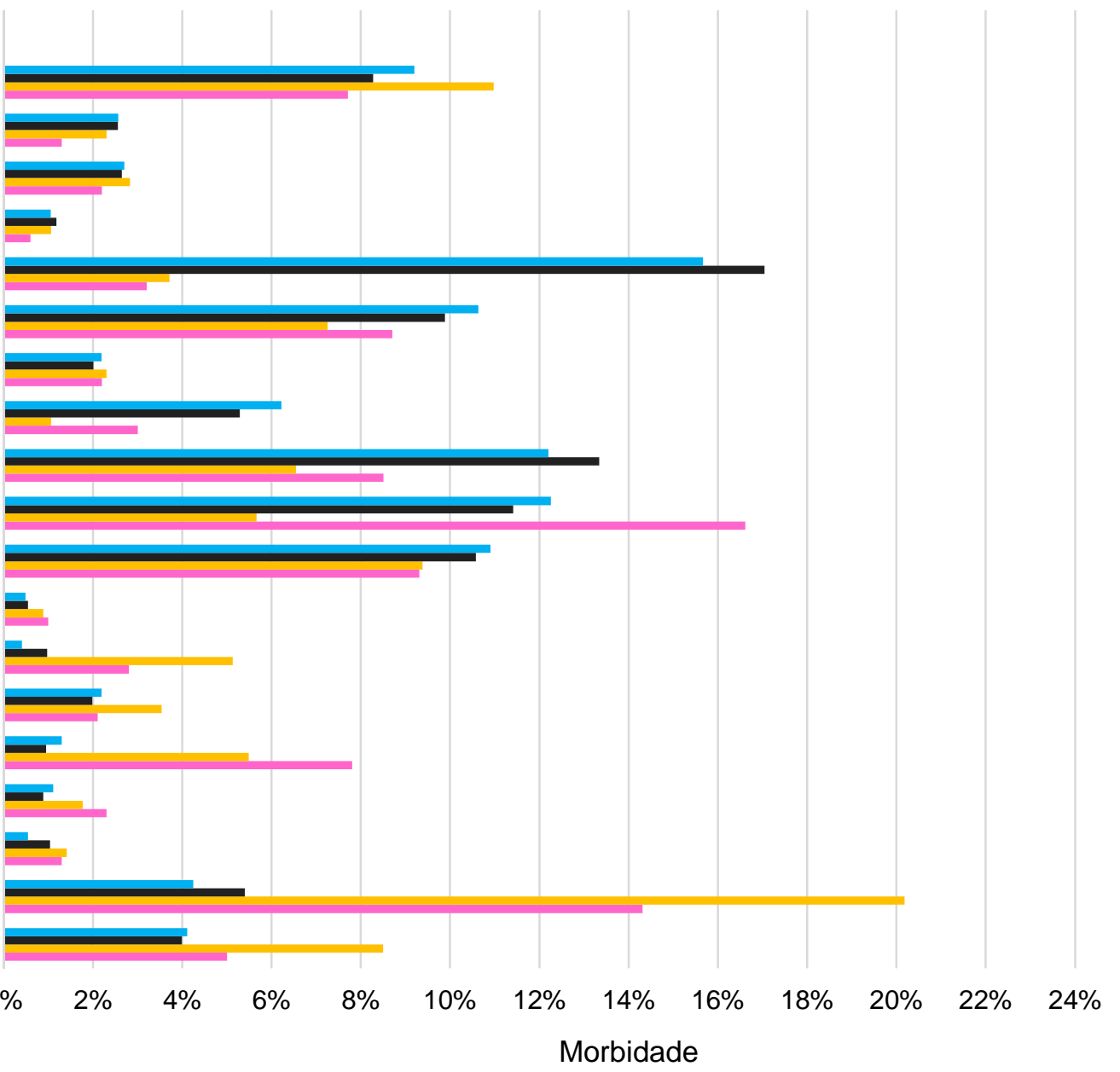

$-2011 \square 2012 \square 2014 \square 2015$

Morbidade

2011: $N=3776 ; 2012: \mathrm{N}=3604 ; 2014: \mathrm{N}=580 ; 2015: \mathrm{N}=1018$ 
Diante do apresentado visualizam-se avanços nas formas de monitoramento das ações em saúde presentes nos RAGMs, haja vista o seu percurso histórico, em que, inicialmente, não dispunha de normativas e sistematização para a sua elaboração. Por outro lado, essas ações de monitoramento atualmente disponíveis possuem limitações na captação das necessidades de grupos sociais vulneráveis, uma vez que a utilização de indicadores padronizados para todos os municípios brasileiros (Brasil, 2016) não considera a realidade de cada município, tampouco a identificação efetiva de grupos expostos à vulnerabilidade social, o que corrobora a reduzida acurácia do monitoramento das ações planejadas. Logo, as metas propostas para superação da realidade não consideram as diversidades locais e suas vulnerabilidades sociais, as quais têm potencial para impactarem as formas de adoecer e morrer da população.

Dessa forma, a articulação entre as necessidades em saúde, que desconsidera uma análise aprofundada por meio da determinação social do processo saúde-doença, e a oferta de serviços de saúde pode ser prejudicada, pois o mero incremento de serviços da APS e de serviços especializados de baixa e média complexidade, como demonstrado nos municípios $A, C$ e $D$ (Gráfico 14, Gráfico 15 e Gráfico 16, respectivamente) não significa, necessariamente, $\mathrm{o}$ atendimento às demandas da população, que se organiza em contextos de vulnerabilidade social.

Porém, frente à ausência da adoção de um referencial teóricometodológico consistente e baseado na determinação social para direcionar as ações gerenciais em saúde no âmbito municipal, classifica-se a ampliação da oferta de serviços de saúde como positiva, uma vez que ela poderia ter, simplesmente, não ocorrido no período analisado dos RAGMs.

Isso reitera a limitação das práticas funcionalistas de gestão para responder às necessidades em saúde da população, visto que elas podem comprometer a alocação dos recursos em saúde, seja pela falta ou pelo desperdício de recursos, bem como a efetividade das ações direcionadas para melhorar a situação de saúde da população, considerando-se inclusive as vulnerabilidades sociais existentes no território sanitário. 
Gráfico 14 - Distribuição dos equipamentos de saúde do município A, segundo os anos dos RAGMSs. São Paulo, 2017.

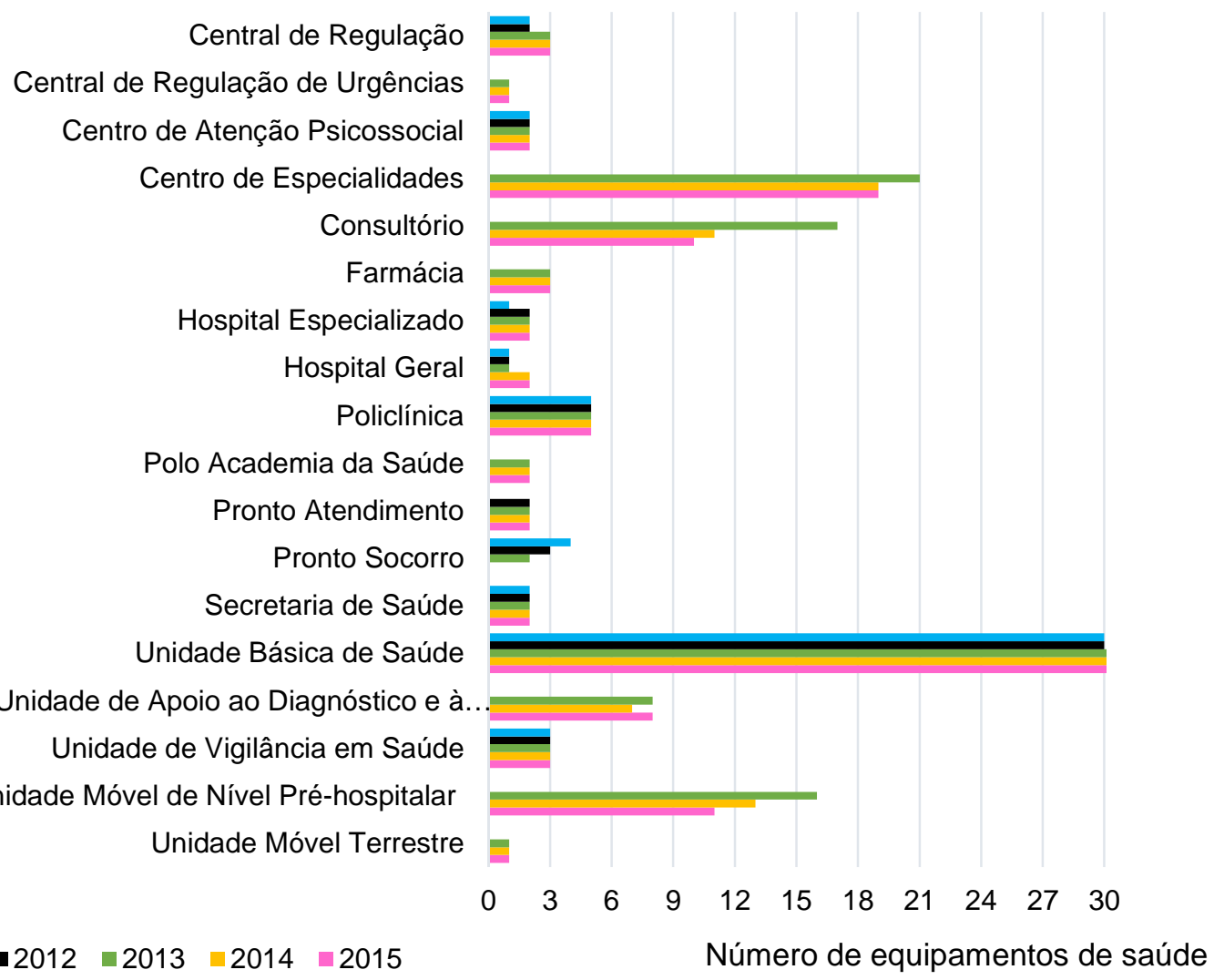

Gráfico 15 - Distribuição dos equipamentos de saúde do município $C$, segundo os anos dos RAGMSs. São Paulo, 2017.

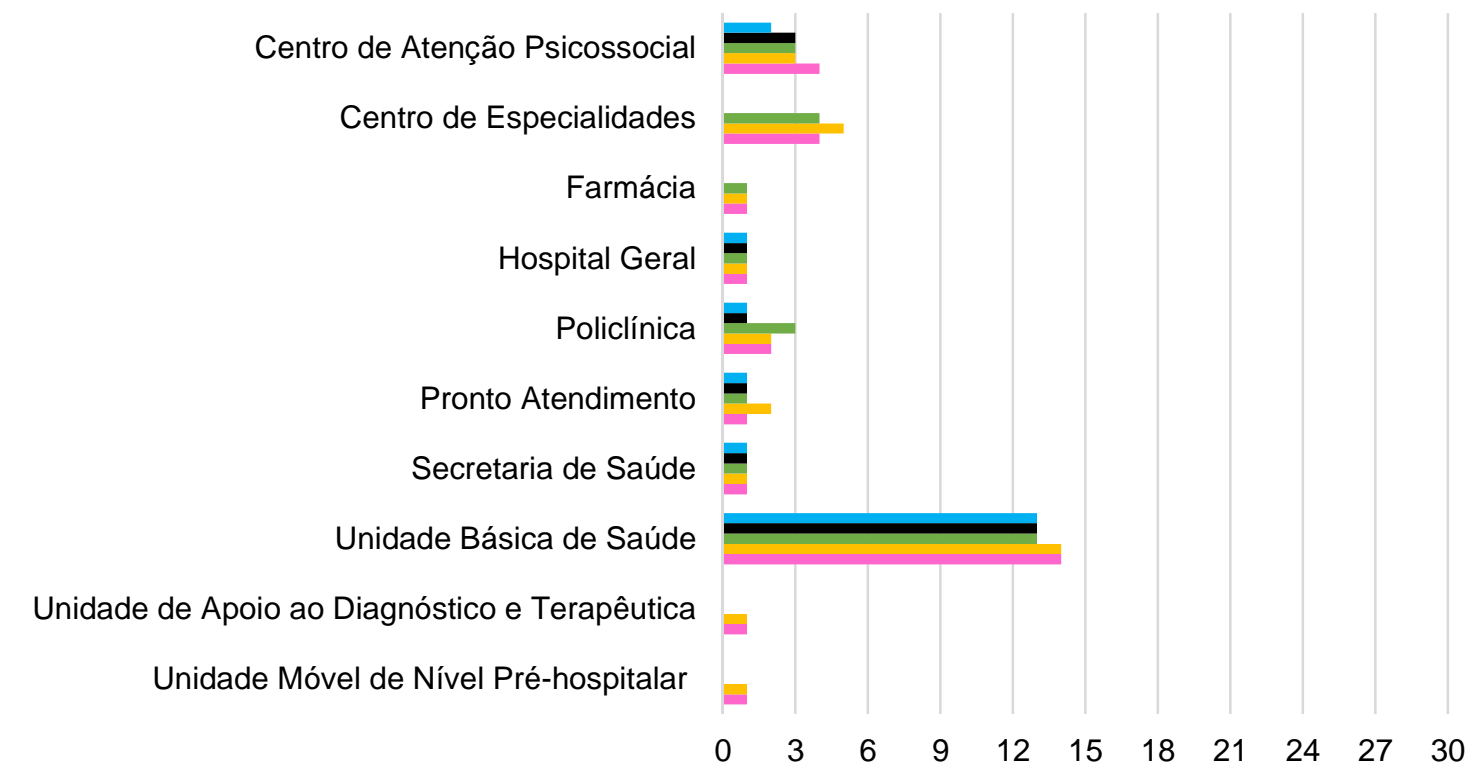

Número de equipamentos de saúde 
Gráfico 16 - Distribuição dos equipamentos de saúde do município D, segundo os anos dos RAGMSs. São Paulo, 2017.

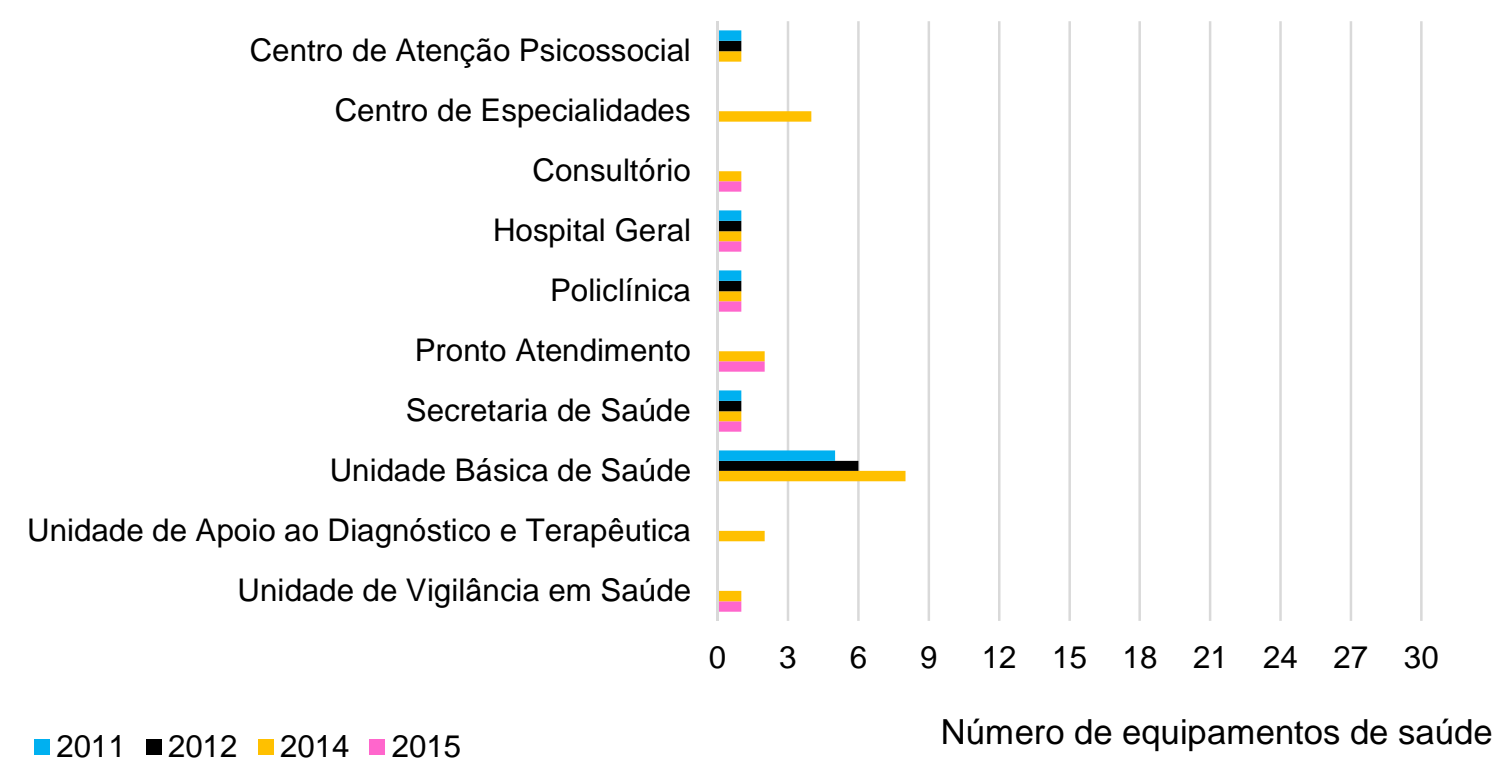

Os gráficos 14, 15 e 16 descreveram o quantitativo de equipamentos de saúde ao longo dos anos nos municípios $\mathrm{A}, \mathrm{C}$ e $\mathrm{D}$, o que traz questionamentos quanto ao atendimento às necessidades em saúde da população, já que os PMSs e os RAGMs não consideram os aspectos da determinação social do processo saúde doença para direcionar a alocação de recursos a partir da identificação de grupos sociais vulneráveis, ou seja, da equidade.

Além do aspecto quantitativo da oferta de serviços de saúde, outros relacionados aos processos de trabalho nestes serviços de saúde são fundamentais para a efetividade da RAS e, consequentemente, para a assistência à população. Tais aspectos envolvem 0 acolhimento às necessidades em saúde, por meio da atuação de profissionais capacitados na perspectiva técnico-científica e inter-relacional, a atenção à saúde organizada em níveis de atenção que ofertem ações articuladas de promoção, prevenção, recuperação, reabilitação e cuidados paliativos, e o monitoramento da atenção à saúde utilizando-se de metodologias e instrumentos que permitam a aproximação com a realidade e a mensuração dos efeitos das ações em saúde implantadas na qualidade de vida das pessoas, inclusive, com o auxílio de sistemas de informação confiáveis e factíveis, que contribuam para os mecanismos de referência e contrarreferência. 
Essa discussão é relevante, visto que a oferta quantitativa de equipamentos de saúde de forma desarticulada das necessidades em saúde, compreendidas a partir da concepção da determinação social do processo saúde-doença, bem como dos aspectos dos processos de trabalho em saúde, possui reduzida possibilidade de contribuição para responder às demandas da população, inclusive, dos grupos com vulnerabilidades sociais importantes.

Diante da totalidade dos resultados apresentados, que problematizaram os limites, as potencialidades e as contradições dos PMSs e RAGMs, foi elaborada uma síntese desses resultados (Quadro 1).

Quadro 1 - Síntese dos resultados, segundo os limites e as potencialidades identificados nos PMSs e RAGMs dos municípios. São Paulo, 2017.

\begin{tabular}{|l|c|c|c|c|}
\hline \multicolumn{1}{|c|}{ Municípios } & A & B & C & D \\
\hline $\begin{array}{l}\text { Limites e Potencialidades } \\
\text { proteção social }\end{array}$ & - & - & $\mathrm{P}$ & $\mathrm{P}$ \\
\hline $\begin{array}{l}\text { PMSs como ferramentas de planejamento em } \\
\text { saúde }\end{array}$ & $\mathrm{P}$ & $\mathrm{P}$ & $\mathrm{P}$ & $\mathrm{P}$ \\
\hline $\begin{array}{l}\text { Identificação das necessidades em saúde por } \\
\text { meio de diagnóstico situacional e da participação } \\
\text { social na gestão do SUS }\end{array}$ & $\mathrm{L}$ & $\mathrm{L}$ & $\mathrm{L}$ & $\mathrm{L}$ \\
\hline $\begin{array}{l}\text { Compreensão das necessidades em saúde a partir } \\
\text { de aspectos multicausais }\end{array}$ & - & $\mathrm{L}$ & $\mathrm{L}$ & $\mathrm{L}$ \\
\hline $\begin{array}{l}\text { Compreensão das necessidades em saúde a partir } \\
\text { de indicadores de morbimortalidade }\end{array}$ & $\mathrm{L}$ & - & - & $\mathrm{L}$ \\
\hline $\begin{array}{l}\text { Compreensão do processo saúde-doença } \\
\text { centrado na doença }\end{array}$ & $\mathrm{L}$ & $\mathrm{L}$ & $\mathrm{L}$ & $\mathrm{L}$ \\
\hline $\begin{array}{l}\text { Monitoramento das ações propostas por meio do } \\
\text { acompanhamento do desenvolvimento social e do } \\
\text { perfil de morbimortalidade }\end{array}$ & $\mathrm{L}$ & $\mathrm{L}$ & $\mathrm{L}$ & $\mathrm{L}$ \\
\hline
\end{tabular}

Legenda: $\mathrm{P}=$ Potencialidade $/ \mathrm{L}$ = Limite $/$ - = Não possuía registro nos PMSs ou nos RAGMs 
Entretanto, a partir da análise dos limites e potencialidades presentes nos PMSs e RAGMs vislumbrou-se a possibilidade de iluminar a superação da realidade, por meio do incremento de temas que colaborem para novos caminhos para a gestão municipal em saúde (Figura 5) comprometida com a efetividade do assessment em saúde e, consequentemente, com a melhoria da qualidade de vida das pessoas e o desenvolvimento social.

Figura 5 - Temas para superação da realidade da gestão municipal, a fim de contribuir com o acolhimento e monitoramento das necessidades em saúde do território. São Paulo, 2017.

$\checkmark$ Sínteses analíticas e críticas dos impactos das ações de saúde no atendimento das necessidades e enfrentamento das vulnerabilidades.

$\checkmark$ Feedback através da participação popular avaliando e reprogramando as ações em saúde ou intersetoriais para diminuir as desigualdades na qualidade de vida e na assistência à saúde.

$\checkmark$ Respeito aos preceitos da determinação social do processo saúdedoença, evidenciando as condições de subalternidade de classe, gênero, geração e etnia.

$\checkmark$ Estratégias de gestão intersetorial para replanejar fenômenos complexos cuja resposta é interdisciplinar e intersetorial.

$\checkmark$ Tradução da análise crítica do perfil dos municípios, por meio de indicadores para monitoramento e avaliação das ações assistenciais de saúde ou de projetos e ações intersetoriais.

Considerando-se os limites e as potencialidades identificados, bem como os temas adicionais propostos para a superação da realidade, a discussão desses resultados ocorrerá por meio dos seguintes blocos temáticos:

- Políticas Públicas,

- Necessidades em Saúde e

- Assessment em Saúde. 
6 DISCUSSÃO 


\section{DISCUSSÃO}

\subsection{POLÍTICAS PÚBLICAS}

As políticas públicas podem ser compreendidas como meios colaborativos para a organização da sociedade contemporânea, pois o Estado que, até o século XIX, se ocupava, prioritariamente, com a preservação da segurança do território, passou a assumir a responsabilidade do desenvolvimento social, por meio de ações em diversas áreas, como: saúde, educação, habitação, entre outras (Behring, Boschetti, 2011).

O advento das políticas públicas decorre da organização social e da luta por direitos sociais frente às contradições impostas pelo modo de produção capitalista, as quais são produto das relações do trabalho, que se coloca como eixo norteador da sociedade de acumulação de capital, o que cria cenários de desigualdades (Behring, Boschetti, 2011).

Essas desigualdades sociais contribuem para a dificuldade, seja do indivíduo, grupos sociais ou coletividades, no enfrentamento de privações cotidianas que podem, quando de forma persistente e contínua, determinar padrões específicos de adoecimento e morte (Arreaza, 2012).

Neste sentido as políticas públicas se configuram como mecanismos sistematizados propostos pelos governos democráticos, a partir da identificação de problemas na sociedade, com vistas a contribuir para a maximização do bemestar social e o interesse público, visando proporcionar a superação de situações contraditórias delineadas pelo capitalismo (Behring, Boschetti, 2011; Boschetti, 2016).

Desta forma, destaca-se o PMS como política pública municipal de saúde com vigência quadrienal (Brasil, 2009b; Brasil, 2013b; Brasil, 2016), que entre os municípios analisados foi apontado como um instrumento de fortalecimento e consolidação do SUS como política nacional de saúde no Brasil.

Nesse contexto a Enfermagem como prática social é capaz de contribuir para a transformação da realidade destes municípios, uma vez que a sua práxis se relaciona com a compreensão crítica da sua prática, com vistas a propor 
ações significativas que se traduzam em melhores condições de saúde à população (David, Bonetti, Silva, 2012).

Uma das formas de contribuição da Enfermagem para a superação da realidade é a sua atuação na APS, por meio da ESF, na qual o enfermeiro tem destaque pela sua formação humanística e centrada em ações direcionadas para a promoção da saúde e prevenção de doenças, prioritariamente, para grupos sociais vulneráveis, como preconiza a Política Nacional de Atenção Básica (Brasil, 2012c).

Essa forma de pensar a superação da realidade se deu por meio das políticas públicas de bem-estar social que tiveram a sua origem com a Escola Keynesiana, cujo idealizador foi John Maynard Keynes (1883-1946). Ele defendia as ações intervencionistas do Estado sobre a economia do país, visando evitar situações de recessão e depressão econômica por meio de políticas públicas (Machado, Pamplona, 2008; Mankiw, 2014).

As suas ideias sofreram forte influência da Crise de 1929 ou Grande Depressão, a qual assolou o mundo durante a década de 1930 e apenas finalizou com a Segunda Guerra Mundial (1939-1945), após a implementação de políticas econômicas do presidente estadunidense Franklin Delano Roosevelt (18821945), no período de 1933 a 1937, as quais foram chamadas de New Deal (Machado, Pamplona, 2008; Mankiw, 2014).

A Crise de 1929 foi um período de grande recessão econômica mundial, - que gerou altas taxas de desemprego, baixa produção industrial e, consequentemente, deficit do PIB de vários países, devido à quebra da Bolsa de Valores de Nova lorque (Boschetti, 2016).

O impacto da Crise de 1929 estendeu-se por vários países, além dos Estados Unidos da América (EUA), como: Reino Unido, Canadá, Itália, Alemanha, Austrália, França e Países Baixos. Este evento evidenciou a limitação do liberalismo em responder à crise do capitalismo, o que por sua vez potencializou a ascensão de regimes totalitaristas, ou seja, aqueles que se propunham a controlar as instituições sociais de um país (economia, educação, cultura, direitos civis e a esfera individual do cotidiano). Um exemplo deste tipo de regime foi o nazismo, representado por Adolf Hitler (Sousa, 2015). 
O liberalismo é proveniente da Escola Clássica, idealizada pelo pensador iluminista Adam Smith (1729-1790) (Reinhardt, 2007). A partir da adoção do pensamento desse teórico, as políticas neoliberais ascenderam e foram forjadas em meados da década de 1980 e estão presentes na atualidade (Boschetti, 2016; Reinhardt, 2007).

Neste regime espera-se a submissão ao capital, por meio da mínima intervenção do Estado sobre as relações de mercado, uma vez que se acredita que aspectos relacionados à concorrência entre fornecedores tem o poder de regular o mercado (Marin, Quintana, 2012; Mendes, 2015).

Entretanto, diante do cenário de crise do liberalismo em 1929, as ideias de Keynes ganharam destaque entre os governos ocidentais Pós-Segunda Guerra Mundial, os quais passaram a implantar políticas de Estado de bem-estar social, que preconizavam, por meio de ações estatais, o controle e a garantia de um padrão mínimo de vida à população (Boschetti, 2016; Machado, Pamplona, 2008).

Desta forma, surgem iniciativas de proteção social relacionadas ao salário mínimo, seguro-desemprego, revisão da jornada de trabalho e sistemas de saúde do tipo seguridade social (Mankiw, 2014; Boschetti, 2016).

Um exemplo de proteção social foi a implantação, em 1948, do Sistema Nacional de Saúde Inglês, o qual se configura como um sistema do tipo seguridade social, ou seja, universalista. Ele foi totalmente influenciado pelas políticas de bem-estar social, sendo concebido a partir da realidade de total destruição do Reino Unido no Pós-Segunda Guerra Mundial frente às necessidades em saúde da população britânica (Tanaka, Oliveira, 2007).

Desta forma, enquanto as políticas de bem-estar social têm o objetivo de responder às necessidades da população, compreendida como cidadãos com direitos constituídos, as práticas neoliberais reduzem a responsabilidade do Estado na provisão de bem-estar àqueles que compõem a sociedade, atendendo de forma seletiva e compensatória aqueles mais deficitários, sem a corresponsabilidade de desenvolvê-los socioeconomicamente, bem como permitindo ao mercado a comercialização, aos estratos mais abastados, de bens 
e serviços relacionados à segurança, saúde, habitação, educação, entre outros (Amadigi et al., 2007).

Esta realidade reforça a possibilidade de atuação do enfermeiro e sua equipe, uma vez que, como problematizado por Rezende, Baptista, AmâncioFilho (2015), a provisão de cuidados em saúde deve ser reforçada por mecanismos de proteção social, como forma de desenvolvimento social, o qual pode se utilizar da prática da promoção da saúde como meio de oportunizar equitativamente o máximo potencial de saúde.

Entretanto, a coexistência da política neoliberal e as políticas de proteção social, como, por exemplo, o SUS, denotam contradições, como aquelas evidenciadas entre os PMSs analisados, os quais são compreendidos como ferramenta de planejamento em saúde, mas que dialeticamente parecem ser utilizados como mecanismos funcionalistas, burocráticos e legalistas para cumprir normas da administração pública e, em menor proporção, para a superação e transformação da realidade da população que tem necessidades em saúde socialmente determinadas.

Diante destas contradições, emergem possibilidades de análise utilizando-se, por exemplo, da Teoria do Bem-Estar Social de Amartya Sen.

Esta teoria tem como idealizador Amartya Kumar Sen, economista indiano, que parte do pressuposto da equidade e da ideia de que as privações de liberdade das pessoas limitam as suas possibilidades de escolhas e oportunidades, agravando aspectos relacionados à desigualdade social. 0 referencial teórico utilizado por ele parte do liberalismo como um tipo de filosofia política ancorada na democracia, direitos civis, liberdade, livre comércio e propriedade privada (Marin, Quintana, 2012).

Apesar da proposta desta teoria avançar ao contribuir para uma visão analítica, ela não considera os aspectos biopsicossociais, o que por sua vez denota a sua limitação ao considerar o impacto das ações do Estado na realidade da população, no sentido de verificar se houve redução, aumento ou estagnação das desigualdades sociais. 
Desta forma, como teorizado por Laswell (1958), faz-se necessário, no âmbito da implantação de políticas públicas, questionar "[...] quem ganha o quê, por quê e que diferença faz [...]" para a sociedade.

Esta abordagem aproxima-se do pensamento ideológico do MHD ao captar a realidade, como discutido por Souza (2006), ao defender que as políticas públicas produzem efeitos específicos sobre a vida daqueles que compõem uma sociedade.

Neste sentido, os PMSs ao serem concebidos como uma política pública da esfera municipal, eles ganham caráter de ferramenta de planejamento em saúde, visto que propõem a aproximação com a realidade e estímulo a uma postura governamental proativa, por meio da identificação das necessidades em saúde da população, da proposição de ações sistematizadas e suas respectivas metas, com vistas a contribuir para a superação da realidade e 0 desenvolvimento social (Brasil, 2016; Souza, 2006).

Entretanto, ficou evidente entre os PMSs analisados a urgente necessidade de adoção de um referencial teórico-metodológico para a compreensão do processo saúde-doença, bem como do desenvolvimento de instrumentais gerenciais com acurácia para o monitoramento das ações propostas e mensuração sobre a situação de saúde da população, compreendida a partir de grupos sociais vulneráveis.

Dessa forma, as políticas públicas são mecanismos de planejamento de ações com impacto no desenvolvimento social, e podem ser classificadas em distributivas, regulatórias, constitutivas e redistributivas (Souza, 2006).

As políticas públicas distributivas têm o objetivo de minimizar as desigualdades sociais por meio de ações assistencialistas, as quais priorizam um grupo social específico em detrimento das demais parcelas da sociedade. Entende-se que estas políticas devam ser temporalmente limitadas, com vistas a permitir o desenvolvimento socioeconômico inicial para posterior estabilização do estrato societário beneficiado com a política pública (Souza, 2006).

As políticas públicas regulatórias visam regulamentar um determinado segmento da sociedade, basicamente envolvem a publicação de resoluções e 
portarias que por meio do amparo legal dão as diretrizes para a organização do setor ou segmento econômico de uma sociedade (Souza, 2006).

As políticas públicas constitutivas são aquelas que propõem procedimentos sistematizados para a organização social, visando colaborar com a ambiência favorável de uma sociedade, para tanto, fazendo uso de diretrizes de maior abrangência em comparação, por exemplo, às políticas públicas regulatórias (Souza, 2006).

As políticas públicas redistributivas abarcam as políticas de proteção social, usualmente, são abrangentes e de grande complexidade operacional (Souza, 2006). Entre estas, pode-se exemplificar o PMS, compreendido como política pública, uma vez que possui natureza para garantir a proteção e o desenvolvimento social (Brasil, 2009b; Brasil, 2013b; Brasil, 2016).

Neste campo, destaca-se, portanto, o SUS, como a maior política pública de proteção social conhecida mundialmente, produto de embates e contradições da sociedade brasileira, em que a Enfermagem teve grande contribuição ao longo do século XX, como prática sociopolítica (David, Bonetti, Silva, 2012) e, que em 1990, por meio das Leis Orgânicas da Saúde oํ 8080/90 e oํ 8142/90, e do arcabouço constitucional de 1988 , foi concebido por meio de seus princípios doutrinários e organizativos (Paim et al., 2011; Souza, 2007).

Entre os princípios doutrinários, que se referem à universalidade, integralidade e equidade, destaca-se a equidade, a qual se relaciona à ideia de compreensão das necessidades em saúde da população inserida em territórios sanitários. Estes são entendidos como espaços geográficos vivos, repletos de dinamicidade e historicidade (Santos, 2006), nos quais as pessoas, concebidas a partir de suas singularidades e inserção em grupos sociais produzem e reproduzem condições societárias que podem reforçar os desgastes ou as potencialidades sobre as suas formas de adoecimento e morte (Paim et al., 2011; Souza, 2007).

Neste sentido, a ideia de saúde como direito e o SUS como instrumento para a garantia desse direito foi identificada em alguns dos PMSs analisados, o que por sua vez se configura como um avanço, na medida em que a compreensão dos PMSs quanto à importância do SUS como produto social se 
mostrou alinhada à consolidação do sistema de saúde brasileiro como política pública constitucionalmente assegurada.

No entanto, para a utilização do PMS como política pública municipal em saúde, faz-se necessária uma mudança de realidade que exige uma prática gerencial profissionalizada e altamente qualificada, inicialmente, para compreender o PMS como política pública que objetiva o desenvolvimento social e não unicamente como um instrumento burocrático de gestão municipal para garantia dos repasses financeiros ao município.

É, portanto, fundamental agregar a compreensão do processo saúdedoença de forma socialmente determinada, diante da limitação de outros referenciais teórico-metodológicos para captar o cerne dos problemas de saúde da população, os quais têm em sua natureza grande complexidade e densidade.

\subsection{NECESSIDADES EM SAÚDE}

A identificação e a interpretação das necessidades em saúde são fundamentais para a prática gerencial pautada na equidade.

Neste estudo, a teoria interpretativa da multicausalidade do processo saúde-doença foi adotada em todos os documentos analisados, em detrimento do que estabelecem os documentos normativos para o planejamento no SUS (Brasil, 2009b; Brasil, 2016).

Esses documentos subsidiam a formação técnico-política dos gestores de planejamento em saúde e preconiza meios para captação e interpretação das necessidades em saúde visando ampliar a qualidade de vida da população e desenvolvimento social, por meio da compreensão do processo saúde-doença socialmente determinado (Brasil, 2009b; Brasil, 2016).

Desta forma, ao adotar a teoria interpretativa da multicausalidade, evidenciada nos PMSs e RAGMs, por meio da análise de aspectos sanitários e do perfil de morbimortalidade, deflagra-se $o$ afastamento do gestor municipal de saúde da complexidade das necessidades da população, denotando uma contradição clássica entre aspectos teóricos e práticos. Apesar de haver orientação quanto ao referencial metodológico, no que tange à teoria 
interpretativa do processo saúde-doença, há a persistência da reprodução nas práticas gerenciais de uma teoria com grandes limitações para compreender e explicar o processo saúde-doença, a qual desconsidera os modos de adoecimento e morte socialmente determinados.

Um exemplo nos PMSs foi a descrição das condições de moradia e saneamento, um avanço quando se pensa na evolução das práticas de gestão em saúde, entretanto, são descritas de forma desarticulada das formas de produção e reprodução social, bem como da identificação de grupos sociais vulneráveis às realidades de condições de moradia.

Para superação desta prática gerencial faz-se necessária a análise da realidade a partir do MHD e, consequentemente, da Teoria da Determinação Social do Processo Saúde Doença e Epidemiologia Crítica, cujos referenciais percebem e compreendem a realidade aproximando-se dos aspectos de fortalecimento e desgaste socialmente determinados, que impactam as formas de adoecimento e morte de indivíduos, grupos sociais e coletividades.

Dessa forma, os instrumentos de gestão em saúde municipal, como os PMSs e os RAGMs, devem ser potencializados a partir de concepções dialéticas do processo saúde-doença, bem como os profissionais envolvidos na gestão e no cuidado à população devem estar alinhados a estes referenciais metodológicos, visto que entre os documentos analisados foi evidenciado que a análise situacional utilizando-se da participação social se configurou como método para a compreensão das necessidades em saúde da população.

A presença da participação social entre os PMSs estudados ocorreu por meio de oficinas, das Conferências Municipais de Saúde e dos CMS, cuja experiência é corroborada por alguns estudos que destacaram o mecanismo de controle social como fundamental para as práticas gerenciais em saúde (Lisboa et al., 2016; Silva et al., 2016).

Um deles, realizado com 12 secretários de saúde de municípios próximos a São Paulo, investigou, por meio de entrevista semiestruturada, como o gestor utiliza a ferramenta de ouvidoria para subsidiar a tomada de decisão. Os resultados deste estudo demonstraram a participação social como exercício 
de cidadania e mecanismo fundamental para a melhoria dos serviços de saúde (Silva et al., 2016).

O estudo de Silva et al. (2016) aponta o serviço de ouvidoria como um mecanismo importante para a captação das demandas em saúde. Porém, é fundamental ponderar em que medida a implantação deste serviço, com a escuta ativa e sistemática das necessidades da população, se traduz em transformação da realidade ou se caracteriza, meramente, em prática funcionalista e burocrática que existe para acatar alguma normativa, sem o compromisso com a melhoria da situação de saúde da população.

Já outro estudo realizado, por meio de entrevista semiestruturada, com 13 conselheiros de saúde do município de Anchieta-ES analisou o processo de criação e implantação de conselhos locais de saúde, bem como a influência destes conselhos na política de saúde municipal. Os resultados deste estudo demonstraram que os conselheiros de saúde enfrentam desafios relacionados à falta de formação para atuação e de vontade política para levar adiante as necessidades da comunidade (Lisboa et al., 2016).

Diante dos resultados apresentados por Lisboa et al. (2016), principalmente no que se refere à formação dos conselheiros de saúde, questiona-se se esta realidade também não é latente em outros municípios brasileiros, fazendo-se necessária a melhoria na educação de base no que se refere à alfabetização, raciocínio lógico, entre outros, bem como à capacitação específica destes profissionais para a atuação nos CMSs, como, por exemplo, utilizando-se de estratégias lúdicas de ensino-aprendizagem, como as apresentadas por Silva, Tanaka, Pires (2015), que desenvolveram jogos específicos sobre o funcionamento do SUS, intitulados: BANFISA e (IN)DICASUS.

Entre os PMSs e RAGMs analisados, apenas se evidenciou a citação dos meios para captação das necessidades em saúde. Entretanto, nenhum deles descreveu eventuais limitações ou necessidades de melhorias, o que pode ser em decorrência da ausência dessa necessidade ou devido à desvalorização dessas estratégias de compreensão das necessidades em saúde, o que pode se configurar como uma grande limitação, haja vista a possibilidade de 
intervenção da secretaria de saúde municipal para melhorar a atuação gerencial nos CMSs, por exemplo.

Neste sentido, estes achados conjuntamente ao estudo de Lisboa et. al (2016) reitera o amadurecimento da implantação do SUS quanto à participação social na sua gestão, porém, destaca-se a pertinência de espaços políticos com o objetivo de contribuir de forma significativa e co-responsável para a proposição de políticas alinhadas às necessidades em saúde da população (Lisboa et al., 2016).

Essa realidade dialetizada nos PMSs - em que não se evidenciou a forma de captação das necessidades em saúde, como, por exemplo, por meio das conferências municipais de saúde, que não apresentaram de forma consistente como a participação social aconteceu e nem em que medida se fizeram necessárias ações para potencializar e melhorar a participação da comunidade no SUS - é corroborada por estudos que reforçam a pertinência de uma análise crítica sobre a qualidade da participação social na gestão do SUS, visto que apontam, para além da ausência de formação dos conselheiros locais de saúde para a sua atuação gerencial efetiva, aspectos relacionados à desmotivação, morosidade processual na operacionalização dos conselhos locais, entre outros que limitam as práticas de controle social (Lisboa et al., 2016; Silva et al., 2016).

Desta forma, apesar dos avanços na implantação da participação da sociedade na gestão do SUS, ainda se vislumbra a necessidade de maior envolvimento da comunidade, por meio de ações de empoderamento, desenvolvimento pessoal e profissional, bem como de criação de espaços políticos para a discussão das necessidades em saúde do território, o que por sua vez tem a potencialidade de proposição e implantação de políticas públicas municipais que atendam à dimensão particular da realidade, considerando-se, inclusive, as necessidades de grupos sociais de maior vulnerabilidade.

Esta possibilidade de envolvimento comunitário colabora com 0 atendimento de forma efetiva às necessidades em saúde da população, uma vez que o setor saúde agrega em sua natureza grande complexidade operacional, o que exige mecanismos que considerem esta densidade, bem como os 
problemas a serem geridos por meio de políticas públicas (Behring, Boschetti, 2011; Lotta, Favareto, 2016).

Nessa perspectiva, as práticas gerenciais ganham em acurácia, pois se aproximam da concretude da realidade e, consequentemente, da densidade dos problemas de saúde, os quais, em sua maioria, demandam ações intersetoriais, cabendo à esfera municipal de gestão de saúde o dever de maximizar o bemestar, por meio de ações que colaborem com a qualidade de vida da população (Arreaza, 2012).

Frente ao exposto, a atuação da Enfermagem inserida na equipe interdisciplinar e orientada como prática social destaca-se, pois tem plena condição de contribuir para a identificação das necessidades em saúde, considerando-se os determinantes de fortalecimento e desgaste de grupos sociais vulneráveis, a fim de propor ações setoriais e intersetoriais, com vistas a colaborar na superação da realidade (Arreaza, 2012; David, Bonetti, Silva, 2012).

Portanto, a compreensão superficial e desarticulada das necessidades em saúde ilustra a alienação social ao supor que, compreendidas de forma descontextualizada socialmente, possam ter potencialidade para ilustrar aspectos particulares da realidade (Arreaza, 2012). Por exemplo, a compreensão das necessidades em saúde da população nos PMSs analisados, que se utilizam, única e isoladamente, de indicadores de morbimortalidade centrados na doença, e não nas formas de produção e reprodução social.

Assim, a captação dos padrões de saúde-doença na perspectiva da determinação social, ou seja, conforme preconizado pela Saúde Coletiva como área do conhecimento, contribui de forma significativa para a percepção de bemestar e qualidade de vida, dialogando de forma direta com a compreensão do indivíduo como um ser livre, solidário, autorrealizado e socialmente participante (Arreaza, 2012). Deste modo, é grande a potencialidade para contribuir qualitativamente para o assessment em saúde, o qual se materializa por meio dos PMSs e RAGMs, como instrumentos de gestão municipal em saúde (Brasil, 2009b; Brasil, 2013b; Brasil, 2016).

Portanto, diante da organização do sistema de saúde centrado no manejo e nas complicações provenientes das doenças, e não na qualidade de 
vida das pessoas, os serviços passam a reproduzir suas ações de forma funcionalista, por meio do aumento da oferta de serviços de saúde de forma descolada da realidade, ou seja, sem conseguir se aproximar da densidade e complexidade das necessidades em saúde. Estas se dão pelas formas de produção e reprodução social, e o aumento na oferta de serviços de saúde, entre os PMSs analisados, não aparenta estar relacionado com a compreensão do processo socialmente determinado, o que pode gerar alocação indevida de recursos em saúde, bem como reduzida efetividade assistencial à população.

Esse aspecto é evidenciado entre os RAGMs analisados ao considerarem um avanço o aumento quantitativo dos equipamentos de saúde, entretanto, reitera-se o questionamento quanto à articulação destes serviços às necessidades em saúde socialmente determinadas.

Diante do apresentado, denota-se a necessidade de estudos futuros para proposição e investimento em modelos efetivos de identificação das necessidades em saúde da população alicerçados sobre a Teoria da Determinação Social do Processo Saúde-Doença, considerando a identificação dos grupos sociais vulneráveis e suas formas de produção e reprodução social que se desdobram em perfis específicos de adoecimento e morte, os quais, atualmente, por meio dos PMSs e RAGMs não são contemplados, impactando diretamente a percepção da efetividade dos serviços de saúde ofertados à população.

\subsection{ASSESSMENT EM SAÚDE}

O termo "assessment" se refere ao desenvolvimento, à implantação, ao monitoramento e à avaliação de ações, como, por exemplo, de políticas públicas de saúde (Kemm, Parry, Palmer, 2004).

Neste sentido, destacam-se os PMSs e os RAGMs como instrumentos gerenciais com potencialidade para a prática do assessment em saúde, visto que o planejamento em saúde como uma atividade de gestão pública é fundamental para a consolidação do SUS, pois contribui para o atendimento às necessidades em saúde da população (Pereira, Tomasi, 2016). Esta ideia foi corroborada pelos achados deste estudo, já que, entre os objetivos dos PMSs analisados, 
destacou-se a sua compreensão como instrumento para afirmação do SUS como política pública em saúde.

Entretanto, faz-se imperativo acoplar à atividade de planejamento em saúde uma prática profissional alinhada à determinação social do processo saúde-doença, a qual possui maior potencialidade para responder às necessidades em saúde, visto que considera a historicidade e a dinamicidade em que indivíduo, grupos sociais e coletividades coexistem (Breilh, 2013).

Nos últimos anos, têm sido investidos esforços no sentido de padronizar os instrumentos de planejamento do SUS, a fim potencializar a atenção à saúde de forma articulada às necessidades percebidas e identificadas. Esses esforços se evidenciam por marcos legais: o Decreto no 7508/2011 (Brasil, 2011), a Lei Complementar no 141/2012 (Brasil, 2012a) e a Resolução da Comissão Intergestora Tripartite (CIT) nำ 5/2013 (Brasil, 2013a).

Essas legislações se propõem a normatizar e padronizar as práticas de planejamento do SUS em âmbito federal, estadual e municipal (Brasil, 2009b; Brasil, 2013b; Brasil, 2016), uma vez que até 2013 estas atividades ocorriam de forma pouco sistematizada, o que dificultava o monitoramento longitudinal das ações propostas e implantadas, bem como a avaliação do impacto destas ações na situação de saúde das pessoas (Brasil, 2009b; Brasil, 2013b; Brasil, 2016).

Entretanto, os indicadores propostos pela Resolução da CIT nำ 5/2013 são de natureza funcionalista, pautados na mensuração da quantidade de serviços prestados e na produção de cuidado realizada (Brasil, 2013a), o que, por sua vez, como evidenciado neste estudo por meio da análise dos PMSs e RAGMs, limita a análise quando interpretados isoladamente, não se traduzindo necessariamente em melhoria da situação da saúde da população, mas como, meramente, a quantificação de serviços de natureza funcionalista.

Essas limitações são decorrentes da forma de captação das necessidades em saúde, uma vez que diretrizes, objetivos e indicadores propostos são idênticos entre todos os municípios (Brasil, 2016), o que pôde ser visualizado por meio dos PMSs e RAGMs submetidos a essa padronização. Este fato pode ser compreendido como uma fragilidade na articulação das necessidades identificadas nos PMSs e as ações monitoradas por meio dos 
RAGMs, uma vez que as realidades entre os municípios são diferentes e, portanto, a proposição de uma matriz gerencial alinhada às diferentes realidades seria plausível.

Neste sentido, a compreensão da realidade é fundamental para a identificação das necessidades em saúde e planejamento de ações. Para essa compreensão, atualmente, os gestores municipais de saúde têm à disposição o Manual de Planejamento no SUS, que descreve o arcabouço teóricometodológico utilizado, o amparo legal para a sua elaboração, bem como os itens necessários do PMS e dos RAGMs (Brasil, 2016). O Manual de Planejamento no SUS aproxima-se do referencial teórico-metodológico da Teoria da Determinação Social do Processo Saúde-Doença, inclusive, recomendando a adoção deste arcabouço teórico.

Porém, em detrimento disso, foi evidenciado entre os PMSs e os RAGMs o distanciamento da compreensão do processo saúde-doença socialmente determinado e a aproximação da concepção multicausal, o que remete à necessidade de desenvolvimento de competências junto aos gestores municipais de saúde para se aproximarem desta perspectiva de compreensão aprofundada dos problemas de saúde da população.

Além disso, entre os municípios analisados, foi observada a parcialidade na divulgação dos PMSs e RAGMs no SARG-SUS, o que se configura como uma contradição, na medida em que, apesar da obrigatoriedade e relativa facilidade de elaboração e divulgação desses instrumentos, eles não foram localizados, o que por sua vez limita o assessment em saúde, haja vista a dificuldade de monitoramento longitudinal das ações e da situação de saúde da população.

A padronização utilizada, seja no PMS ou nos RAGMs, não esgota as possibilidades de compreensão da realidade e proposição de ações, haja vista que entre as métricas de monitoramento das ações em saúde destacaram-se os indicadores de desenvolvimento social e o perfil de morbimortalidade.

Essas métricas de acompanhamento das ações em saúde não devem ser traduzidas de forma linear como componente salutogênico, uma vez que a ideia de ausência de doença como melhora ou manutenção da saúde é falível e 
limitada, diante da disponibilidade de teorias com maior arcabouço para explicar o fenômeno, como, por exemplo, a Teoria da Determinação Social do Processo Saúde-Doença.

Além disso, o assessment em saúde de forma efetiva exige um exercício de compreensão complexa e densa da saúde, no sentido de que se faz pertinente os municípios articularem ações intersetoriais, já que isoladamente os setores sociais têm reduzida capacidade para responder às necessidades em saúde da população.

Por exemplo, no estudo dos RAGMs visualizou-se maior contingente e longevidade de mulheres em relação aos homens, o que denota ser imprescindível a implantação de ações intersetoriais que oportunizem a escolarização de mulheres, uma vez que ela oferece à mulher acesso à educação e ao trabalho e, consequentemente, aos seus filhos, rompendo com processos desgastantes de produção e reprodução social, o que, em última análise, potencializa o desenvolvimento social.

Para tanto, a articulação de ações intersetoriais é fundamental, já que a oferta de vagas de bancos escolares, por meio da construção de escolas e programas de captação e permanência dessas mulheres é responsabilidade da área da educação, enquanto a área da saúde pode contribuir por meio da identificação dessas mulheres com o auxílio dos agentes comunitários de saúde da ESF, bem como pelo estímulo à escolarização em reuniões, oficinas e grupos realizados nas Unidades Básicas de Saúde, cenário em que a Enfermagem compreendida como prática social ganha relevância, pois pode colaborar com o rompimento de paradigmas e superação da realidade.

A Enfermagem dispõe da Classificação Internacional das Práticas de Enfermagem em Saúde Coletiva (CIPESC) como instrumento de assessment desenvolvido sob a égide da Determinação Social do Processo Saúde-Doença, cuja natureza assistencial e gerencial permite ao enfermeiro realizar o diagnóstico de Enfermagem, com vistas à proposição de intervenções e acompanhamento sistematizado dos cuidados direcionados ao indivíduo, rede de apoio e comunidade (Egry, Cubas, 2006; Cubas, Nóbrega, 2015). 
Entretanto, o monitoramento das ações de saúde é imprescindível, o que exige instrumentos de gestão com acurácia suficiente para aproximar-se dos resultados em saúde da população e de grupos sociais vulneráveis, situação em que a Enfermagem tem condições de contribuir de forma significativa, pois possui expertise para atuar na perspectiva dos determinantes sociais de saúde e no enfrentamento de vulnerabilidades (Cubas, Nóbrega, 2015).

Portanto, reitera-se a necessidade do desenvolvimento de instrumentos fortalecidos na perspectiva da interpretação dialética do processo saúde-doença, haja vista a ausência deles entre os PMSs e RAGMs analisados neste estudo. 
7 CONCLUSÕES 


\section{CONCLUSÕES}

Este estudo, ao analisar os PMSs e os RAGMs como instrumentos de gestão pública para o assessment de políticas públicas municipais em saúde, evidenciou como potencialidades a compreensão do SUS como política pública de proteção social; o PMS como ferramenta de planejamento em saúde; as metodologias para compreensão e identificação das necessidades em saúde, por meio do diagnóstico situacional e da presença da comunidade na gestão do SUS, bem como mecanismos de monitoramento das ações em saúde propostas no PMS.

Esse avanço quanto ao assessment em saúde é produto da evolução ao longo dos anos da gestão pública em saúde no SUS, evidenciada, recentemente, pela publicação do Manual de Planejamento no SUS, que traz o referencial teórico-metodológico baseado na Teoria da Determinação Social do Processo Saúde-Doença para a captação e compreensão das necessidades em saúde, bem como a sistematização para elaboração, monitoramento e divulgação dos PMS e RAGMs.

Em detrimento desses avanços, este estudo demonstrou que a concepção do processo saúde-doença presente nos PMSs e RAGMs analisados alicerçou-se sobre a multicausalidade, portanto, visualizou-se contradição entre o preconizado pelo Manual de Planejamento no SUS - que se utiliza da concepção da determinação social do processo saúde-doença - e o praticado nas secretarias municipais de saúde, que utilizaram da interpretação multicausal, resultando em intervenções que respondem à lógica da Saúde Pública, em oposição à lógica da Saúde Coletiva, tal como inspiraria a determinação social do processo saúde-doença, o que por sua vez traz grandes limitações para acolher as necessidades em saúde da população e, consequentemente, identificar os grupos socialmente vulneráveis, impactando negativamente as práticas de gestão ancoradas na equidade.

A limitação a que se refere é que apesar de haver a identificação incipiente de grupos vulneráveis, eles apresentaram como recorte de análise desses grupos aspectos relacionados à faixa etária e ao perfil de morbimortalidade, formando conjuntos populacionais homogêneos de acordo 
com as características biológicas ou nosológicas. Ao contrário, ao se adotar a concepção da determinação social do processo saúde-doença, forçosamente o território municipal deveria ser dividido entre os que tem os mais qualificados processos de reprodução social e os menos qualificados, mostrando as diversidades das necessidades em saúde entre esses grupos sociais e mais ainda, as vulnerabilidades, o que ensejaria distribuição não igualitária, mas equânime dos recursos, ações e atenções em saúde envolvendo, inclusive, outros setores da sociedade a que se relacionam a qualificação da vida cotidiana.

Frente ao exposto, a expectativa é de que os gestores municipais, compreendidos como os tomadores de decisão, se interessem por este tipo de estudo e sejam capacitados para atuar na perspectiva da teoria interpretativa socialmente determinada do processo saúde-doença, bem como utilizem de forma crítico-reflexiva os instrumentos de gestão, como o PMS e os RAGMs.

Diante da necessidade de capacitação desses gestores, as Universidades públicas têm potencialidade para contribuir, seja na instrumentalização teórico-prática dos profissionais e de outros envolvidos com a gestão pública municipal, seja com atividades de consultoria aos municípios, o que se configura como atividades de extensão universitária e que colaboram para o desenvolvimento social.

Entretanto, recomenda-se que estudos futuros entrevistem os gestores municipais, uma vez que o estudo documental traz em si uma tradução parcial da realidade. Esses estudos poderiam se apropriar de métodos qualitativos de análise de conteúdo de entrevistas com os gestores, a fim de aprofundar a captação da realidade e, consequentemente, possibilitar a superação de contradições, eventualmente, não identificadas por meio dos PMSs e RAGMs.

Da mesma maneira, um estudo etnográfico da atuação dos conselheiros nos CMSs faz-se relevante para acompanhar a elaboração dos PMSs e dos RAGMs e, assim, evidenciar as contradições presentes também nessas instâncias de assessment das políticas públicas municipais em saúde.

Outra limitação identificada nos PMSs e RAGMs se referiu às formas de monitoramento das ações em saúde, as quais se deram por meio de indicadores 
de desenvolvimento social e do perfil de morbimortalidade, os quais perdem em acurácia por não se aproximar das realidades singulares de vulnerabilidade de grupos sociais específicos, e tem os seus resultados em saúde diluídos na massa populacional dos municípios.

Isto ocorre porque as ações salutogênicas de viver não estão simplesmente relacionadas com a ausência do adoecimento e morte, mas sim com o desenvolvimento social, que implica ações intersetoriais que empoderem as pessoas para a transformação da realidade.

Recomenda-se a continuidade deste estudo em municípios com menor IDH, por meio de metodologias que oportunizem profundidade de compreensão, uma vez que as ações em saúde desenvolvidas de forma intersetorial potencializam o desenvolvimento social, o qual pode ser captado por medidas quantitativas, como o IDH, o coeficiente de Gini, entre outros.

Apesar do subfinanciamento da saúde no Brasil, é possível pensar para além do aumento quantitativo do investimento, fazendo-se urgente melhorar a qualidade da alocação dos recursos em saúde, o que exige dos gestores compreensão aprofundada e crítica da realidade do município, bem como a proposição de ações intersetoriais, minimizando a fragmentação das políticas públicas municipais e otimizando o uso dos recursos financeiros.

Além disso, a análise dos orçamentos municipais para a saúde, os quais estão descritos nos RAGMs, é relevante, visto que este estudo não tomou este objeto para análise. No entanto, faz-se importante problematizar que não basta os municípios proporem ações em saúde desprovidas de recursos, tampouco utilizarem-se destes recursos sem conseguir realizar o monitoramento efetivo dessas ações sobre a situação de saúde das pessoas. Essa temática ganha especial destaque frente ao momento político-econômico atípico do país, em que se vivencia uma recessão econômica que impõe a redução da captação de recursos financeiros para vários segmentos sociais, entre eles, o da saúde.

Portanto, os instrumentos de gestão em saúde, representados pelos PMSs e RAGMs, mostraram-se de extrema validade. Entretanto, eles somente conseguirão reduzir as desigualdades sociais e melhorar a qualidade de vida da população quando forem orientadas pela concepção da produção e reprodução 
socialmente determinadas para compreender saúde, o que evidenciará as condições de subalternidade de classe, gênero, geração e etnia, e permitirá a construção de sínteses analíticas e críticas dos impactos das ações de saúde no atendimento às necessidades e no enfrentamento de vulnerabilidades. Consequentemente, esses instrumentos fortalecerão práticas direcionadas à equidade, sobre as quais a Enfermagem em Saúde Coletiva pode atuar de forma significativa no desenvolvimento, implantação, avaliação e monitoramento de políticas públicas de saúde que contribuam para a superação de realidades limitantes que pouco agregam para a melhoria da condição de saúde de grupos sociais vulneráveis. 
8 REFERÊNCIAS 


\section{REFERÊNCIAS}

ADHB. Atlas do Desenvolvimento Humano no Brasil. Rio de Janeiro: Fundação João Pinheiro; 2013. Disponível em:<http://www.atlasbrasil.org.br/2013>. Acesso em: 10 jan. 2017.

Aguiar-Neto Z. SUS - Sistema Único de Saúde: antecedentes, percurso, perspectivas e desafios. São Paulo: Martinari; 2011.

Albuquerque MSV, Costa AM, Lima LP, Melo-Filho DA. Equidade e inclusão de grupos sociais na política de saúde: o caso do Recife, Brasil. Rev Bras Saude Mater Infant, 2011. 11(1):73-82. DOI: 10.1590/S1519-8292011000100008.

Alves CN, Corrêa ACL, Soares MC, Meincke SMK. O cuidado de enfermagem e sua evolução histórica: uma revisão integrativa. Cultura de los Cuidados, 2015. 19(43):83-94. DOI: 10.14198/cuid.2015.43.08.

Amadigi FR, Albuquerque GL, Gonçalves ER, Erdmann AL. A relação públicoprivado na saúde brasileira: refletindo eticamente sobre os impasses e tendências para o SUS. Cienc Cuid Saude, 2007. 6(4):508-13. DOI: 10.4025/cienccuidsaude. v6i4.3896.

Andrade ARB, Vaitsman J. A participação da sociedade civil nos conselhos de saúde e de políticas sociais no município de Piraí RJ (2006). Cien Saude Colet, 2013. 18(7):2059-68. DOI: 10.1590/S1413-81232013000700021.

Arreaza ALV. Epidemiologia crítica: por uma práxis teórica do saber agir. Cien Saude Colet, 2012. 17(4):1001-13. Disponível em: <http://www.scielo.br /pdf/ csc/v17n4/v17n4a22.pdf>. Acesso em: 10 jan. 2017.

Bardin L. Análise de conteúdo. Lisboa: Edições 70; 1977.

Behring ER, Boschetti I. Política social: fundamentos e história. São Paulo: Cortez; 2011.

Blackman T, Harrington B, Elliott E, Greene A, Hunter DJ, Marks L, McKee L, Williams $G$. Framing health inequalities for local intervention: comparative case studies. Sociol Health IIIn, 2012. 34(1):49-63. DOI: 10.1111/j.1467-9566.2011. 01362.x.

Boschetti I. Tensões e possibilidades da política de assistência social em contexto de crise do capital. Argum, 2016. 8(2):16-29. DOI: 10.18315/argumentum. v8i2.12800.

Brasil. Casa Civil. Decreto n. 7.508 de 2011. Disponível em: <http://www. planalto.gov.br/ccivil_03/_ato2011-2014/2011/decreto/D7508.htm>. Acesso em: 10 jan. 2017. 
Casa Civil. Emenda Constitucional n. 29 de 2000. Disponível em: <http:// www.planalto.gov.br/ccivil_03/constituicao/emendas/emc/emc29.htm>. Acesso em: 10 jan. 2017.

Casa Civil. Lei Complementar n. 141 de 2012a. Disponível em: <http://www.planalto.gov.br/ccivil_03/leis/LCP/Lcp141.htm>. Acesso em: 10 jan. 2017.

Conselho Federal de Enfermagem. Lei n. 7498 de 1986. Disponível em: <http://www.cofen.gov.br/lei-n-749886-de-25-de-junho-de-1986_4161.html>. Acesso em: 10 jan. 2017.

Conselho Nacional de Saúde. Resolução no 466 de 2012b. Disponível em: <http://conselho.saude.gov.br/resolucoes/2012/Reso466.pdf>. Acesso em: 10 jan. 2017.

Conselho Nacional de Secretarias Municipais de Saúde. Reflexões aos novos gestores municipais de saúde. Brasília: Conasems; 2009a. Disponível em: $<$ http://bvsms.saude.gov.br/bvs/publicacoes/reflexoes_novos_gestores_municip ais. pdf>. Acesso em: 10 jan. 2017.

Ministério da Saúde. Comissão Intergestores Tripartite. Resolução n. 5 de 2013a. Disponível em: <http://bvsms.saude.gov.br/bvs/saudelegis/cit/2013 /res0005_19_06_2013.html>. Acesso: 10 jan. 2017.

- Ministério da Saúde. Manual de planejamento no SUS. Brasília: Ministério da $\quad 2016 . \quad$ Saúde, Disponível em: $<$ http://bvsms.saude.gov.br/bvs/publicacoes/ articulacao_interfederativa _v4_manual_planejamento_atual.pdf>. Acesso em: 10 jan. 2017.

Ministério da Saúde. Pacto da Saúde. Portaria n. 399, de 22 de fevereiro de 2006. Disponível em: <http://bvsms.saude.gov.br/bvs/saudelegis/gm/2006/ prt0399_22_02_2006.html>. Acesso em: 10 jan. 2017.

Ministério da Saúde. Diretrizes para o processo de planejamento no âmbito do Sistema Único de Saúde. Portaria n. 2.135, de 25 de setembro de 2013b. Disponível em: <http://bvsms.saude.gov.br/bvs/saudelegis/gm/2013/ prt2135_25_09_2013.html>. Acesso em: 10 jan. 2017.

- Ministério da Saúde. Secretaria de Atenção à Saúde. Política Nacional de Atenção Básica. Brasília: Ministério da Saúde; 2012. Disponível em: <http:// 189.28.128.100/dab/docs/publicacoes/geral/pnab.pdf>. Acesso em: 10 jan. 2017.

Ministério da Saúde. Secretaria-Executiva. Departamento de Apoio à Descentralização. Pacto de gestão: garantindo saúde para todos. Brasília: Ministério da Saúde; 2005. Disponível em: <http://bvsms.saude.gov.br/bvs/publicacoes/pacto_gestao.pdf>. Acesso em: 10 jan. 2017. 
Ministério da Saúde. Sistema de Planejamento do SUS (PlanejaSUS): uma construção coletiva - trajetória e orientações de operacionalização. Brasília: Ministério da Saúde; 2009b. Disponível em: <http://bvsms.saude.gov.br/bvs/publicacoes/planejaSUS_livro_1a6.pdf>. Acesso em: 10 jan. 2017.

Breilh J. Epidemiologia crítica: ciência emancipadora e interculturalidade. Rio de Janeiro: Editora Fiocruz; 2006.

Epidemiología crítica latinoamericana: raíces, desarrolos recientes y ruptura metodológica. In: Morales C, Eslava JC. (Editores). Tras las huellas de la determinación - Memorias del Seminario InterUniversitario de Determinación Social de la Salud. Bogotá: Universidad Nacional de Colombia; 2014.

Epidemiología del siglo XXI y ciberespacio: repensar la teoría del poder y la determinación social de la salud. Rev Bras Epidemiol, 2015. 18(4):972-82. DOI: 10.1590/1980-5497201500040025.

La determinación social de la salud como herramienta de transformación hacia una nueva salud pública (salud colectiva). Rev Fac Nac Salud Pública, 2013. 31(1):13-27. Disponível em:<http://www.scielo.org.com/pdf.rfnsp/v31s1/ v31s1a02.pdf >. Acesso em: 10 jan. 2017.

Bueno RE, Moysés ST, Bueno PAR, Moysés SJ. Governança, sustentabilidade e equidade no plano de saúde de São José dos Pinhais, Brasil. Rev Panam Salud Publica, 2013. 34(6):416-21. Disponível em: <http://www.scielosp.org/ scielo.php? script=sci_arttext\&pid=S1020-49892013001200007\&lng=en\&nrm= iso>. Acesso em: 10 jan. 2017.

Carvalho V. Sobre a identidade profissional na Enfermagem: reconsiderações pontuais em visão filosófica. Rev Bras Enferm, 2013. 66(Esp):24-32. DOI: 10.1590/S0034-71672013000700003.

Conrad P, Leiter V. The sociology of health \& illness. New York: Worth; 2013.

Cubas MR, Nóbrega MML. Atenção primária em saúde: diagnóstico, resultado e intervenções de enfermagem. Rio de Janeiro: Elsevier; 2015.

David HMSL, Bonetti OP, Silva MRF. A Enfermagem brasileira e a democratização da saúde: notas sobre a Política Nacional de Educação Popular em Saúde. Rev Bras Enferm, 2012. 65(1):179-85. DOI: 10.1590/S003471672012000100026.

Egry EY, Cubas MR. (Organizadoras). O Trabalho da Enfermagem em Saúde Coletiva no Cenário CIPESC. Curitiba: ABEn-PR; 2006.

Egry EY, Fonseca RMGS, Campos MA. Ciência, Saúde Coletiva e Enfermagem: destacando as categorias de gênero e geração na espisteme da práxis. Rev Bras Enferm, 2013. 66(Esp):119-33. DOI: 10.1590/S0034-71672013000700016. 
Egry EY. Saúde coletiva: construindo um novo método em enfermagem. São Paulo: Ícone; 1996.

Ferraz OLM, Vieira FS. Direito à saúde, recursos escassos e equidade: os riscos da interpretação judicial dominante. Dados [on line]. 2009; 1:223-51. Disponível em: <http://www.scielo.br/pdf/dados/v52n1/v52n1a07.pdf >. Acesso em: 10 jan. 2017.

Fonseca RMG, Egry EY, Bertolozzi MR O Materialismo Histórico e Dialético como Teoria da Cognição e Método para a Compreensão do Processo Saúde Doença. In: Egry EY, Cubas MR. (Organizadoras). O Trabalho da Enfermagem em Saúde Coletiva no Cenário CIPESC. Curitiba: ABEn-PR; 2006.

Fonseca RMGS, Egry EY. Epidemiologia social. In: Garcia TR, Egry EY. Integralidade da atenção no SUS e sistematização da assistência de Enfermagem. Porto Alegre: Artmed; 2010.

Gram L, Soremekun S, Ten Asbroek A, Manu A, O'Leary M, Hill Z, Danso S, Amenga-Etego S, Owusu-Agyei S, Kirkwood BR. Socio-economic determinants and inequities in coverage and timeliness of early childhood immunization in rural Ghana. TMIH, 2014. 19(7):802-11. DOI: 10.1111/tmi.12324.

IBGE. Instituto Brasileiro de Geografia e Estatística; [s.d.] Disponível em: <http://www.censo2010.ibge.gov.br/sinopse/index.php?dados=12>. Acesso em: 10 jan. 2017.

IPEA. Instituto de Pesquisa Econômica Aplicada. Objetivos de Desenvolvimento do Milênio: Relatório Nacional de Acompanhamento. Brasília: IPEA; 2014. Disponível em: < http://www.ipea.gov.br/portal/images/stories/PDFs/140523_ relatorioodm.pdf>. Acesso em: 10 jan. 2017.

Jannuzzi PM. Indicadores Sociais no Brasil: conceitos, fontes de dados e aplicações. Campinas: Alinea; 2009.

Kemm J, Parry J, Palmer S. Health impact assessment: concepts, theory, techniques and applications. Oxford: Oxford University Press; 2004.

La Forgia GM, Couttolenc BF. Hospital performance in Brazil: the search for excellence. Washington: The World Bank; 2008.

Larsen M, Rantala R, Koudenburg AO, Gulis G. Intersectoral action for health: the experience of a Danish municipality. Scand J Public Health, 2014. 42:649-57. DOI: $10.1177 / 1403494814544397$.

Laswell HD. Politics: who gets, what, when, how. Cleveland: Meridian Books; 1958.

Laurell AC. A saúde-doença como processo social. In: Nunes ED (Organizador) Medicina social: aspectos históricos e teóricos. São Paulo: Global; 1983. 
Lisboa EA, Sodré F, Araújo MD, Quintanilha BC, Luiz SG. Conselhos locais de saúde: caminhos e (des)caminhos da participação social. Trab Educ Saúde, 2016. 14(3):679-98. DOI: 10.1590/1981-7746-sol00013.

Lotta G, Favareto A. Desafios da integração nos novos arranjos institucionais de políticas públicas no Brasil. Rev Sociol Polit, 2016. 24(57):49-65. DOI: 10.1590/1678-987316245704.

Machado JGR, Pamplona JB. A ONU e o desenvolvimento econômico: uma interpretação das bases teóricas da atuação do PNUD. Economia e Sociedade, 2008. 17(32):53-84. Disponível em: <http://www.scielo.br/pdf/ecos/v17n1/ a03v17n1.pdf>. Acesso em: 10 jan. 2017.

Mankiw NG. Introdução à Economia. São Paulo: Cengage Learning; 2014.

Marin SR, Quintana AM. Amartya Sen e a escolha social: uma extensão da Teoria da Justiça de John Rawls? Rev Econ Contemp, 2012. 16(3):509-32. DOI: 10.1590/S1415-98482012000300007.

Mendes A. A saúde pública brasileira no contexto da crise do Estado ou do capitalismo? Saúde Soc, 2015. 24(1): 66-81. DOI: 10.1590/S0104$12902015 S 01006$.

Mendes EV. As redes de atenção à saúde. Brasília: Organização Pan-Americana da Saúde; 2011. Disponível em: <http://apsredes.org/site2012/wpcontent/uploads/ 2012/03/Redes-de-Atencao-mendes2.pdf>. Acesso em: 10 jan. 2017.

Menicucci TMG. Público e privado na política de assistência à saúde no Brasil. Rio de Janeiro: Fiocruz; 2007.

Meyer SB, Mamerow L, Taylor AW, Henderson J, Ward PR, Coveney J. Demographic indicators of trust in federal, state and local government: implications for Australian health policy makers. Australian Health Review, 2013. 37:11-18. DOI: 10. 1071/AH11073.

Nightingale F. Notas sobre Enfermagem: o que é e o que não é. São Paulo: Cortez; 1989.

OPAS. Organização Pan-Americana da Saúde. A atenção à saúde coordenada pela APS: construindo as redes de atenção no SUS. Brasília: Ministério da Saúde; 2011. Disponível em: <http://apsredes.org/site2012/wpcontent/uploads/2012/03/aps_verde_new.pdf> Acesso em: 10 jan. 2017.

Paim J, Travassos C, Almeida C, Bahia L, Macinko J. O sistema de saúde brasileiro: história, avanços e desafios. The Lancet, 2011. 11-31. DOI: 10.1016/S0140-6736 (11)60054-8. 
Pereira BS, Tomasi E. Instrumento de apoio à gestão regional de saúde para monitoramento de indicadores de saúde. Epidemiol Serv Saúde, 2016. 25(2):411-8. DOI: 10.5123/S1679-49742016000200019.

Regis CG, Batista NA. O enfermeiro na área da saúde coletiva: concepções e competências. Rev Bras Enferm, 2015. 68(5):830-6. DOI: 10.1590/0034-7167. $2015680510 \mathrm{i}$.

Reinhardt EU. US health care stands Adam Smith on his head. BMJ, 2007. 335(7628):1020. DOI: 10.1136/bmj.39398.601655.59.

Rezende M, Baptista TWF, Amâncio-Filho A. O legado da construção do sistema de proteção social brasileiro para a intersetorialidade. Trab Educ Saúde, 2015. 13(2):301-22. DOI: 10.1590/1981-7746-sip00011.

Rocha D, Deusdará B. Análise de conteúdo e de discurso: aproximações e afastamentos na (re)construção de uma trajetória. ALEA, 2005. 7:305-323. DOI: 10. 1590/S1517-106X2005000200010.

Rocha SMM, Almeida MCP. O processo de trabalho da enfermagem em saúde coletiva e a interdisciplinaridade. Rev Latino-Am Enfermagem, 2000. 8(6): 96101. Disponível em: <http://www.scielo.br/pdf/rlae/v8n6/12354.pdf>. Acesso em: 10 jan. 2017.

Santos AM, Giovanella L. Governança regional: estratégias e disputas para gestão em saúde. Rev Saúde Pública, 2014. 48(4):622-31. DOI: 10.1590/S00348910. 2014048005045.

Santos M. A natureza do espaço: técnica e tempo, razão e emoção. São Paulo: EDUSP; 2006.

Por uma economia política da cidade: o caso de São Paulo. São Paulo: EDUSP; 2009.

São Paulo (Estado). Plano Estadual 2012-2015. São Paulo: Secretaria da Saúde; 2012. Disponível em: <http://www.saude.sp.gov.br/resources/ses/perfil/ gestor/documentos-de-planejamento-em-saude/plano-estadual-de-saude-20122015 -sessp/pes_2012_2015.pdf>. Acesso em: 10 jan. 2017.

Silva LVS, Tanaka PS, Pires MRGM. BANFISA e (IN)DICA-SUS na graduação em saúde: o lúdico e a construção de aprendizados. Rev Bras Enfermagem, 2015. 68:124-30. DOI: 10.1590/0034-7167.2015680117p.

Silva RP, Jesus EA, Ricardi LM, Sousa MF, Mendonça AVM. O pensamento dos gestores municipais sobre a ouvidoria como um potencial instrumento de gestão participativa do SUS. Saúde debate, 2016. 40(110):81-94. DOI: 10.1590/01031104201611006.

Sousa BO. Nazismo, socialismo e as políticas de direita e esquerda na primeira metade do século XX. RBHCS, 2015. 7(14):141-163. DOI: 10.14295/ rbhcs.v7i14.229. 
Souza C. Políticas Públicas: uma revisão da literatura. Sociologias, 2006. 8(16): 20-45. Disponível em: <http://www.scielo.br/pdf/soc/n16/a03n16>. Acesso em: 10 jan. 2017.

Souza RR. Políticas e práticas de saúde e equidade. Rev Esc Enferm USP, 2007. 41(Esp):765-70. DOI: 10.1590/S0080-62342007000500004.

Starfield B. Atenção primária: equilíbrio entre necessidade de saúde, serviços e tecnologia. Brasília: Unesco, Ministério da Saúde; 2002. Disponível em: $<$ http://bvsms.saude.gov.br/bvs/publicacoes/atencao_primaria_p1.pdf>. Acesso em: 10 jan. 2017.

Tanaka OY, Oliveira VE. Reforma(s) e Estruturação do Sistema de Saúde Britânico: lições para o SUS. Saúde e Sociedade, 2007. 16(1):7-17. Disponível em: <file:///C:/ Users/Alexandra\%20Nascimento/Downloads/7505-10003-1PB.pdf>. Acesso em: 10 jan. 2017.

Vieira S. Introdução bioestatística. Rio de Janeiro: Elsevier; 2011. 
9 APÊNDICE 


\section{Apêndice A - Instrumento de Coleta de Dados}

Parte 1 - Caracterização do Município

Nome do município:

Número de habitantes: DRS:

IDH: Coeficiente de Gini:

Parte 2 - Compreensão dos conteúdos dos PMSs e dos RAGMs

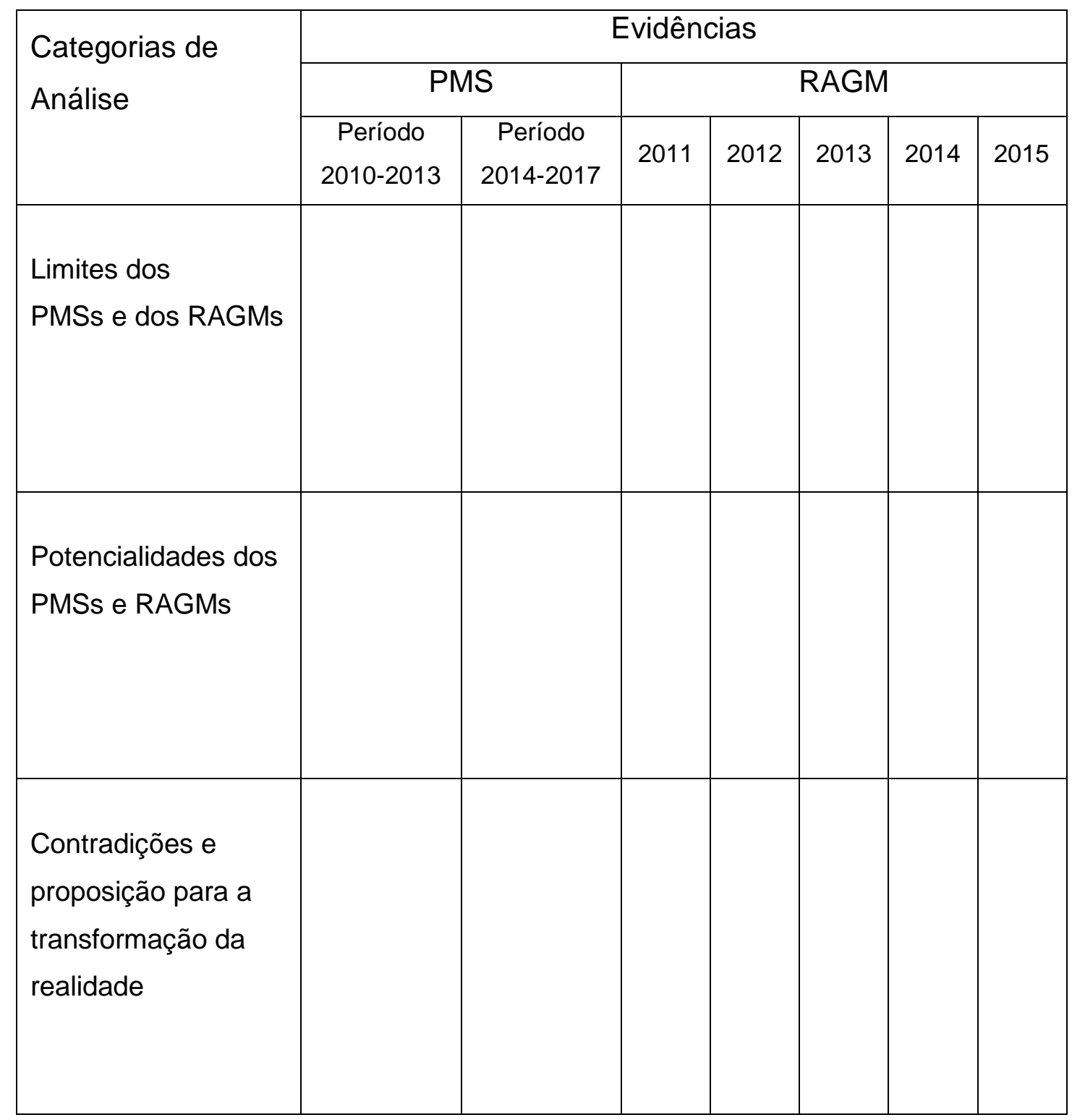

